\title{
Turbulence structure in the viscous layer of strongly heated gas flows
}

\author{
A. Mohsen Shehata \\ (Xerox Corporation) \\ Donald M. McEligot \\ (Lockheed Idaho Technologies Company)
}

Published November 1995

Idaho National Engineering Laboratory

U. S. Department of Energy

Lockheed Idaho Technologies Company

Idaho Falls, Idaho 83415-3885

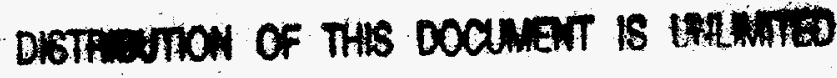

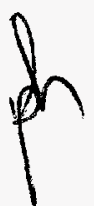

Prepared for the

U. S. Department of Energy

Under DOE Idaho Operations Office

Contract DE-AC07-94ID13223 


\section{ABSTRACT}

For dominant forced convection with significant gas property variation, even in low Mach number flow through a circular tube, apparently the only published profile data available to guide (or test) the development of predictive turbulence models are K. R. Perkins' measurements of mean temperature structure [Perkins, 1975]. The work here takes the next step: the first mean velocity distributions for this situation are presented.

In order to dissect the anatomy of the viscous layer in gaseous, turbulent, tube flow with strong heating, it has been probed via thermal anemometry coupled with diagnostic application of simple computational thermal fluid dynamics. Experiments for air flowing upward in a vertical circular tube were conducted for heating rates causing significant property variation. An unheated entry of fifty diameters preceeded the heating.

Two entry Reynolds numbers of approximately 6000 and 4000 were employed, concentrating on three heating rates, $\mathrm{q}^{+}=\mathrm{q}^{\prime \prime}{ }_{\mathrm{w}} / \mathrm{Gc}_{\mathrm{p}, \text { in }} \mathrm{T}_{\text {in }} \approx 0.0018$, 0.0035 and 0.0045 , to give conditions considered to be "turbulent," "subturbulent" and "laminarizing," respectively. Exit Reynolds numbers were above 3000 in all cases.

Examination emphasizes the wall region which would conventionally be expected to contain the viscous layer, $0<\mathrm{y}^{+}<\sim 30$, if the flow were unheated. In the flow called "turbulent", after being disturbed in the first few diameters by the heating (and its accompanying variation of viscosity, density and thermal conductivity), profiles representing the turbulence quantities -$1 / \mathrm{y}, \varepsilon_{\mathrm{m}} / v,-\rho \overline{\mathrm{uv}} / \tau_{\mathrm{w}}$ and $-\rho \mathrm{c}_{\mathrm{p}} \overline{\mathrm{vt}} / \mathrm{q}^{\prime \prime}{ }_{\mathrm{w}}$-- appear to recover to approximately selfpreserving conditions. In the other two runs with higher heating rates, the turbulence quantities decrease after the immediate thermal entrance until they are small relative to molecular effects. 


\section{DISCLAIMER}

This report was prepared as an account of work sponsored by an agency of the United States Government. Neither the United States Government nor any agency thereof, nor any of their employees, makes any warranty, express or implied, or assumes any legal liability or responsibility for the accuracy, completeness, or usefulness of any information, apparatus, product, or process disclosed, or represents that its use would not infringe privately owned rights. Reference herein to any specific commercial product, process, or service by trade name, trademark, manufacturer, or otherwise does not necessarily constitute or imply its endorsement, recommendation, or favoring by the United States Government or any agency thereof. The views and opinions of authors expressed herein do not necessarily state or reflect those of the United States Government or any agency thereof. 


\section{DISCLAIMER}

Portions of this document may be illegible electronic image products. Images are produced from the best available original document. 


\section{ACKNOWLEDGEMENTS}

The study reported was partly supported through the Laboratory Directed Research and Development Program and the Long Term Research Initiative Program of EG\&G Idaho and Lockheed Idaho Technologies Company under DOE Idaho Field Office Contracts DE-AC07-76ID01570 and DE-AC07-94ID13223, respectively. Earlier incarnations were financed by the National Science Foundation (Dr. Win Aung, Program Manager), the Office of Naval Research (Mr. M. Keith Ellingsworth, Program Manager) and the Aerospace and Mechanical Engineering Department of the University of Arizona while the authors were at the University of Arizona. As should be evident from the text, the foundations of the present work were laid via earlier studies by Dr. Kenneth R. Perkins, now of Brookhaven National Laboratory. At the University of Arizona, Mr. Kenneth E. Bauer constructed most of the apparatus, Mr. Kerry Heaton provided electronic assistance and the late $\mathrm{Mr}$. Maynard F. (Bud) Taylor and Professors H. C. (Skip) Perkins, Robert B. Kinney and Francis $\mathrm{H}$. Champagne gave valuable advice. At Idaho National Engineering Laboratory Dr. Michael G. McKellar has helped with the preparation of this report. To all we are extremely grateful. 


\section{CONTENTS}

Abstract $\quad$ ii

Acknowledgements $\quad$ iii

$\begin{array}{ll}\text { Contents } & \text { iv }\end{array}$

Nomenclature $\quad$ V

1. Introduction 1

2. Experimental apparatus 3

2.1 Test section 4

2.2 Flow control 4

2.3 Hot wire probe $\quad 5$

2.4 Instrumentation 6

3. Experiment 6

3.1 Preliminary checks $\quad 6$

3.2 Hot wire anemometry $\quad 8$

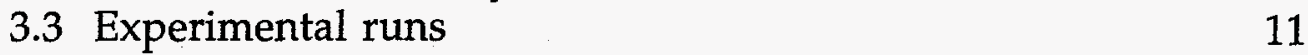

4. Results 12

4.1 Range of variables 12

4.2 Axial variation of integral parameters 13

4.3 Turbulent, Run $618 \quad 14$

4.4 "Subturbulent," Run $635 \quad 15$

4.5 "Laminarizing," Run 445

$\begin{array}{ll}\text { 4.6 Comparisons for the viscous layer } & 17\end{array}$

4.7 Distribution of mean turbulence quantities in
conventional viscous layer

5. Concluding remarks 26

Appendix A. Integral results and inlet conditions A-1

B. Mean velocity and temperature profiles B-1

$\begin{array}{ll}\text { Figures } & \text { F-1 }\end{array}$

$\begin{array}{ll}\text { References cited } & \text { R-1 }\end{array}$ 


\section{NOMENCLATURE}
A, $A_{C S} \quad$ cross-sectional area
b property variation exponent
$c_{p}$ or $C_{p} \quad$ specific heat at constant pressure
D tube inside diameter
$\mathrm{E}, \dot{\mathrm{E}}$ total enthalpy flow rate across a tube cross section
g acceleration of gravity
G mean mass flux, $\dot{\mathrm{m}} / \mathrm{A}_{\mathrm{CS}}$
gc units conversion factor, e.g., $32.174(\mathrm{lbm} / \mathrm{lbf}) /\left(\mathrm{ft} / \mathrm{sec}^{2}\right)$
h convective heat transfer coefficient
$\mathrm{H} \quad$ specific enthalpy, i.e., enthalpy per unit mass
k thermal conductivity
$1 \quad$ mixing length
$\dot{\mathrm{m}} \quad$ mass flow rate
p pressure
$\mathrm{P} \quad$ perimeter, period
q"w wall heat flux
r radius
t relative temperature
$\mathrm{T} \quad$ absolute temperature
u streamwise velocity component
$\mathrm{u}_{\tau} \quad$ friction velocity, $\left(\mathrm{g}_{\mathrm{c}} \tau_{\mathrm{w}} / \rho\right)^{1 / 2}$ 

radial velocity component

$\mathrm{Vb} \quad$ bulk or mixed-mean velocity, also bridge voltage

$\overline{\mathrm{V}}_{\mathrm{B}} \quad$ mean bridge voltage

$x$ axial location, measured upward from start of heating y coordinate perpendicular to the wall

\section{Non-dimensional quantities}

\begin{tabular}{|c|c|}
\hline $\mathrm{Gr}^{*}$ & modified Grashof number, $\mathrm{g} \mathrm{D}^{3} / \mathrm{vin}^{2}$ \\
\hline $\mathrm{Gr}_{\mathrm{q}}$ & local Grashof number based on heat flux, $\mathrm{g} \mathrm{D}^{4} \mathrm{q}^{\prime \prime} \mathrm{w} /\left(\mathrm{vb}^{2} \mathrm{~kb}_{\mathrm{b}} \mathrm{T}_{\mathrm{b}}\right)$ \\
\hline $\mathrm{K}_{\mathrm{V}}$ & acceleration parameter, $\mathrm{K}_{\mathrm{V}}=\left(\mathrm{vb}_{\mathrm{b}} / \mathrm{V}_{\mathrm{b}}{ }^{2}\right)\left(\mathrm{d} \mathrm{V}_{\mathrm{b}} / \mathrm{dx}\right)$ \\
\hline $\mathrm{Nu}$ & Nusselt number, e.g., hD/k \\
\hline $\mathrm{P}^{+}$ & pressure defect, $\rho_{\text {in }} g_{c}\left(p_{i n}-p\right) / G^{2}$ \\
\hline $\mathrm{Pet}_{\mathrm{t}}$ & turbulent Peclet number, $(\varepsilon / v) \operatorname{Pr}$ \\
\hline $\operatorname{Pr}$ & Prandtl number, $c_{p} \mu / k$; Prt, turbulent Prandtl number \\
\hline $\mathrm{q}^{+}$ & $\begin{array}{l}\text { heat flux, } \mathrm{q}^{\prime \prime} / \mathrm{Gc}_{\mathrm{p}} \mathrm{T} ; \mathrm{q}_{\mathrm{i}}^{+} \text {, based on inlet conditions, } \\
\qquad \mathrm{q}_{\mathrm{w}}^{\prime \prime} / \mathrm{Gc}_{\mathrm{p}, \mathrm{in}} \mathrm{T}_{\mathrm{in}}\end{array}$ \\
\hline $\operatorname{Re}$ & Reynolds number, $4 \dot{\mathrm{m}} / \Pi \mathrm{D} \mu$ \\
\hline$t^{+}$ & temperature, \\
\hline$u^{+}$ & streamwise velocity component, $\mathrm{u} / \mathrm{u}_{\tau}$ \\
\hline & wall distance, $y\left(g_{c} \tau_{W} / \rho\right)^{1 / 2} / v$ \\
\hline
\end{tabular}




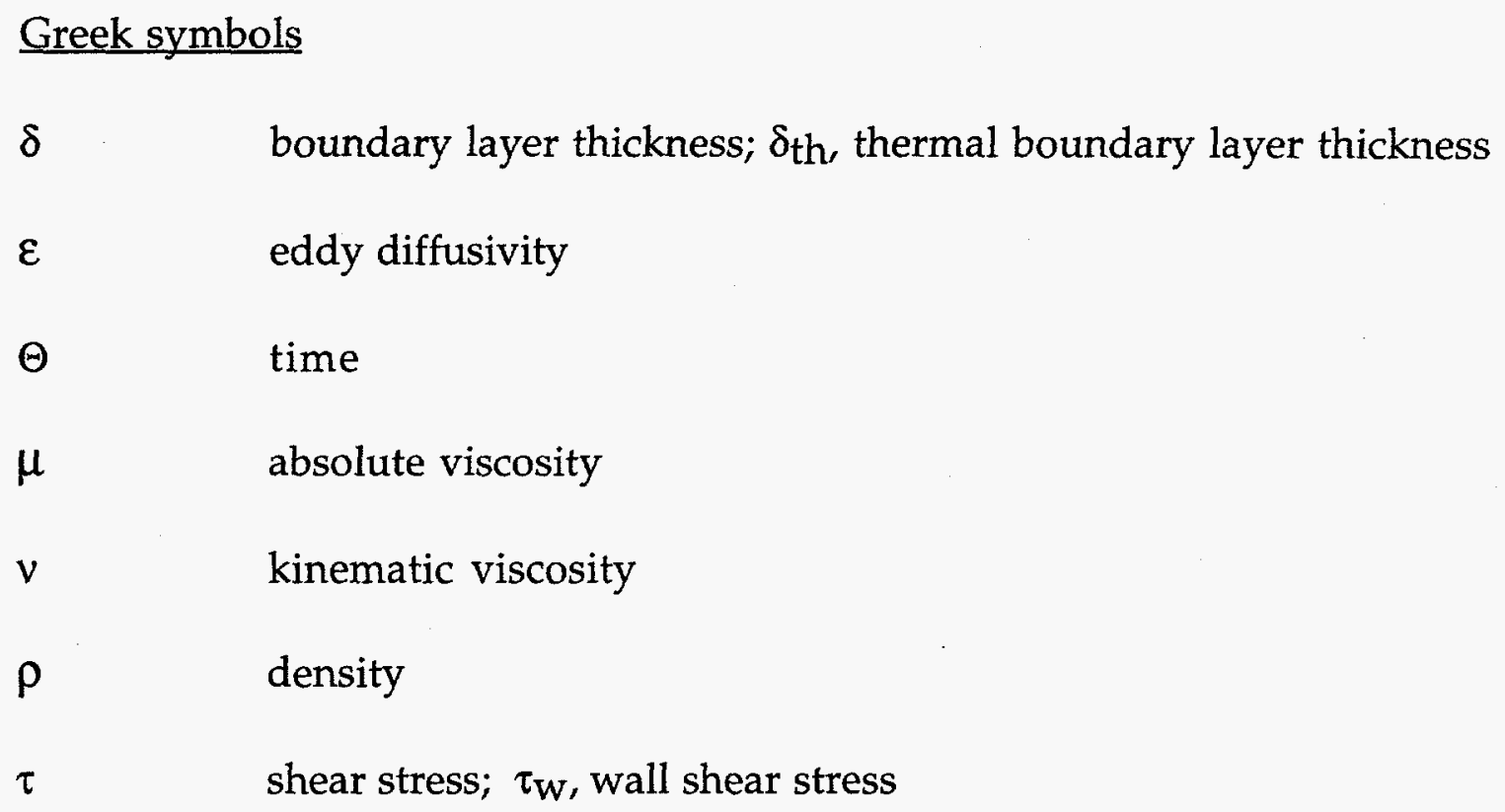


Miscellany

$\begin{array}{ll}\sim & \text { varies as, approximately } \\ \text { fin } & \text { natural logarithm } \\ \text { Overbar } & \text { time-mean quantity }\end{array}$




\section{INTRODUCTION}

A wide variety of basic studies has been conducted examining turbulence structure in simple boundary layers; fewer have been done for isothermal accelerating flows induced by a convergence (e.g., Blackwelder and Kovasznay [1972], Narasimha and Sreenivasan [1979]). But almost none have been accomplished for accelerating flows with significant transport property variation as induced by strong heating of a gas in internal flow, as inside a circular tube. These flows develop continuously downstream. There are several phenomena that relate to the flow development: thickening of the viscous sublayer, flow acceleration and buoyancy effects for example. In our terminology, the viscous layer is operationally defined to include both the socalled "linear" layer, where molecular effects dominate, and the next region where molecular effects are still significant but not dominant. For unheated flows, these regions typically extend to $\mathrm{y}^{+}$of about five and thirty, respectively. This usage follows that suggested by Bradshaw [1971].

For dominant forced convection with significant gas property variation, even in low Mach number flow through a circular tube, apparently the only published profile data available to guide (or test) the development of predictive turbulence models are K. R. Perkins' measurements of mean temperature structure [Perkins, 1975]. The work here takes the next step: the first mean velocity distributions for this situation are presented.

The reason for the paucity of data tends to be related to size. The region controlling the transfer of heat and momentum in turbulent wall flows is primarily the viscous layer which occupies a small fraction of the cross section. This fraction grows as the Reynolds number is lowered. With strong heating, the large turbulent temperature fluctuations make simultaneous measurement of instantaneous temperature and velocity desireahle - but available multisensor probes generally do not provide the spatial resolution necessary without "large" size. However, if one choses a large tube and a low Reynolds number (for thicker viscous layers) to improve spatial resolution, the problem quickly becomes one of dominant natural convection. The experimenter must compromise in order to obtain data which the theorist can extend to conditions where the experimenter cannot easily tread.

In terrestrial-based experiments, the attempt to obtain some reasonable spatial resolution while measuring turbulence structure in strongly heated, internal gas flows leads the experimenter to flirt with laminar flow and its approach, called "laminarization" [Narasimha and Sreenivasan, 1979] or "reverse transition" [Perkins and Worsoe-Schmidt, 1965]. For this latter situation, a tube flow turbulent at its inlet gradually begins to approach results corresponding to laminar theory (in terms of integral parameters) although turbulent fluctuations are still evident. The situation is comparable to apparent laminarization in flows accelerating due to a convergence [Murphy, 
Chambers and McEligot, 1983]. For further general background on laminarization in unheated flows the review by Narasimha and Sreenivasan [1979] is recommended and for internal convective heat transfer to gases a couple surveys by McEligot [1986a,b] may be useful.

The general goal of the present study is to obtain greater understanding of the structure of strongly heated, internal, turbulent gas flows and their "transition" to apparent laminar flows, with the current emphasis being on mean structure. Accordingly, the immediate objectives were to measure and document the distributions of the mean streamwise velocity and temperature in a well defined experiment involving significant variation of the gas transport properties and, from them, to deduce the related mean turbulence quantities. Another objective was to document the data so they can be used to test hypothesized turbulence models. For example, it is likely that the first application of direct simulation of turbulence with significant transport property variation will be done at low Reynolds numbers; these data are waiting to provide a test. Some advanced methods use "parabolic sublayers" based on mixing length models near the wall to reduce computer storage requirements and calculation times for complex flows or geometries (or complex models) [Launder, 1987]; therefore a minor objective was to examine the validity of the popular van Driest model [1956] which is usually used for this purpose.

Of necessity, an intermediate objective was to develop a technique to obtain useful mean data from a single small hot wire sensor in severely nonisothermal gas flow. The present approach was selected in contrast to laser Doppler velocimetry in a short rectangular duct (e.g., Waranda, Ueda and Mizomoto [1992, 1994]) to avoid a three-dimensional base flow. Since LDV techniques can yield biased mean velocity results, particularly in the region of interest near the wall due to thermophoresis and refractive-index fluctuations as well as having a decrease in the number density of seeding particles there [Stabile and McEligot, 1978; Waranda, Ueda and Mizomoto, 1994], laser Doppler anemometry was avoided for the present study.

Although not the primary objective, the present work also should provide an excellent proving ground for turbulence models developed to predict wall shear flows with temperature-dependent transport properties (e.g., Kawamura, 1979; Inagaki and Komori, 1993; Torii et al., 1993; Mikielewicz, 1994). Flow rates and heating rates were chosen to yield experimental conditions leading to results which range from predominantly turbulent to predominantly near laminar flow in integral terms.

The present data are for flows where forced convection dominates. They further supplement and extend earlier data for internal turbulent flows in small tubes with temperature dependent transport properties that could only provide integral parameters, such as local Nusselt numbers and local 
skin friction coefficients. These earlier data gave initial tests of turbulence models accounting for temperature-dependent transport properties, as demonstrated by Bankston and McEligot [1970] and Kawamura [1979]. The current data also complement measurements by Steiner [1971] and Carr, Connor and Buhr [1973] who used "large" tubes for mean profile measurements so buoyancy forces probably dominated their flows. Consequently, their results may be useful for testing turbulence models which have been developed to handle mixed or natural convection. (Steiner has not documented the inlet and boundary conditions in sufficient detail to use in testing numerical predictions, but such data are available in the thesis by Connor.)

It is probably also appropriate to point out that the use of resistive heating, as in the present experiment, poses a severe challenge for turbulence models. An approximately constant wall heat flux evolves. With significant property variation due to large temperature ratios, it is easier to model turbulent flows with constant wall temperature as the boundary condition than those with a specified wall heat flux. With a constant wall temperature, the fluid properties in the viscous region do not change substantially in the axial direction. With a constant or increasing wall heat flux, the transport properties in the viscous region change continuously and rapidly for strong heating rates as one progresses downstream; this situation can lead to concern for the "history" of the turbulence quantities in the viscous layer. Since many current versions of higher order turbulence models employ a wall function locating the first calculation point at $y^{+} \approx 50$, they cannot be expected to give reliable predictions in this case without further analytical development.

\section{EXPERIMENTAL APPARATUS}

The experiment was conducted in an open loop built around a vertical, resistively-heated, circular test section exhausting directly to the atmosphere in the laboratory. The experiment was designed to approximate a constant wall heat flux to air, entering with a fully-developed turbulent velocity profile at a uniform temperature. Small single wire probes were introduced through the open exit in order to obtain pointwise temperature and velocity measurements. Figure 1 is a schematic view of the overall apparatus. Details plus tabulations of resulting data are available in the thesis by Shehata [1984] with some additional information given by Perkins [1975]. The measured wall parameters and mean velocity and temperature distributions from Shehata have also been reproduced in Appendices A and B of the present report. 


\subsection{Test section}

A resistively-heated, seamless, extruded Inconel 600 tube of 1.08 inch $(27.4 \mathrm{~mm})$ inside diameter was employed as the test section. Wall thickness was measured to be 0.025 inch $(0.635 \mathrm{~mm})$. Heated length between the electrodes was about thirty two diameters and it was preceeded by a fifty diameter, adiabatic entry region for flow development; the short heated length was picked to permit high heating rates with this material while possibly approaching quasi-developed conditions. From the observations of Perkins and McEligot [1973] it was estimated that the relative roughness would be less than 0.004 even after the test section had been heated for long periods, so it could be considered smooth. Regulated sixty cycle alternating current provided the power.

Outside wall temperatures were determined with premium grade, Chromel Alumel thermocouples distributed along the tube. These were 0.010 inch $(0.25 \mathrm{~mm})$ in diameter and were spot welded to the wall with the parallel junction method [Moen, 1960] to reduce thermocouple conduction error. The temperatures were transformed to inside wall temperatures by a conduction calculation in the data reduction process.

The axial variation of the static pressure was obtained with pressure taps electrostatically drilled through the wall to avoid creating burrs on the inside of the tubing. The orifices were about 0.01 inch $(0.25 \mathrm{~mm})$ in diameter.

Convective and radiative heat losses from the outside of the tube were reduced by insulating with a $1 / 2$ inch $(13 \mathrm{~mm})$ thick layer of fine silica bubbles ("Eccospheres" by Emerson and Cuming), surrounded in turn by electrical heating tapes for guard heating. This annulus extended about eight diameters below the nominal location for the start of heating. By this method, heat losses were constrained to less than ten per cent of the thermal energy generation rate except within a few diameters of the electrodes; the heat losses were calibrated so the consequent uncertainties in $\mathrm{q}^{\prime \prime} \mathrm{w}\{\mathrm{x}\}$ were considerably less than the heat loss magnitudes.

\subsection{Flow control}

The inlet flow system was designed to provide symmetric, steady, fully turbulent flow at the start of heating. Mass flow rate measurement was also accomplished upstream of the test section. Room air was compressed, passed through a dryer, was stored in a large tank at about $125 \mathrm{psig}\left(8.6 \times 10^{5} \mathrm{~N} / \mathrm{m}^{2}\right)$ and then passed through a sequential series of five pressure regulators and a filter en route to a variable area flowmeter. The regulators minimized pressure surges accompanying the compressor cycling. 
A small, removable plenum system was attached to the entrance of the test section. Recommendations of Loehrke and Nagib [1976] and Tan-Atichat, Nagib and Loehrke [1982] were followed to maintain the flow with reasonable turbulence. The chamber had two pairs of porous sheets and screens to minimize the effects of directional change and to reduce large scale turbulence. A section of honeycomb was inserted in the entrance of the test section for further flow straightening and to minimize lateral velocity fluctuations. The chamber was designed to be removable in order to serve as an inspection port for checking correct alignment of the probe when it was inside the test section.

\subsection{Hot wire probe}

The probe was a miniature boundary layer type as detailed in Figure 2. It was a modified version of a commercial TSI-1220-U probe. Its sensor was employed as a hot wire for velocity measurements and as a resistance thermometer for pointwise temperatures. The wire material was chosen to be platinum $10 \%$-rhodium as it proved to have more stable resistance values for a longer time than the other available alloys for the temperatures, such as platinum-iridium. A 10 micrometer wire, about one $\mathrm{mm}$ long, was used for strength considerations. A single sensor was chosen, in preference to an Xprobe or other multiple sensor probe, in order to minimize flow disturbances and blockage by prongs and support in the one inch $(27 \mathrm{~mm})$ tube and to permit measurements closer to the wall. Wire supports were gold-plated stainless steel 302 , with the plating necessary to reduce the thermal emissivity of the prongs. This boundary layer probe was designed utilizing the findings of Comte-Bellot, Strohl and Alcaraz [1971] to reduce aerodynamic disturbances caused by the probe prongs and body at the measuring location.

Internal flow data were obtained at five axial locations: $3.17,8.73,14.20$, 19.87 and 24.54 diameters beyond the lower electrode. At the first three locations the probe was held by a specially designed articulating probe support. For the latter two a straight 18 inch long support was employed [Barney, 1976].

The articulating probe support was similar to a pivoting probe used by Perkins [1975] which was based on an approach by Pennell, Eckert and Sparrow [1972]. As shown in Figure 3 the support was fabricated in two parts: (1) a 12 inch vertical section moving parallel to the vertical axis of the tube and (2) a connected 22 inch pivoting section which held the miniature probe. The latter section pivoted about two centering fins and a spring wire about half-way along. This configuration required a careful calibration procedure for sensor location as described later. Near the probe end were attached three guard pins. These pins were to achieve four functions: 1 ) to protect the probe from accidentally touching the wall (and breaking the sensor), 2) to help align the wire parallel to the wall, 3) to center the probe on the diameter and 4) to 
determine the wall location. Lead wires inside the support were made of copper for minimal electrical resistance, except at the flexible joint where stainless steel 302 was used for fatigue strength.

\subsection{Instrumentation}

Test section power was measured with a Weston 370 ammeter in conjunction with a Weston 327 current transformer, giving an uncertainty of $0.25 \%$ of full scale, and a Weston 341 voltmeter, also with $0.25 \%$ of full scale. The air mass flow rate was determined with a Brooks variable area flowmeter, calibrated to one per cent of full scale. A Fluke $8810 \mathrm{~A}$ multimeter measured thermocouple and pressure transducer signals as well as the mean outputs of the anemometer circuits; it had an uncertainty of $0.005 \%$ of reading +0.2 millivolts. Pressure differences were evaluated with a Setra 239 linear pressure transducer with uncertainty of $0.1 \%$ of reading.

As shown in Figure 1 the electronic circuit for the hot and "cold" wire anemometry was provided by a pair of Disa 55D01 units with a Disa 55D35 root mean square voltmeter for auxiliary observations. The output voltage of the anemometer circuit was passed through an integrating circuit, with a time constant of about 10 seconds, to the Fluke multimeter. Ultimately, the mean briclge voltage for the velocity measurement was taken as the average of ten independent readings; as discussed later, the mean value of the streamwise velocity component was deduced from this mean voltage via a procedure Shehata [1984] derived to account for the non-linearity of the velocity calibration (and other problems).

\section{EXPERIMENT}

\subsection{Preliminary checks}

Adiabatic flow runs were conducted for a variety of confidence tests. The flow symmetry was checked by measuring the mean velocity profiles fifty diameters downstream from the plenum chamber for three Reynolds numbers: about 4000,6000 and 8000 . These measurements were obtained in two perpendicular directions and they coincided, indicating axial symmetry of the flow.

Skin friction coefficients were calculated from static pressure differences between near the start of heating and $x / D \approx 19.7$ for Reynolds numbers from about 3000 to 10,000 . Here, as in the rest of the paper, the axial distance $\mathrm{x}$ is denoted from the effective "start of heating" location at the lower electrode which was approximately fifty diameters from the tube entrance. These data fell between accepted correlations for fully developed turbulent 
flow: those of Blasius [Schlichting, 1968] and of Drew, Koo and McAdams [1932]. They agreed to within one to two per cent.

Adiabatic mean velocity profiles were measured for Reynolds numbers of about 4200,6000 and 8800 at $x / D=3.17$ using the constant resistance hotwire anemometer. This location is close enough to the start of heating to serve as measurements of the initial conditions for the heated runs. Figure 4 shows the measured velocity profiles in wall coordinates; here the friction velocity was estimated from the Blasius correlation [Schlichting, 1968]. These data show the same behavior as for fully-developed, low-Reynolds-number pipe flow as measured by H. C. Reynolds [1968] and Patel and Head[1969] and predicted by McEligot, Ormand and Perkins [1966], H. C. Reynolds [1968] and others. In the turbulent core region velocities are higher than suggested by the so called Universal Velocity Profile and this difference is found to decrease as the Reynolds number increases.

Heat loss calibration was performed by heating the test section without flow for a range of test section temperatures. From the deduced radial conduction in the annulus between the test section and the guard heater, the effective thermal conductivity of the insulation was determined as a function of its temperature. The same runs were also employed to obtain the temperature dependence of the electrical resistivity for the Inconel test section via current and incremental voltage measurements [Perkins, 1975]. These data were later applied to calculate the thermal boundary conditions present during the individual experiments.

Several runs were carried out without a probe inserted in the test section in order to determine control settings for the experimental conditions selected. These measurements were compared to the wall temperature data during the runs with the probe inserted to check that the probe had no significant effect on thermal boundary conditions between the start of heating and the measuring location.

As consequences of the wide range of temperatures during the experiments, slight variations in the deflection and orientation of the probe and its support were observed. These affected the deduced position of the sensor. Further, the lead wire resistance within the probe support varied with its location (and therefore its temperature distribution) during the axial and radial traverses. These problems were largest at the first axial measuring position where temperature gradients were greatest. To correct the apparent location and the anemometer measurements appropriately, Shehata [1984] developed complicated calibration procedures that were part of the preliminary measurements for each run. Details are provided in his thesis, but with a dummy probe and a clear view of the probe he essentially took advantage of the slow thermal response of the test section and probe support 
to calibrate the changes from near wall positions to the centerline (beyond the growing thermal boundary layer).

\subsection{Hot wire anemometry}

As noted above, a single wire was employed as a resistance thermometer for temperature measurements and as a heated wire for deducing the velocity. In addition to the usual difficulties of hot wire anemometry [Sandborn, 1972], the temperature range of the present experiment introduced additional problems. High temperature differences between the wall and the prongs make thermal radiation to the prongs important for "short" wires. The question arises: how to handle gas property variation in the convective heat transfer correlation which serves as the basis for the calibration procedure? Accounting for the non-linearity of the correlation with large temperature fluctuations present also becomes an issue. This section describes how these problems were addressed.

The sturdy hot wire sensor was short in the sense that its characteristic length for thermal conduction, $(\mathrm{hP} / \mathrm{kA})^{1 / 2} \mathrm{~L}$, was less than fifty for some conditions near the wall. Therefore, when using the wire for temperature measurement, thermal radiation from the wall raised the prong temperature which (via thermal conduction) raised the sensor temperature above the local gas temperature. Thin fin theory [Kreith, 1973] was applied to the sensor and to the prongs to derive an iterative correction for this effect. Convective heat transfer coefficients were deduced from the approaches of Collis and Williams [1959; Andrews, Bradley and Hundy, 1972] for the sensor and of Scadron and Warshawsky [1952] for the prongs. The temperature dependence of the sensor's unit electrical resistance (ohms $/ \mathrm{m}$ ) was calibrated in an isothermal heated box developed by Barney [1976] for the experiment and determination of the thermal emissivity of the gold-plated prongs was a consequence of the velocity calibration technique described below. In the experiment the axial temperature variation of the test section wall was included in the representation of thermal radiation exchange with the prongs.

When using the sensor for velocity measurement, radiation again raises the prong temperature, which serves as a boundary condition for the thermal conduction from the heated wire to the prongs. Again fin theory was employed to couple the two heat transfer problems, the sensor and the prongs, and thus to deduce the velocity from the calibration data (iteratively with the temperature calculation).

Since the temperature and velocity varied continuously in the radial and axial directions, a combination of calibration and correlation techniques was used to relate the velocity to the measured electrical signal and the temperatures. An air heater, a heated circular brass nozzle, a heated tubular 
steel shield and a traversing mechanism comprised the calibration equipment. The air heater and nozzle could provide a laminar, isothermal air stream at a constant velocity for a range of temperatures between room and $1000 \mathrm{~F}(800 \mathrm{~K})$ at a velocity range up to $36 \mathrm{ft} / \mathrm{sec}(11 \mathrm{~m} / \mathrm{s})$ [Barney, 1976]. The shield was a two inch $(50 \mathrm{~mm})$ tube, four inches $(100 \mathrm{~mm})$ long, wrapped in heating tape and insulation; it was used to simulate the hot wall of the test section in the experiment. Calibration data were collected for adiabatic conditions and with heated air temperatures up to $817 \mathrm{~F}(709 \mathrm{~K})$ while the shield temperature was adjusted between room temperature and $800 \mathrm{~F}(700 \mathrm{~K})$.

To apply the data at conditions other than the actual calibration points and to account for turbulent fluctuations around the mean, a convective heat transfer correlation is needed that accounts for the effects of the temperature dependencies of the gas properties. A variety of approaches has been suggested in the literature [King, 1914; Cole and Roshko, 1954; Collis and Williams, 1959; Davies and Fisher, 1964; Ahmad, 1968; Chevray and Tutu, 1972; Pessoni and Chao, 1974; etc.]. Using the calibration data, we chose to examine the validity of three representative versions for our probe and conditions. (A correction for rarefied gas effects at high temperatures was also included.) Collis and Williams [1959] and Andrews, Bradley and Hundy [1972] recommended evaluating the gas properties at the film temperature, $\left(\mathrm{T}_{\mathrm{w}}+\mathrm{T}_{\mathrm{g}}\right) / 2$. The classic paper of King [1914] suggested using the freestream temperature, $\mathrm{T}_{\mathrm{g}}$ in this case. And Davies and Fisher [1963] introduced a mixture, $\mathrm{T}_{\mathrm{g}}$ as reference for all properties except gas thermal conductivity which was evaluated at the wire temperature.

Calibration data for unheated flow with the shield also unheated were applied to determine the correlation coefficients, A and B, in conjunction with the conduction/radiation and slip flow corrections. The resulting correlations were then compared to data at two sets of high temperature conditions: 1) $\mathrm{T}_{\mathrm{W} \text {,avg }}=727 \mathrm{~F}(659 \mathrm{~K})$ with $\mathrm{T}_{\mathrm{g}}=400 \mathrm{~F}(478 \mathrm{~K})$ and (2) $\mathrm{T}_{\mathrm{W} \text {,avg }}=$ $947 \mathrm{~F}(782 \mathrm{~K})$ with $\mathrm{T}_{\mathrm{g}}=817 \mathrm{~F}(709 \mathrm{~K})$. The approach of Andrews, Bradley and Hundy [1972] fared best and was used in the rest of the experiment to interpolate for conditions between the calibration points.

Due to the non-linearity of the calibrating relation and the sensitivity to gas property variation, velocity and/or temperature fluctuations cause the mean bridge voltage measured by the anemometer system to differ from the voltage which would correspond to the actual mean velocity. The large temperature gradients of the present study increase this difficulty compared to isothermal turbulent flows. Further, the property variation across and along the flow spatially changes the relationship between the mean voltage and mean velocity. Accordingly, a correction technique was developed in order to determine the mean velocity from measurement of (1) the mean bridge 
voltage of the hot wire, (2) the mean temperature and (3) the rms temperature fluctuations at the same location.

During the preliminary stages of the study, simultaneous signals from the hot and cold wires of a two-wire probe were obtained. They showed an almost perfect negative correlation in cases both close and away from the wall. Such correlated signals are expected since a low velocity, high temperature signal would correspond to an ejection from the hot wall and a high velocity, low temperature corresponds to a sweep from the cooler central region [Corino and Brodkey, 1969; Iritani, Kasagi and Hirata, 1983]. This observation combined with approximations of the results from Blackwelder and Kaplan [1976] and Antonia and Atkinson [1976] served as the bases for the mean velocity calculation.

Antonia and Atkinson pointed out that temperature fluctuations in turbulent shear flows could be modeled as ramp-like signals, upon which relatively high frequency Gaussian fluctuations are superposed. Likewise, the conditionally-averaged velocity signal deduced by Blackwelder and Kaplan may be described approximately in the same fashion. Shehata [1984,

Appendix D] approximated the typical velocity signal as a linear ramp and the temperature signal as its mirror image, i.e.,

$$
\tilde{\mathrm{u}}(\theta)=U+\mathrm{u}_{\mathrm{m}}-2 \mathrm{u}_{\mathrm{m}} \theta / P
$$

and

for $0<\theta<P$

$$
\tilde{\mathfrak{t}}(\theta)=t_{\text {mean }}+t_{m}-2 t_{m} \theta / P
$$

where $u_{m}$ and $t_{m}$ are the peak amplitudes of these signals and $P$ is their time period. The quantity $U$ is the desired mean streamwise velocity at the point. From these assumed descriptions, one may deduce the value of $t_{m}$ that corresponds to measured values of $t_{\text {mean }}$ and $t_{r m s}$ by integration over the period to be $t_{r m s}=t_{m} /(3)^{1 / 2}$. Conceptually, the approximate ramp velocity representation may then be combined with these values and the calibration correlation to relate the unknown values of $U$ and $u_{r m s}$ to the measured mean bridge voltage $\overline{\mathrm{V}}_{\mathrm{B}}$ and its root-mean-square fluctuation.

We developed a first order correction along the above lines with the further simplifying approximations that the normalized turbulence intensities for velocity and temperature were the same and that the gas properties could be evaluated at the pointwise mean velocity and mean temperature. Using the calibration correlation of Andrews, Bradley and Hundy, one may derive by integration the correction relation to deduce the 
desired bridge voltage corresponding to the mean quantitites $V_{B}\{U, \operatorname{tg}$, mean $\}$ from the measured mean bridge voltage $\bar{V}_{B}$ to be

$$
\frac{\bar{V}_{B}\left(u, t_{g}\right)}{V_{B}\left(U, t_{\text {g,mean }}\right)}=\frac{\frac{1}{2 \xi} \int_{-\xi}^{\xi} \alpha(\gamma) \beta(\gamma) d \gamma}{\left[\left(1+C_{3} U^{0.45}\right)\left(t_{w, \text { mean }}-t_{g_{\text {, }} \text { mean }}\right)\right]^{\frac{1}{2}}}
$$

where

$$
\begin{aligned}
& \alpha(\gamma)=\left[1+C_{3} U^{0.45}(1+\gamma)^{0.45}\right]^{1 / 2} \\
& \beta(\gamma)=\left[t_{w, \text { mean }}-t_{\text {wall }} \gamma-t_{\text {g,mean }}(1+\gamma)\right]^{1 / 2} \\
& \gamma=\xi(1+2 \theta / P), \quad \xi=u_{m} / U
\end{aligned}
$$

and $C_{3}$ is a properties coefficient evaluated at the mean film temperature of the wire. This relation is evaluated iteratively to obtain $U$ and $t_{g}$, mean, which are coupled thanks to the thermal radiation to the prongs. Details and the computer program are provided by Shehata [1984] (there appears to be a typographical mistake in the corresponding equation D. 32 of the thesis, but it did not propagate into the computer subroutine which performed the actual evaluation).

\subsection{Experimental runs}

The first steps at each axial location were the determination of the wall location and the orientation of the angular position of the probe with the test section heated and with a dummy probe. This process was accomplished with an inspection mirror and with the inlet plenum removed. After mounting the inlet section the desired settings of flow rate and power were applied. When steady state was reached, calibrations were performed for probe deflection and increase in the electrical resistance of leads inside the probe support. The actual probe was then substituted.

The probe was moved so that its guard pin touched the wall at the start of a radial profile measurement. The axial wall temperature distribution, mass flow rate, barometric pressure and electrical current and voltage were checked against the data without a probe and were recorded. On the anemometer control unit the decade resistance was adjusted to its calibration value plus the correction for the change in lead resistance. At each radial location the indicated distance, mean bridge voltage and rms bridge voltage in the hot wire mode and the cold resistance were recorded. During the 
measurements the local wall temperature was monitored; maximum variation over the ten hour period required for a profile was $+/-4 \mathrm{~F}(+/-2 \mathrm{C})$.

After completing a profile, the power, flow rate and wall temperature distribution were compared to their initial values. Probe resistance was rechecked at room temperature; if it had changed, the wire calibration was repeated. The articulated probe support was used for profiles at 3.2, 8.7 and 14.2 diameters and the straight version was employed for 19.9 and 24.5 diameters.

\section{RESULTS}

\subsection{Range of variables}

Experimental conditions were selected to correspond to three generic situations: 1) essentially turbulent flow with slight, but significant, air property variation, 2) severe air property variation evolving to near laminar flow (as implied by the integral heat transfer parameters) and 3) moderate gas property variation, yielding behavior that was intermediate or transitional between the first two (and may correspond to "laminarescent" in the terminology of Kline). The thermal development of the latter situation was the most difficult of the three to predict [Perkins, 1975]. Inlet Reynolds numbers of about 6080,6050 and 4260 with non-dimensional heating rates, $\mathrm{q}^{+}$ $=\mathrm{q}^{\prime \prime}{ }_{\mathrm{w}} /\left(\mathrm{Gc}_{\mathrm{p}} \mathrm{T}_{\mathrm{i}}\right)$, of about $0.0018,0.0035$ and 0.0045 , respectively, yielded this range.

Wall temperatures reached $1510 \mathrm{R}(840 \mathrm{~K})$, maximum wall-to-bulk temperature ratio was about 1.9 and the Mach number was less than 0.013, indicating that compressibility effects would have been negligible. On the other hand, the buoyancy parameter $\mathrm{Gr}_{\mathrm{q}} / \operatorname{Re}^{2}$ reached 0.53 for the highest heating rate and lower Reynolds number. The maximum wall-to-inlet temperature ratio was about 2.7 , indicating that gas properties such as viscosity varied by a factor of two in the test section. Exit bulk Reynolds numbers were above 3000 in all cases, corresponding to turbulent flow if the test section had been adiabatic.

Experimental uncertainties were estimated employing the technique of Kline and McClintock [1953], with the sensitivities to the 22 variables involved being deduced by exercising the data reduction program. The uncertainties in pointwise velocity and temperature were most sensitive to the uncertainties in the calibration coefficients and the wire resistance at the gas temperature. The latter was taken as $+/-0.005 \mathrm{ohm}$ and an uncertainty analysis gave $3.6 \%$ and $3.8 \%$ for $\mathrm{A}$ and $\mathrm{B}$, respectively, in the correlation $\mathrm{Nu}=$ $A+B R^{n}$. The uncertainties in these coefficients were dominated by the 
uncertainty in the wire diameter which was about two per cent. The resulting uncertainties in velocity and temperature are tabulated as functions of position and experimental run by Shehata [1984].

In general, the uncertainty in velocity was calculated to be in the range of 8 to 10 per cent of the pointwise value, with the larger percent uncertainties occuring near the wall. The uncertainty in temperature was typically one to two percent of the pointwise absolute temperature. These estimates are believed to be conservative (i.e., pessimistic) since comparisons of the integrated and measured total mass flow rates for each profile showed better agreement. The uncertainty of the variable area flowmeter was one to two per cent of the flow rate. Agreement with the integrated flow rate was of the order of three per cent or less, except near the exit in the runs with the two highest heating rates.

\subsection{Axial variation of integral parameters}

The streamwise variations of some of the pertinent integral parameters are shown in Figure 5. These quantities were deduced with the aid of energy balances which accounted for radial heat loss through the insulation, axial conduction along the test section to the electrodes and the slight variation of the electrical resistivity. The individual runs are identified by three digits representing the inlet Reynolds number and the non-dimensional heating rate (e.g., run 635 is for $\operatorname{Re}_{\mathrm{i}}$ approximately 6000 and $\mathrm{q}^{+}=0.0035$ ).

The first subfigure compares the measured wall temperatures. For the most severe situation the temperature increases by a factor of almost three, indicating that the viscosity and thermal conductivity vary by factors of about two in the test section. After the immediate thermal entry the wall temperature varies almost linearly despite the property variation; this behavior is comparable to the case with constant properties and constant wall heat flux [Kays and Crawford, 1980] but the magnitudes differ. One sees that the unheated entry region is not completely adiabatic at these high heating rates due to axial thermal conduction in the Inconel tube and axial thermal radiation from the internal wall downstream. The bulk temperature variation is nearly linear in these experiments because the wall heat flux and the specific heat of the air are both almost constant.

The bulk Reynolds number, defined as

$$
\operatorname{Re}_{\mathrm{m}}=\mathrm{GD} /\left(\mu\left\{\mathrm{T}_{\mathrm{b}}\right\}\right)=4 \dot{\mathrm{m}} /\left(\pi \mathrm{D} \mu_{\mathrm{b}}\right)
$$

decreases up the tube as a consequence of the increasing bulk temperature and viscosity. However, even for the most severe case it is not as low as 3000, 
which is still well above the value for transition in long tubes, according to conventional wisdom .

The local buoyancy parameter,

$$
\mathrm{Gr}_{\mathrm{q}} / \operatorname{Re}_{\mathrm{m}}^{2}=\frac{\mathrm{gD}^{4} \mathrm{q}_{\mathrm{w}}^{\prime \prime}}{v_{\mathrm{b}}^{2} \mathrm{k}_{\mathrm{b}} \mathrm{T}_{\mathrm{b}}} \frac{1}{\operatorname{Re}_{\mathrm{m}}^{2}}=\frac{\mathrm{gD}^{3}}{v_{\mathrm{b}}^{2}} \frac{\mathrm{q}_{\mathrm{x}, \mathrm{m}}^{+} \operatorname{Pr}_{\mathrm{b}}}{\operatorname{Re}_{\mathrm{m}}}
$$

behaves in an unexpected but explicable manner. (Properties are evaluated at the local bulk temperature, e.g., $\mathrm{q}^{+} \mathrm{m}$ is defined as $\mathrm{q}^{\prime \prime} \mathrm{w}, \mathrm{x} /\left(\mathrm{G}_{\mathrm{cp}, \mathrm{m}} \mathrm{T}_{\mathrm{m}}\right)$.) The numerator remains constant for a gas with constant heat flux, while the denominator increases as $\mathrm{T}^{3.8}$ approximately. Consequently, the parameter is highest near the thermal entrance and then decreases along the test section. The maximum values indicate that buoyancy effects could be significant -and, in predictive techniques, must be treated in the momentum equation at least and possibly in the turbulence model directly.

The local acceleration parameter,

$$
K_{V}=\left(V_{b} / V_{b}^{2}\right)\left(d V_{b} / d x\right)
$$

remained near constant after the immediate thermal entry, except for the last few diameters near the exit. It reached values of $1.2 \times 10^{-6}, 2.2 \times 10^{-6}$ and $4 \times$ $10^{-6}$ for runs 618,635 and 445 , respectively. For unheated accelerating flows, Kline et al. [1967] noted that turbulent bursts apparently ceased when their comparable $K_{u}$ reached a critical value of $3.7 \times 10^{-6}$. On the other hand, for a value of $\mathrm{K}_{\mathrm{V}}$ of about $1.5 \times 10^{-6}$ Chambers, Murphy and McEligot [1983] found the bursting rate to remain approximately constant at the turbulent value when based on wall scaling. In these terms, the present experiments could be expected to span a range from fully turbulent to "laminarizing."

\subsection{Turbulent, Run 618}

The first set of data is for the "low" heating rate conditions characterized as turbulent by Perkins [1975]. The reference control parameters were $\mathrm{Re}_{\mathrm{i}} \approx 6000$ and $\mathrm{q}^{+} \approx 0.0018$ (i.e., run 618 ), leading to an acceleration parameter of about $1.2 \times 10^{-6}$ as shown in Figure 5. The non-dimensional radius of the unheated upstream section is about $\mathrm{r}^{+} \approx 200$. It is expected that the heat transfer parameters would correspond to turbulent predictions, with allowance for a reduction in local Nusselt number due to the gas property variation along the tube and across the viscous layer. 
Figure 6 presents the thermal and momentum development axially in terms of mean profiles at 3.17, 14.2 and 24.5 diameters. Obtaining the mean streamwise velocity data was the main objective of the present work since Perkins [1975] was unable to obtain meaningful velocity measurements in his attempts with an impact tube. Velocities are normalized by the local value of the bulk velocity while the non-dimensional temperatures are based on the (absolute) inlet temperature.

Velocity profiles appear representative of normal, developed turbulent flow in a circular tube, as expected. As the flow progresses downstream, the gradient at the wall decreases with the progressive decrease in Reynolds number. No surprises are evident.

For the present results a thermal boundary layer thickness is operationally defined as the distance from the wall beyond which there is no observable difference from the inlet temperature, as observed on the figures. At $x / D=3.17$, the thermal boundary layer reached about forty per cent of the tube radius. By 14.2 diameters, the thermal boundary layer already extended to the centerline and the profile is typical of a developed turbulent flow, distinguished by a high gradient near the wall (most of the thermal resistance) and a well mixed flow in the interior. The last profile is qualitatively the same, with an increase in level corresponding to the higher bulk temperature.

The temperature data of Perkins [1975] behave in much the same way as the data in this study. Variations between the two are mainly due to minor differences in the heating rates and inlet Reynolds numbers.

\section{4 "Subturbulent," Run 635}

The second set of data is at the intermediate heating rate $\left(\operatorname{Re}_{i}\right.$ still 6000 and $\mathrm{q}^{+} \approx 0.0035$ ) which was described as subturbulent by Perkins [1975]. The acceleration parameter was about $2 \times 10^{-6}$ along most of the tube. This set has almost twice the heating rate and $\mathrm{K}_{\mathrm{V}}$ as the first set, while having the same inlet flow rate. For these conditions, Perkins has shown that the integral heat transfer parameters do not agree with turbulent, variable properties correlations nor with laminar, variable properties numerical predictions.

Since this run is considered the most difficult of the three to model [Perkins, 1975], mean profile data were obtained at more stations. Figure 7 shows the thermal development at five axial locations. The first three profiles indicate that the thermal boundary layer reached the centerline near $x / D=9$ or 10. Near the wall the temperature profile was near linear over a substantial region. This region grew thicker as the flow progressed downstream, reaching $y / r_{W} \approx 0.25$ by the last station. Although significant thermal resistance appears distributed across a large portion of the cross section, a near flat profile is still 
evident in the central region at the last three locations. This last observation implies that turbulent mixing is not suppressed there (it is not a case of being outside the thermal boundary layer, since the centerline temperature is above $\mathrm{T}_{\mathrm{i}}$ ).

Again the velocity distribution appears to represent typical developed turbulent flow in a tube. If the normalized profiles are compared directly with the previous set of profiles from run 618 (in Figure 6), one sees no large differences. At $x / D \approx 3.2$ the profiles are almost coincident. Again at $x / D \approx 14.2$ they also are. Finally at the last location, run 635 is slightly more "peaked" than run 618. That is, the (non-dimensional) gradient near the wall is lower and the central velocities are higher than for run 618 . This observation is consistent with a thicker viscous layer -- and with the lower local Reynolds number due to the higher heating rate. In both cases the gradients near the wall became less steep as the flow progressed downstream.

\section{5 "Laminarizing," Run 445}

The last set of runs is at the highest non-dimensional heating rate and lowest inlet flow rate $\left(\operatorname{Re}_{\mathrm{i}} \approx 4000\right.$ and $\mathrm{q}^{+} \approx 0.0045 \rightarrow-->$ run 445$)$. These conditions were categorized as being on the borderline between subturbulent and laminarizing flow by Perkins (his Figure 8). Figure 5 shows that $\mathrm{K}_{\mathrm{V}}$ exceeds $3.5 \times 10^{-6}$, which is considered by Sreenivasan [1982] and others as a critical value for laminarization to set in. The parameter $\mathrm{Gr}_{\mathrm{q}} / \operatorname{Re}^{2}$ peaks at over 0.4 , implying possible buoyancy effects.

The measurements at 3.17 diameters (Figure 8) show that the thermal boundary layer had grown to $y / r_{W} \approx 0.4$ by this distance. Presumably this growth is partially a consequence of upstream axial conduction and axial thermal radiation to the tube wall of the "unheated" entry region, as is evident in earlier Figure 5. By $x / D=14.2$ the thermal boundary layer again filled the tube. The temperature profile started to take a parabolic shape, except in the central region where the effects of turbulent mixing still appear significant. At $\mathrm{x} / \mathrm{D}=24.5$, the measured temperature profile resembles a parabola more closely.

One recalls that the analytic profile for fully established laminar flow with constant properties is a fourth-order parabola [Kays and Crawford, 1980] but, in these data, viscosity and thermal conductivity vary by factors of about two and at this Reynolds number a laminar flow would require a longer distance to become fully established. However, Perkins [1975] did demonstrate that a laminar, variable properties calculation - starting from the existing turbulent velocity profile in the entry - could provide reasonable predictions of the mean temperature distribution for comparable conditions. 
The mean velocity profiles in the wall region (Figure 8 ) show a near Blasius shape while progressing downstream. In the central region, about half the radius, the profiles are almost flat for the measurements at $x / D=14.2$ and 24.5 , indicating high turbulent mixing, effects of acceleration, reduced shear stress and/or buoyancy effects there.

The velocity profile at 14.2 diameters possesses an obviously distorted shape, consistent with buoyant forces in a heated, vertical gas flow. The velocity reached a maximum at $y / \mathrm{r}_{\mathrm{W}} \approx 0.45$ after which it decreased to $\mathrm{y} / \mathrm{r}_{\mathrm{W}} \approx$ 0.6 and then remained approximately constant to the centerline. The local value of $\mathrm{Gr}_{\mathrm{q}} / \mathrm{Re}^{2}$ is about 0.3 at this location. With a tube of larger diameter, Carr, Connor and Buhr [1973] noticed a profile with comparable distortion at $\mathrm{Gr}_{\mathrm{q}} / \operatorname{Re}^{2} \approx 0.46$ but at $\mathrm{Gr}_{\mathrm{q}} / \operatorname{Re}^{2} \approx 0.28$ they observed none. By using a larger tube, they reached these values with lower heating rates, i.e., less gas property variation. At the last measuring station, the velocity profile does not show an obvious maximum away from the centerline but it possesses a significant flat portion across a broad core region. The local value of $\mathrm{Gr}_{\mathrm{q}} / \operatorname{Re}^{2}$ has decreased to below 0.2 at this position so this observation of no maximum near the wall is consistent with the data of Carr, Connor and Buhr.

\subsection{Comparisons for the viscous layer}

Mean velocity and temperature profiles for the various runs are compared to each other for the viscous layer after the immediate thermal entry in Figure 9. The temperature profiles correspond to those of Perkins [1975] while the velocity profiles are the major new contributions of the current work. Their shapes are also compared to conventional predictions for fullyestablished, constant-property, forced convection at $x / D \approx 24$, the furthest location downstream. The wall coordinate $\mathrm{y}^{+}$is defined in this presentation and the rest of the paper unambiguously in terms of the wall quantities as $y\left(\tau_{w} / \rho_{w}\right)^{1 / 2} / \nu_{w}$, i.e., all properties and the shear stress are evaluated at the wall rather than at the pointwise value of $y$.

Direct measurements of the local wall shear stress are generally not feasible for the conditions of this experiment (and it cannot be deduced from local estimates of $d p / d x$ as in unheated flow since $u\{y\}$ varies continuously in the streamwise direction), so to form the non-dimensional wall coordinates $\tau_{w}$ has been estimated from a correlation for variable gas properties suggested by Taylor [1967]. (This approach is employed for presentation purposes in only Figure 9 and Section 4.6 here.) The shape of the temperature profile $t^{+}\left(y^{+}\right)$is not sensitive to the uncertainty in $\tau_{w}$ since its error affects $t^{+}$and $y^{+}$in the same direction. The velocity profile definitely is sensitive since $\tau_{W}$ appears in the numerator for $\mathrm{y}^{+}$and in the denominator for $\mathrm{u}^{+}$. Consequently the 
presentation in this section should be treated as qualitative; this one figure is not suitable for testing turbulence models except in a coarse sense (= "warning" to analysts).

Temperature profiles show the trends identified by Perkins. These trends are slight at $x / D \approx 14$ where the thermal boundary layer has apparently barely reached the centerline and are more evident at $x / D \approx 24$ where there has been more opportunity for development in response to the thermal disturbance at the wall. Examining Run 618 (low $\mathrm{q}^{+}$, higher $\mathrm{Re}_{\mathrm{i}}$ ), one sees evidence of a logarithmic profile beyond the viscous layer. Then as $\mathrm{q}^{+}$ increases and $\operatorname{Re}_{i}$ decreases, the non-dimensional temperature profile $\mathrm{t}^{+}\left(\mathrm{y}^{+}\right)$ increases. Such an increase in $\mathrm{t}^{+}\left(\mathrm{y}^{+}\right)$corresponds to a reduction in turbulent transport with a greater fraction of $\mathrm{q}^{\prime \prime}(\mathrm{y})$ being due to molecular transport. Comparable behavior has been observed for momentum transport in the viscous layer of flows with favorable streamwise pressure gradients [McEligot and Eckelmann, 1993] and of flows with drag reduction by polymer addition [Brodkey, 1975].

The conditions at $x / D \approx 25$ (Figure $9 \mathrm{c}$ ) might be expected to be quasideveloped. The data from Run 618 are compared to the log law prediction of Johnk and Hanratty [1962],

$$
\mathrm{t}^{+}=3.32+5.09 \log _{10} \mathrm{y}^{+}
$$

and to a lower Reynolds number version presented by Kays and Crawford (their equation 13-6), with gas properties evaluated at the wall. The data are higher than either prediction; this observation is consistent with a thicker viscous layer, which would increase the thermal resistance and lower the Nusselt number as observed for heated, turbulent flows with gas property variation [McEligot, 1986a,b].

The fourth-order parabola for fully-established, constant-property laminar flow,

$$
\mathrm{t}^{+}=\operatorname{Pr} \cdot \mathrm{y}^{+}\left[1+\left(0.5 \mathrm{y} / \mathrm{r}_{\mathrm{w}}\right)-\left(\mathrm{y} / \mathrm{r}_{\mathrm{w}}\right)^{2}+0.25\left(\mathrm{y} / \mathrm{r}_{\mathrm{w}}\right)^{3}\right]
$$

has been evaluated at the conditions of Run 445. At the tube center $\mathrm{y}^{+} \mathrm{c} \approx 70$, $t^{+}\left(y^{+} c\right)$ is predicted to be about 37 . One sees agreement with this prediction for pure molecular transport to $y^{+} \approx 20-30$ and then possible evidence of turbulent transport further from the wall, in the sense that $t^{+}\left(\mathrm{y}^{+}\right)$data are lower than the laminar prediction. The comparable run presented by Perkins was at slightly more severe heating conditions $\left(\mathrm{q}^{+} \approx 0.0055\right.$ vice 0.0045$)$ and gave close agreement almost to the centerline. 
Run 635 temperature results fall intermediate between those of Runs 618 and 445. There is an indication of less turbulent transport of thermal energy than Run 618 and more than Run 445. The measurements of Run 635 do not fall near either limiting prediction and there is no apparent log law region.

Mean velocity profiles $\mathrm{u}^{+}\left(\mathrm{y}^{+}\right)$are compared to one another at $\mathrm{x} / \mathrm{D} \approx 14$ and 25 in Figures $9 \mathrm{~b}$ and $d$. As with $\mathrm{t}^{+}\left(\mathrm{y}^{+}\right)$, Run 618 has a profile shape as expected for normal fully-developed, turbulent tube flow at both locations (as well as the entering adiabatic profile). In fact, at 25 diameters an adjustment of eight to ten per cent in $\left(\tau_{\mathrm{W}}\right)^{1 / 2}$ would provide reasonable agreement both with the molecular transport prediction,

$$
\mathrm{u}^{+}=\left(\mathrm{y}^{+} / 2\right)\left[1+\left(\mathrm{r} / \mathrm{r}_{\mathrm{w}}\right)\right]
$$

at low $\mathrm{y}^{+}$and with turbulent recommendation based partly on a relation for eddy viscosity by Reichardt (Kays and Crawford, equation 11-5)

$$
\mathrm{u}^{+}=5.5+\ln \left\{1.5 \mathrm{y}^{+}\left[1+\left(\mathrm{r} / \mathrm{r}_{\mathrm{W}}\right)\right] /\left[1+2\left(\mathrm{r} / \mathrm{r}_{\mathrm{W}}\right)^{2}\right]\right\}
$$

for $\mathrm{y}^{+}>\sim 30$.

At fourteen diameters, Run 445 has $\mathrm{u}^{+}\left(\mathrm{y}^{+}\right)$measurements in approximate agreement with Run 618 to $\mathrm{y}^{+} \approx 30$ (which is about one-third of the distance to the centerline) and then the profile flattens, possibly due to the buoyant thermal boundary layer. The buoyancy parameter $\mathrm{Gr}_{\mathrm{q}} / \operatorname{Re}^{2}$ is about 0.3 at this location. The maximum velocity occurs between $\mathrm{y}^{+}$of 30 and 40 so the core region "sees" the wall region flow as a higher velocity mixing layer, as if it were a concentric annular jet.

At 25 diameters the Run 445 profile data again agree with the higher Reynolds number run to $\mathrm{y}^{+} \approx 20-30\left(\mathrm{y} / \mathrm{r}_{\mathrm{W}} \approx 0.35-0.5\right)$, then there is a sharp change in the velocity gradient - corresponding to increased turbulent transport - followed by a relatively flat central core. The buoyancy parameter $\mathrm{Gr}_{\mathrm{q}} / \operatorname{Re}^{2}$ has decreased to about 0.2 by this location and the maximum velocity is no longer near the wall. This behavior is as one might expect for the physical entry of a pipe, with the central core accelerating uniformly with a flat profile until the momentum boundary layer grows to the center. But in the present case the turbulent velocity profile is approximately fully-developed ahead of the heating section. The high wall heat flux leads to a rapid increase in wall temperature in the axial direction and, in turn, to higher viscosity $\left(\mu \sim \mathrm{T}^{0.7}\right)$. Thus, the thermal boundary layer may appear to the oncoming turbulent flow as a slight contraction or pseudo tube entry would. (This profile is also reminiscent of a 
transition spot in a wind tunnel boundary layer.) Also acceleration with $K_{V} \approx 4$ $x 10^{-6}$ is comparable to flow through a converging nozzle as by Launder [1964].

For Run $635, \mathrm{u}^{+}\left\{\mathrm{y}^{+}\right\}$shows a conventional turbulent shape at both 14 and 25 diameters and generally is intermediate between Runs 618 and 635 . One could identify approximately linear viscous layer and "log law" regions, but the magnitudes do not agree with accepted levels for fully-developed, constantproperty flows. It is difficult to establish bounds for these regions (and it may not be appropriate to examine these developing flows, with multiple

phenomena, in terms of these concepts), but a possible interpretation is that the viscous layer is effectively thickened near the wall while momentum transport is enhanced away from the wall.

The effects of significant gas property variation on the mean velocity profiles appear to differ from those on the mean temperature profiles. Whereas the temperature profiles vary as the velocity profiles of accelerated flows and drag-reducing polymer flows do, the present velocity profiles do not.

One may compare Figures $9 \mathrm{c}$ (temperature) and 9d (velocity), where correlations of conventional wisdom have been sketched for reference. For $\mathrm{t}^{+}\left\{\mathrm{y}^{+}\right\}$, as the non-dimensional heating rate becomes more severe, profiles away from the wall approach the laminar prediction with increasing values implying reduction in the turbulent transport of energy. For $u^{+}\left\{y^{+}\right\}$the opposite is observed: away from the wall the profiles decrease as $\mathrm{q}^{+}$increases, corresponding to increased turbulent transport of momentum or a trend like increasing wall roughness. Direct measurements of other mean turbulence quantities are not available from our single wire sensor, but insight on effects in the viscous layer can be obtained by further data reduction via turbulence modeling as in the next section.

\subsection{Distribution of mean turbulence quantitites in conventional viscous layer}

While mixing length turbulence models are going out of fashion for prediction of complex turbulent flows, they can still be valuable to provide a diagnostic technique for deducing additional mean turbulence quantities from measurements of mean velocity and temperature distributions. For example, once one establishes agreement with measured $U(y, x)$ and $T(y, x)$ fields, the distributions of $\varepsilon / v, 1 / r_{W},-\overline{u v},-\overline{v t}$, etc. -- that are required for that matching -may be considered to be indirectly deduced data. (And as mentioned in the Introduction, so-called advanced turbulence models typically are adjusted to agree with the van Driest [1956] mixing length model in the wall region anyhow.) This approach could be thought to be an extension of the earlier technique of deducing eddy diffusivity profiles for simple fully-developed, adiabatic flows by fitting mean velocity profiles. It is also akin to the use of 
simple turbulence models to deduce $\tau_{\mathrm{W}}$ in streamwise accelerating flows from single point velocity measurements [McEligot and Eckelmann, 1990].

Based primarily on comparison to $\mathrm{Nu}\{\mathrm{x}\}$ data from small tube experiments, McEligot and Bankston [1969] extended the van Driest model to treat turbulent-to-laminar transition due to strong heating. Essentially they extended a history/delay function from Nash and MacDonald [1967] and modified the van Driest representation to include Reynolds number dependence. Adjusting the quantities which control the pointwise values of $1 / r_{W}$ allows matching the mean velocity and temperature development. Lacking velocity data to check prediction of turbulent momentum transport, Perkins [1975] applied this technique to provide some preliminary estimates of variations of viscous layer thickness and of $\varepsilon / v$ from his adjusted van Driest model. Now that we also have mean axial velocity data available as well for comparable conditions, such indirectly deduced data can be derived and presented with more confidence.

Figure 10 demonstrates that our adjustments of the van Driest model do correlate the mean velocity and temperature measurements adequately for our Run 635 , the most difficult of the three to predict. The range $0<\mathrm{y} / \mathrm{r}_{\mathrm{W}}<0.5$ was selected for presentation, corresponding to $0<y^{+}<40$ at the exit (and $y^{+}<100$ at the start of heating). These numerical predictions were obtained by applying the finite control volume program of Bankston and McEligot [1970] with the addition of a body force term in the momentum equation. There is no direct functional accounting for buoyancy effects in the turbulence model itself; however, adjustment of the turbulence model for flows in this range of parameters would imply indirect allowance for buoyancy effects.

The deduced distributions of mixing length, eddy diffusivity, Reynolds shear stress and turbulent heat flux are presented in Figures 11 through 14 in non-dimensional form. For these figures, $u_{\tau}, \tau_{\mathrm{W}}$ and related quantities are derived from the predictions (which were shown in Figure 10 to agree with the velocity and temperature measurements) rather than from the correlation used earlier. With the exception of $-\rho c_{p} \overline{v t} / q^{\prime \prime}{ }_{w}$, the upstream adiabatic profiles are included for comparison. The range of the abscissa, $0<\mathrm{y}^{+}<40$, is chosen to cover the region which would extend beyond significant molecular effects -- if the flow were not heated. For this series of figures the circular symbols indicate the profile at the end of the adiabatic entry, the solid line represents the first measuring location inside the heated region, the small triangles are for the last profile and various broken lines are used for stations in between.

The mixing length is normalized by the distance from the wall as $1\{y\} / y$. Results are presented in Figure 11 for the conditions of the three experimental runs. For unheated flows at high Reynolds number, the van Driest version of 
this quantity would asymptote to the von Karman constant (about 0.4) as $\mathrm{y}^{+}$ becomes large. In Figure 11a, the van Driest mixing length [1956] is plotted with centerline symbolism for reference purposes. The low Reynolds number yields a slightly lower mixing length than the asymptotic relation. For Run 618 (labeled "turbulent") the adiabatic profile is almost coincident with the values deduced at $x / D \approx 3.2$, then they decrease slightly as the axial distance, temperature and viscosity increase. The bulk Reynolds number decreases from about 6000 to 5300 from the entry to the last station. For the range from 14 to 25 diameters, $1\{y\} / y$ appears to have settled to an approximately constant (selfpreserving) profile.

For Run 635 ("subturbulent" - Figure 11b) the 1/y profile dropped very slightly in the range $10<y^{+}<40$ from the entry to $x / D \approx 3.2$, the first heated station. Then, although within the region usually expected to have significant turbulent transport (i.e., $\mathrm{y}^{+}>5$ ), the level of this profile dropped continuously to the end of the heated region. As one may surmise from Figure 9, this region also becomes physically thicker as both $\mathrm{q}^{+}$and $\mathrm{x} / \mathrm{D}$ increase, since $\mathrm{y}^{+} \mathrm{c}$ decreases as $\mathrm{q}^{+}$and $\mathrm{x} / \mathrm{D}$ increase.

Compared to the other two runs, Run 445 ("laminarizing" - Figure 11c) has a slightly lower profile of $1 / y$ in the adiabatic entry as a consequence of the lower inlet Reynolds number. Then with the higher heating rate $\mathrm{q}^{+}$there is a substantial reduction before the first measuring station in the heated region. As with Run 635, the mixing length profile decreases continuously the rest of the way to the end of the measuring region; values are lower than Run 635 at $x / D \approx 14$ and about the same at $x / D \approx 25$.

The non-dimensional eddy diffusivity for momentum, $\varepsilon_{\mathrm{m}}\{\mathrm{y}\} / \nu\{y\}$, generally shows the same trends as $1 / y$ except in Run 618 , with the lowest heating rate. As a consequence of its definition, $\varepsilon_{\mathrm{m}} / v$ can also be considered to be $-\rho \overline{\mathrm{uv}} / \tau_{\text {lam. }}$. Results are plotted in Figure 12. In Run 618 at $\mathrm{x} / \mathrm{D} \approx 3.2$, an indirect effect of the significant increase in viscosity near the wall apparently is to increase $\varepsilon_{\mathrm{m}} / v$ slightly in the region $7<\mathrm{y}^{+}<40$. For this location Figure 6 shows that the thermal boundary layer extends to $y / \mathrm{r}_{\mathrm{w}} \approx 0.4$, which corresponds to $\mathrm{y}^{+} \approx 60$. By $\mathrm{x} / \mathrm{D} \approx 8.7$ where $\delta_{\mathrm{th}} / \mathrm{r}_{\mathrm{w}} \approx 2 / 3$, the required eddy diffusivity profile has settled back to the entry level; then there is a gradual reduction to an approximately constant profile downstream in the range $14<$ $x / D<25$. For the most part, the behavior is as one would expect for fullydeveloped or quasi-developed turbulent flow at a low Reynolds number. However, near the exit the kinematic viscosity at the wall is a factor of about two higher than at the centerline. 
As a measure of the viscous layer thickness or a length scale for the viscous layer, we can choose the distance from the wall where $\varepsilon_{\mathrm{m}}$ is equal to $v$, i.e., where $\varepsilon_{\mathrm{m}} / v=1$ on the figure. For convenience, we call this location $\mathrm{y}^{+} \mathrm{v}$. For the entry profile $\mathrm{y}_{\mathrm{v}}^{+} \approx 12$; it decreases to about 11-1/2 and then increases to $\mathrm{y}_{\mathrm{v}}^{+} \approx 14$ downstream. This thickening of the viscous sublayer is consistent with empirical correlations for turbulent flow that show reductions in integral heat transfer parameters with increasing gas property variation.

In Run 635 there is a continuous decrease in the values of $\varepsilon_{\mathrm{m}} / v$ with the exception of the first few diameters of heating. Again the profile values are higher at $x / D \approx 3.2$ than for the adiabatic entry - and are higher than for Run 618 by a miniscule amount at the same location. They then decrease continuously with axial location rather than approaching an apparent asymptote as in Run 618. By the last station $\varepsilon_{m} / \nu$ is less than about $1 / 2$ from the wall to $\mathrm{y}^{+}=40$; that is, molecular transport dominates throughout the region conventionally considered to be the viscous layer. It should perhaps be noted that this reduction is not solely a consequence of the accompanying reduction in Reynolds number: this last profile is at a bulk Reynolds number of about 4800 whereas the adiabatic profile for $\operatorname{Re} \approx 4300$ is considerably higher (i.e., the inlet condition for Run 445, Figure 12c). In terms of our viscous layer length scale, $\mathrm{y}^{+} \mathrm{v}$ is about 12 at the entry and decreases to 11 at $\mathrm{x} / \mathrm{D} \approx 3.2$ before increasing successively to $15,27,42$ and 56 for $x / D \approx 8.7,14.2,19.9$ and 24.5 , respectively. One might say the viscous layer, which conventionally would have significant turbulent transport from $\mathrm{y}^{+} \approx 5$ to 30 , has laminarized although integral heat transfer parameters would not agree with laminar predictions [Perkins, 1975].

For Run 445 heating conditions are sufficiently severe that throughout the range of measurements $\varepsilon_{\mathrm{m}} / v$ decreases with $\mathrm{x}$. The inlet profile still represents normal turbulent flow albeit reduced compared to asymptotic high Reynolds number values, as hypothesized by McEligot, Ormand and Perkins [1966] and shown by Reynolds, Davenport and McEligot [1968] and Patel and Head [1969]. The viscous layer length scale $\mathrm{y}^{+}{ }_{\mathrm{v}}$ thickens continuously with $\mathrm{x}$, almost reaching $\mathrm{y}^{+}=40$ at $\mathrm{x} / \mathrm{D} \approx 14$. At $\mathrm{x} / \mathrm{D} \approx 24.5, \varepsilon_{\mathrm{m}} / v<1 / 4$ from the wall to $y^{+}=40$ (but increasing beyond this region to a maximum of 0.6 near the centerline, though not shown). If the viscous layer is defined as the region where molecular transport is important [Bradshaw, 1971], at this station it extends across the entire tube. At the last station the bulk Reynolds number is about 3300 . While Run 635 might be considered to be laminarizing 
downstream, Run 445 appears to be laminarizing along the entire heated length but it is a matter of degree. Perkins [1975] has shown that the local Nusselt number for conditions like this run could be expected to agree with a laminar, variable properties correlation for the thermal entry to within close to ten per cent downstream (the present data agree within about twenty per cent). However, although $\varepsilon_{\mathrm{m}} / v$ shows an essentially laminar layer, hot wire signals showed turbulent fluctuations -- apparently they are not transporting much momentum (in comparison to molecular transport).

As seen earlier in Figures 8 and 9 , the mean velocity profile beyond $y^{+} \approx$ 30 becomes approximately uniform (with a possible local maximum at $x / D \approx$ 14.2 and $y^{+} \approx 30$ ) so $\varepsilon_{m} / \nu$ becomes near zero there in an apparently well-mixed central core. This trend would be consistent with the buoyancy effects observed by Carr, Connor and Buhr [1973] at $\mathrm{Gr}_{\mathrm{q}} / \mathrm{Re}_{\mathrm{m}}{ }^{2} \approx 0.46$ in mixed convection with near constant properties. For our data in Run 445, $\mathrm{Gr}_{\mathrm{q}} / \mathrm{Re}_{\mathrm{m}}{ }^{2}$ decreases from $\sim 0.4$ to $\sim 0.2$ over the distance from $x / D \approx 6->25$.

The required Reynolds shear stress or turbulent shear stress distribution, $-\rho \bar{u} \bar{v}$, which is required in order to obtain agreement of predictions and measurements, is shown normalized by the local wall shear stress in Figure 13. While trends observed generally mirror those discussed for $1 / y$ and $\varepsilon_{\mathrm{m}} / \nu$, there are slight differences due to the manner in which molecular property variation enters into the calculation as we discuss now.

For fully-developed, adiabatic turbulent flow the total shear stress, $\mu(\partial \mathrm{U} /$ $\partial y)-\rho \overline{u v}$, decreases linearly from the wall to the centerline. Therefore, across the viscous layer the normalized Reynolds stress increases from zero to approach the value for the total shear stress, as molecular effects become less important, and then follows this decreasing ramp-like function to zero at the centerline. For each run, one can discern the beginning of this behavior in the adiabatic entry profile of $-\rho \overline{u v} / \tau_{w}$.

With the significant heating of Runs 618 and 635, the levels of these Reynolds stress profiles decrease from the entry to $x / D \approx 3.2$, whereas we saw that $\varepsilon_{\mathrm{m}} / \nu$ increased initially with heating. However, $\tau_{\mathrm{w}}$ increased more than $\varepsilon_{\mathrm{m}} / v$ did, yielding the reduction observed in the normalized profile. Otherwise $-\rho \overline{\mathrm{u} v} / \tau_{\mathrm{w}}$ behaves as implied by the variation of $\varepsilon_{\mathrm{m}} / v$ in Figure 12 . For the "turbulent" run (618) the normalized Reynolds stress settles to an approximately constant profile from $x / D \approx 8$ to 25 with slight variation. For the other two runs at higher heating rates, these profiles decrease to negligible values as the axial distance increases. For Run 445 the reduction in the first few 
diameters is more severe than for Run 635; in a sense, Run 445 laminarizes more quickly (as might be expected for lower $\operatorname{Re}_{\mathrm{i}}$ and higher $\mathrm{q}^{+}{ }_{\mathrm{i}}$ ).

The turbulent heat flux, $-\rho c_{p} \overline{v t}$, is shown in Figure 14 normalized by the local wall heat flux, i.e., q"turb $\{y, x\} / q^{\prime \prime}\{x\}$. However, $q^{\prime \prime}\{x\}$ is not a significant function of axial position except near the lower electrode, so the denominator is approximately constant. No profile is presented for the adiabatic entry (since the denominator would be zero). In matching the mean temperature profiles to the measurements a constant value of unity was used for the turbulent Prandtl number in the turbulence model, so it is implied in the deduction of the turbulent heat flux as well.

For fully-established flows with constant properties, $\mathrm{q}^{\prime \prime}\{\mathrm{y}\} / \mathrm{q}_{\mathrm{w}}$ behaves qualitatively as $\tau\{y\} / \tau_{w}$ does, although not linearly [Kays and Crawford, 1980]. For that case, $-\rho c_{\mathrm{p}} \overline{\mathrm{vt}} / \mathrm{q}^{\prime \prime}{ }_{\mathrm{w}}$ will likewise behave qualitatively as the adiabatic values of $-\rho \overline{\mathrm{uv}} / \tau_{\mathrm{w}}$ presented in Figure 13. However, the reader is reminded that the present flows do not become fully-established but develop continuously as the properties vary.

For Run 618 , as $\mathrm{x}$ increases, the profile decreases slightly near the wall ( $\left.\mathrm{y}^{+}<\sim 13\right)$ and increases further away. The increase at $\mathrm{y}^{+}=O(30)$ corresponds to the growth of the thermal boundary layer.

For Runs 635 and 445 the reduction in $\rho c_{p} \overline{v t}=-k \cdot\left(\varepsilon_{m} / v\right) \cdot\left(\operatorname{Pr}_{\mathrm{Pr}}\right) \partial \mathrm{T} / \partial \mathrm{r}$ leads to turbulent transport accomplishing a lower fraction of the heat transfer than for the low $\mathrm{q}^{+}$run. Then in both cases the values decrease with $\mathrm{x}$ as $\mathrm{T}\{\mathrm{y}, \mathrm{x}\}$ and, therefore, molecular transport properties increase. For example, at the last station the thermal conductivity $\left(\mathrm{k}_{\mathrm{w}} / \mathrm{k}_{\mathrm{in}}\right)$ has increased by factors of about 1.5, 2.2 and 2.3 for Runs 618,635 and 445 , respectively. While the magnitude of $\rho c_{p} \overline{v t} / q^{\prime \prime}{ }_{w}$ decreases with $x / D$, its local peak value shifts toward the center as $\delta_{\text {th }}$ grows. At comparable axial locations the magnitude of $\rho c_{p} \overline{v t} / q^{\prime \prime}$ for Run 445 is lower than for Run 635; again Run 445 is more "laminarized." In this run, by $x / D \approx 14$ the maximum fractional contribution from turbulent transport is less than ten per cent -- which would help explain why integral parameters would approach agreement with a laminar heat transfer correlation. 


\section{CONCLUDING REMARKS}

The anatomy of the viscous layer in gaseous, turbulent tube flow with strong heating has been probed via thermal anemometry coupled with diagnostic application of simple computational thermal fluid dynamics. Experiments for air flowing upward in a vertical circular tube were conducted for heating rates causing significant property variation. An unheated entry of fifty diameters preceeded the heating. Two entry Reynolds numbers of approximately 6000 and 4000 were employed concentrating on three heating rates, $\mathrm{q}^{+} \approx 0.0018,0.0035$ and 0.0045 , giving conditions considered to be "turbulent," "subturbulent" and close to "laminarizing," respectively. The acceleration parameters and buoyancy parameters were significant with ranges of $1.2 \times 10^{-6}<\mathrm{K}_{\mathrm{V}}<4.1 \times 10^{-6}$ and $0.1<\mathrm{Gr}_{\mathrm{q}} / \operatorname{Re}_{\mathrm{m}}{ }^{2}<0.53$, respectively.

Examination emphasizes the wall region which would conventionally be expected to contain the viscous layer, $0<\mathrm{y}^{+}<\sim 30$, if the flow were unheated.

Development was measured by obtaining internal mean axial velocity and temperature profiles at axial stations from about 3.2 to 24.5 diameters. These measurements required a substantial development effort and calibration to account for the effects of large temperature differences on the thermal anemometry employed. In addition to these profile data, application of a simple turbulence model in our predictive program led to deduction of the associated profiles of mixing length, eddy diffusivity, Reynolds shear stress and turbulent heat flux required at the same stations.

General effects of strong heating of a gas are variation of the transport properties, reduction of density causing acceleration of the flow in the central core, and - in some cases - significant buoyancy forces. Growth of the internal thermal boundary layer leads to readjustment of the previously fullydeveloped turbulent momentum profile. No truly fully-established conditions are reached because the temperature rises -- leading, in turn, to continuous axial and radial variation of properties such as the gas viscosity.

In these flows the thermal boundary layer reached the centerline by about fourteen diameters. At the higher Reynolds number and lowest heating rate (called "turbulent" above), after being disturbed in the first few diameters by the heating and its accompanying variation of viscosity, density and thermal conductivity, profiles representing the turbulence quantities $-1 / y, \varepsilon_{m} / v$, $-\rho \bar{u} \bar{v} / \tau_{w}$ and $-\rho c_{p} \overline{v t} / q^{\prime \prime}{ }_{w}$-- appear to recover to an approximately selfpreserving condition. In the other two runs with higher heating rates, the turbulence quantities decrease after the entrance until they are small relative to molecular effects. At the highest heating rate the velocity profiles show evidence of buoyancy effects from $x / D \approx 14$ to 25 . 
Results for the range $0<\mathrm{y}^{+}<40$ demonstrate the unliklihood of a turbulence model based on wall functions providing reasonable predictions. Without appropriate adjustment, the original van Driest mixing length model does not match the local 1/y profile. Until these data became available, "advanced turbulence models" for internal flow with variable properties (e.g., Kawamura [1979], Inagaki and Komori [1993], Torii et al. [1993]) have not even had mean velocity profiles to verify or refute their assumptions for the viscous layer. And recent comparisons by Mikielewicz [1994] have shown that most are refuted for these conditions. 


\section{Appendix A}

\section{Integral results and inlet conditions}

Shehata's [1984] data for wall measurements and inlet conditions are provided in this Appendix. Organization is in terms of the nominal run conditions for the three cases featured in this report, Runs 618, 835 and 445. (These three digit numerals provide the approximate inlet Reynolds number and heating rate, e.g., Run 445 corresponds to $\operatorname{Re}_{i n} \approx 4000$ and $\mathrm{q}^{+} \approx 0.0045$, respectively.)

For each run the following tables are presented sequentially:

1. Axial distributions of selected deduced wall and integral parameters.

2. An adiabatic velocity profile taken near the lower electrode at a Reynolds number near $\operatorname{Re}_{\text {in }}$ for the heated run.

3. The wall temperature distribution upstream of the lower electrode during the heated run.

4. The deduced distribution of the non-dimensional pressure defect, $\mathrm{P}^{+}$, in the tube - for comparison to predictions which include the vertical body force in the momentum equation.

The axial data were reduced via a Fortran program developed by Perkins [1975] based on earlier ones by H. C. Reynolds [1968] and, in turn, McEligot [1963]. Appendix $C$ by McEligot describes the general approach and Appendix $E$ by Reynolds treats part of his data reduction program. The main difference is that the heat transfer data were obtained from a test section surrounded by a vacuum so the radial heat loss was radiative rather than conductive as in the present experiment.

From the axial heat flux distribution, a numerical analyst can specify the thermal boundary condition of the experiment in developing or testing his/her predictions. Resulting local bulk temperatures may be determined from the deduced inner wall temperatures and $\mathrm{T}_{\mathrm{W}} / \mathrm{T}_{\mathrm{b}}$, which are tabulated.

The axial distances $x / D$ are measured from the nominal start of heating at the end of the fillet of braze material on top of the lower electrode. These locations are the thermocouple positions, accounting for thermal expansion [McEligot, 1963]. To calculate the electrical power to the test section per unit length, the resistance has been calibrated by Perkins [1975] as

$$
R^{\prime}(\mathrm{ohms} / \mathrm{ft})=0.00587+4.64 \times 10^{-7}\left[\mathrm{t}_{W}(\mathrm{~F})-300.0\right]
$$


Heat losses are calculated from an axial conduction heat loss term [McEligot, 1963] and radial conduction through the insulation with its thermal conductivity,

$$
k(B t u / h r f t F)=0.0238+0.00025\left[T_{\text {inner }}(F)+T_{\text {outer }}(F)\right]
$$

also calibrated by Perkins [1975].

The friction factors and pressure defects calculated in the data reduction program apparently do not include consideration of the difference between the hydrostatic heads in the vertical manometer lines and in the heated tube itself. For high Reynolds number flow this difference is generally negligible, but it can be substantial at low Reynolds numbers in "large" diameter tubes. Therefore, the deduced pressure defect has been recalculated from the measurements to be consistent with the predictions of a numerical program which accounts for the variation of density in the body force, as by Perkins [1975; Perkins and McEligot, 1975]. The approach follows.

The pressure defect is defined as

$$
\mathrm{P}^{+}=\rho_{\text {in }} \mathrm{g}_{\mathrm{c}}\left(\mathrm{p}_{\mathrm{in}}-\mathrm{p}\right) / \mathrm{G}^{2}
$$

Provided the vertical manometer lines are isothermal, the hydrostatic heads in them can be represented as

$$
\Delta \mathrm{P}^{+} \text {man } \approx-\left(\rho_{\operatorname{man}} / \rho_{\text {in }}\right) \mathrm{Gr}^{*} \Delta(\mathrm{x} / \mathrm{D}) / \operatorname{Re}_{\mathrm{in}}{ }^{2}
$$

where $\mathrm{Gr}^{*}=\mathrm{g} \mathrm{D}^{3} / v_{\mathrm{in}}{ }^{2}$ and $\mathrm{g}$ is considered positive in the positive $\mathrm{x}$ direction. Thus, with upflow the numerical value of $\mathrm{g}$ is negative and $\Delta \mathrm{P}^{+}$man increases in the upward direction, corresponding to the hydrostatic decrease of pressure. Typically, $\rho_{\text {man }}$ and $\rho_{\text {in }}$ will both be at approximately room temperature and approximately the same absolute pressure, so their ratio is about unity. To calculate the indicated pressure defect in the tube from the pressure difference measured in the manometer system, $\Delta \mathrm{P}^{+}$observ, one forms

$$
\Delta \mathrm{P}^{+}{ }_{\text {indic }}=\Delta \mathrm{P}^{+} \text {observ }+\Delta \mathrm{P}^{+} \operatorname{man}
$$

where $\Delta \mathrm{P}^{+}$indic is the quantity to compare to the code predictions. For upflow then, $\mathrm{p}$ is lower than measured at the manometer so ( $\left.p_{i n}-p\right)$ is greater than ( $p_{i n}-p_{m a n}$ ), giving an increase in $\mathrm{P}^{+}$. The recalculated pressure defect distributions are included in the tables; these estimates are based on the assumptions that the quantity ( $\rho_{\text {man }} /$ $\left.\rho_{i n}\right)$ is unity and that the preheating of the gas flow below the lower electrode may be neglected. 
One may calculate apparent local friction friction factors from these data; these are the friction factors one obtains from one-dimensional measurements without profile data - as explained by McEligot [1963] and Bankston and McEligot [1970]. These $f_{a p p}$ values can be expected to differ from $f_{S}=\mu_{W}(\partial U / \partial y)_{W} /\left(G^{2} / 2 p_{b g c}\right)$ as usually calculated by analysts. While the analyst can predict $f_{\text {app }}$ from two-dimensional profile results (see the section on laminar thermal entry results in the paper by Bankston and McEligot for the import), it would generally be easier to compare predicted and measured values of the non-dimensional pressure defect directly.

The tabular headings and symbols in the tables may be decoded with the aid of the following table. The items are listed in the order in which they appear and generally are not repeated if they appear again on a later table. "Self-explanatory" items are not included.

Symbol

Usual nomenclature

\section{Definition, description, comment}

Run $x x x$

POSITION

$x / D$

Dimensionless axial location

(X/D)

TW

$\mathrm{T}_{\mathrm{W}}$

Local test section inner wall

temperature $\left({ }^{\circ} \mathrm{F}\right)$

HEAT LOSS

$\mathrm{q}_{\mathrm{l}}^{\prime \prime} / \mathrm{q}_{\mathrm{g}}^{\prime \prime}$

$\operatorname{Local}\left(q_{\text {gen }}^{\prime \prime}-q_{\text {gas }}^{\prime \prime}\right) / q_{\text {gen }}^{\prime \prime}$

BULK REYNOLDS

$\mathrm{Re}_{\mathrm{m}}$

Local bulk Reynolds number,

$\mathrm{GD} / \mu_{\mathrm{m}}\{x\}$

XPLUS

$x^{+}$

$2 x /\left(D \operatorname{Re}_{m} \operatorname{Pr}_{m}\right)$

$\mathrm{TW} / \mathrm{TB}$

$\mathrm{T}_{\mathrm{w}} / \mathrm{T}_{\mathrm{m}}$

Local temperature ratio

BULK NUSSELT

$\mathrm{Nu}_{\mathrm{m}}$

Local Nusselt number based on bulk temperature, $h\{x\} D / k_{m}\{x\}$

QPLAMIN

$\mathrm{Q}^{+}$

$D q_{w}^{\prime \prime} /\left(2 k_{i} T_{i}\right)$

QPTURB or Q+

$\mathrm{q}^{+}$

$\mathrm{q}_{\mathrm{w}}^{\prime \prime} /\left(\mathrm{G} \mathrm{C}_{\mathrm{P}_{\mathrm{i}}} \mathrm{T}_{\mathrm{i}}\right)$ 
Symbol

Usual

nomenclature

Definition, description, comment

BULK STANTON

St

$\mathrm{h}\{\mathrm{x}\} /\left(\mathrm{GC}_{\mathrm{P}, \mathrm{m}}\right)$

Local Stanton number,

$\mathrm{T}$ (DEG.F)

$\mathrm{T}_{\mathrm{s}}$

Temperature measured on copper

shield under guard heating tapes

Adiabatic velocity profiles

$\operatorname{Re}_{i}$

$\operatorname{Re}_{i}$ or $\operatorname{Re}_{i n}$

Reynolds number based on inlet temperature

$\dot{\mathrm{m}}$

$\dot{\mathrm{m}}$

Mass flow rate through tube

$\mathrm{T}_{\mathrm{i}}$

$\mathrm{T}_{\mathrm{i}}$ or $\mathrm{T}_{\mathrm{in}}$

Air inlet temperature

$\mathrm{y} / \mathrm{r}_{\mathrm{W}}$

$\mathrm{y} / \mathrm{r}_{\mathrm{W}}$

Non-dimensional sensor location, measured from wall

$\overline{\mathrm{U}} / \mathrm{U}_{\mathrm{B}}$

$\mathrm{U} / \mathrm{V}_{\mathrm{b}}$ or $\mathrm{U} / \mathrm{V}_{\mathrm{m}}$

Pointwise, streamwise mean velocity normalized by bulk or mixed mean velocity

$\mathrm{y}^{+}$

$\mathrm{y}^{+}$

Non-dimensional distance from wall, $y \sqrt{\left(g_{\mathrm{c}} \tau_{\mathrm{w}} / \rho_{\mathrm{w}}\right)} / v_{\mathrm{w}}$

$\mathrm{u}^{+} \mathrm{u}^{+}$

Non-dimensional mean streamwise velocity, $\bar{U} / \sqrt{\left(g_{c} \tau_{w} / \rho_{w}\right)}$

Axial temperature profile

pi

pi or pin

Inlet static pressure in tube

Non-dimensional pressure distributions

$T$,in

$\mathrm{T}_{\text {in }}$ or $\mathrm{T}_{\mathrm{i}}$

Air inlet temperature

$p$,in

pi or pin

Inlet static pressure in tube 
Symbol

$\mathrm{m}$

Rho,in

Rho,man

Rho,room

D

$\mathrm{A}, \mathrm{cs}$

$\mathrm{Re}$, in

$\mathrm{Gr}^{*}$

$\mathrm{Gr}^{*} / \operatorname{Re} 2$

$\mathrm{dP}+$, observ

Non-dimensional pressure

$\mathrm{dP}+$, man

$\Delta \mathrm{P}^{+} \operatorname{man}$

$\mathrm{dP}+$,indic

$\mathrm{Gr}^{*} / \operatorname{Re}_{\mathrm{in}}{ }^{2}$

$\Delta \mathrm{P}^{+}$observ

\section{Definition, description, comment}

Mass flow rate through tube

Air density evaluated at $T_{i n}$, pin

Air density in vertical lines to manometer

Air density in the laboratory room

Inside diameter of tube

Cross-sectional flow area

Reynolds number evaluated at

Tin, pin

Modified Grashof number, $\mathrm{gD}^{3} / \mathrm{vin}^{2}$ ( $\mathrm{g}$ is taken as positive in the flow direction, i.e., the value $g$ is negative for upflow)

Pressure defect as measured at the

pressure transducer)

electronic manometer (differential

distributions (cont.)

Hydrostatic pressure difference vertically along manometer lines, non-dimensionalized in terms of $\mathrm{P}^{+}$, - $\left(\rho_{\operatorname{man}} / \rho_{\text {in }}\right) \mathrm{Gr}^{*} \Delta(\mathrm{x} / \mathrm{D}) / \operatorname{Re}_{\mathrm{in}}{ }^{2}$

Deduced measurement of difference in $\mathrm{P}^{+}$inside the tube (i.e., at pressure tap locations) 
04

-4

$\omega=$

wz

1

는

in

m

$m$

a

I

in

nus

등

$-10$

04

- ar

ou

을

픈

1

U1

$r=$

$-2$

$\infty$

$\infty$

$\pm$
200 manu 0 NoM menn

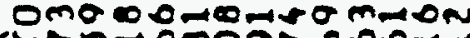
Yhpinmomooredomm

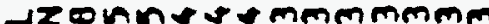
.40000000000000 - 0000000000000

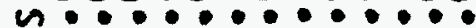

z ononormarmomo mereorecosonoto

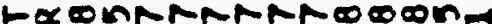

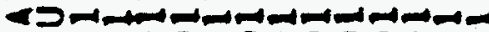
uto000000000000 工a 00000000000 en

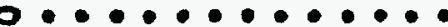
is

Zzmonpapocononns ompmadotoprperine - z conominfo- thino n< 0 - $1000000000 \mathrm{Nm}$ Z we tmmmmmenmmmn $>\mathrm{n}$

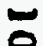

$$
\vdash
$$

HOM a mmMnTONOO yuroogrmintonandon m $\bullet \cdot \bullet \cdot \bullet \cdot \bullet \cdot \cdot \cdot$ Suntrvoronstrmm-a oDmNNm 2

- monro-inmmmmoo - Nommmatatstom - NNmmma $55575 m$

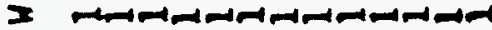
$-$

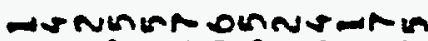
$n$ minstrmotonsonar $=$ oominanteommin I 00000000 mathmat a 0000000000000

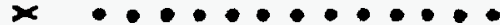
n

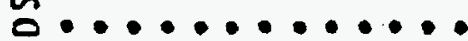
x dunminommmto oron

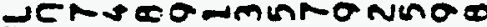
Szo00000 ons smnN c) Doninininininininin ш

$\propto$

maneo anNOOOntom rn-00 5 mmmm-wonn wCO-DOnO00000NA I...?....... i

$\bullet \bullet \bullet \bullet \bullet \bullet \bullet \bullet \bullet \bullet \bullet \bullet$

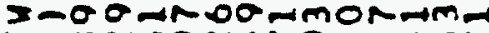
HLONOONAROMNAmR -anNNMmmmotatm

2

mannormmmornmoo bo............ mo minicatoonino nxe 으

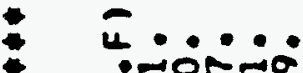
-OOO-ANo - UNmm佂 $\sum 0$ $=$

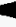

는

0

22

2

WOD ONOO -1.... axnonmo no a-ANN a 
ADIABATIC VELOCITY PROFILE

$$
\operatorname{Re}_{i}=6030 ; \dot{m}=19.001 \mathrm{~b}_{\mathrm{m}} / \mathrm{hr} ; \mathrm{x} / \mathrm{D} \simeq 3.17 ; \mathrm{T}_{\dot{i}}=535^{\circ} \mathrm{R}
$$

\begin{tabular}{|c|c|c|c|c|c|}
\hline $\begin{array}{l}\text { Distance from } \\
\text { Wall, in. }\end{array}$ & $\begin{array}{c}\bar{J} \\
\mathrm{ft} / \mathrm{sec}\end{array}$ & $y / r_{w}$ & $\bar{U} / U_{B}$ & $y^{+}$ & $u^{+}$ \\
\hline $\begin{array}{l}0.020 \\
0.022 \\
0.025 \\
0.028 \\
0.037 \\
0.035 \\
0.040 \\
0.045 \\
0.050 \\
0.055 \\
0.060 \\
0.070 \\
0.080 \\
0.095 \\
0.170 \\
0.125 \\
0.145 \\
0.170 \\
0.195 \\
0.220 \\
0.245 \\
0.270 \\
0.295 \\
0.330 \\
0.370 \\
0.420 \\
0.470 \\
0.520 \\
0.530 \\
0.540\end{array}$ & $\begin{array}{l}5.723 \\
5.744 \\
6.076 \\
6.751 \\
7.190 \\
7.924 \\
8.654 \\
9.224 \\
9.789 \\
10.237 \\
10.505 \\
11.074 \\
11.526 \\
11.948 \\
12.332 \\
12.684 \\
13.009 \\
13.425 \\
13.732 \\
14.037 \\
14.314 \\
14.581 \\
14.773 \\
15.115 \\
15.378 \\
15.708 \\
15.932 \\
16.014 \\
16.036 \\
16.044\end{array}$ & $\begin{array}{l}0.0370 \\
0.0407 \\
0.0463 \\
0.0519 \\
0.0574 \\
0.0648 \\
0.0741 \\
0.0833 \\
0.0926 \\
0.1019 \\
0.1111 \\
0.1296 \\
0.1482 \\
0.1759 \\
0.2037 \\
0.2315 \\
0.2685 \\
0.3148 \\
0.3611 \\
0.4074 \\
0.4537 \\
0.5000 \\
0.5463 \\
0.6111 \\
0.6852 \\
0.7778 \\
0.8704 \\
0.9630 \\
0.9815 \\
1.0000\end{array}$ & $\begin{array}{l}0.4748 \\
0.4766 \\
0.5041 \\
0.5601 \\
0.5965 \\
0.6573 \\
0.7178 \\
0.7650 \\
0.8117 \\
0.8488 \\
0.8709 \\
0.9181 \\
0.9554 \\
0.9903 \\
1.0220 \\
1.0511 \\
1.0779 \\
1.1124 \\
1.1377 \\
1.1630 \\
1.1860 \\
1.2080 \\
1.2239 \\
1.2523 \\
1.2740 \\
1.3013 \\
1.3199 \\
1.3267 \\
1.3285 \\
1.3292\end{array}$ & $\begin{array}{r}7.5059 \\
8.2564 \\
9.3823 \\
10.5080 \\
11.6340 \\
13.1350 \\
15.0120 \\
16.8880 \\
18.7650 \\
20.6410 \\
22.5180 \\
26.2710 \\
30.0230 \\
35.6530 \\
41.2820 \\
46.9120 \\
54.4170 \\
63.8000 \\
73.1820 \\
82.5640 \\
91.9470 \\
101.3300 \\
110.7100 \\
123.8500 \\
138.8600 \\
157.6200 \\
176.3900 \\
195.1500 \\
198.9100 \\
202.6600\end{array}$ & $\begin{array}{r}7.0940 \\
7.1795 \\
7.5312 \\
8.3678 \\
8.9119 \\
9.8212 \\
10.7260 \\
11.4330 \\
12.1330 \\
12.6890 \\
13.0200 \\
13.7260 \\
14.2860 \\
14.8090 \\
15.2850 \\
15.7210 \\
16.1240 \\
16.6400 \\
17.0200 \\
17.3980 \\
17.7420 \\
18.0720 \\
18.3100 \\
18.7350 \\
19.0600 \\
19.4690 \\
19.7480 \\
19.8490 \\
19.8760 \\
19.8870\end{array}$ \\
\hline
\end{tabular}


AXIAL TUBE TEMPERATURE PROFILE UPSTREAM FROM THE START OF HEATING Run $61800 ; \dot{m}=19.02 \mathrm{Tbm} / \mathrm{hr} ; T_{i}=73.3^{\circ} \mathrm{F} ; P_{i}=13.44$ p.s.i.a.

Distance Upstream from the Upper Surface of the Lower Electrode Inches

15.615

7.655

3.628

1.650

0.656

0.000
External Wall Temperature

74.0

82.0

86.0

94.3

117.5

157.5 
Non-dimensional pressure distributions from the data of Shehata [1984]

Bun 618

$$
\begin{aligned}
& T \text {, in }(F)= \\
& 73.3 p \text {, in }(p s i a)= \\
& (R)= \\
& 533.0 \\
& 13.44 \mathrm{~m}(\mathrm{lbm} / \mathrm{hr})= \\
& 0.0681 \\
& 0.654 \\
& D(\text { in })= \\
& \mathrm{Re}, \mathrm{in}=6.033 \mathrm{E}+03
\end{aligned}
$$

(Assumption: rho, $\operatorname{man}=$ rho,room $=$ rho, in)

$\begin{array}{cccc}\frac{x / D}{2.9} & \frac{d P+.0 b s e r v}{0.094} & \frac{d P+\text { man }}{0.057} & \frac{d P+\text {.indic }}{0.151} \\ 8.5 & 0.252 & 0.166 & 0.418 \\ 14.0 & 0.410 & 0.273 & 0.683 \\ 19.7 & 0.562 & 0.384 & 0.946 \\ 25.2 & 0.747 & 0.492 & 1.239\end{array}$


a

2

1

un 1 zinnmanpontnmmm oentsonpob-5 x- 0 nomonmoo jzacut 2 mmmmmnN $\$ 20000000000000$ -

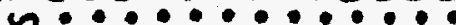

0

Z ononammoonnon

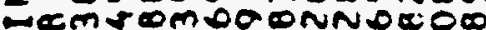

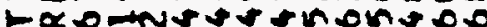
- 5 mmmmmmmmmen un 0000000000000 In0000000000000 n

u

$1 . .1 .0$

us

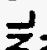

zzo-omineomenonoo

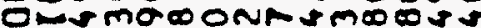

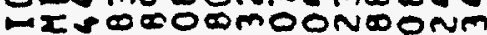
nacorosinowomos

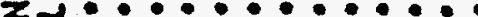

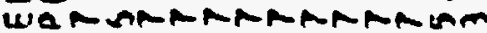
wa

$\infty$

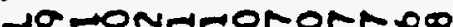

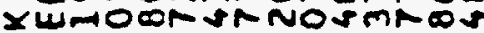
Jun $\bullet \bullet \bullet \bullet \bullet \bullet$ Sus omes otmn$\infty$

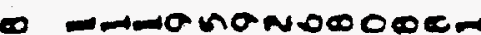

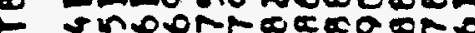

- - a co I -1 $+$

minounmmoonoto a tintomo osmunuo

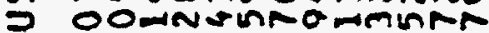

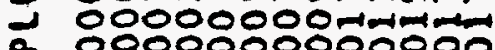
×

n

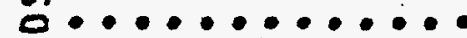
x untmonnompromo

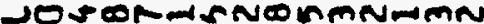

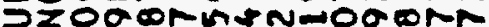
Dosuminuminntsto u

-uominaronomoonLno 50 mnmm-tomim uro-no0000000m-

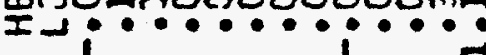

$\cdots \cdot \bullet \cdot \bullet \cdot \cdot \cdot \cdot$ I- oonmo- amonono - $40 n m-\infty+00-1000$

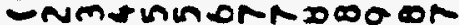

$\stackrel{n}{n}$

2

menNow inmmormm-1m

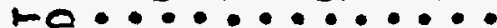
- M minomino vinoo

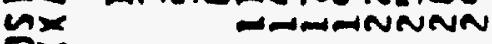
$\underset{2}{2}$
- u. ionir 20 20 DÓOnor -n. : . -xinomato n- andin Q 
TUBE WALL TEMPERATURE PROFILE UPSTREAM FROM THE START OF HEATING Run $63500 ; \dot{m}=19.00 \mathrm{lbm} / \mathrm{hr} ; T_{i}=74.4^{\circ} \mathrm{F} ; P_{i}=13.44$ p.s.i.a.

Distance Upstream from the Upper Surface of the Lower Electrode Inches External Wall Temperature

15.615 76.0

7.655 88.8

3.628 98.0

1.650 115.5

0.656 160.8

0.000 233.0 
Non-dimensional pressure distributions from the data of Shehata [1984]

\section{Bun 635}

$$
\begin{aligned}
& T \text {, in }(F)= \\
& 74.4 p \text {,in }(\text { psia })= \\
& 13.44 \mathrm{~m}(\mathrm{lbm} / \mathrm{hr})= \\
& 19.0 \\
& (R)= \\
& 534.1 \\
& 0.0680 \\
& 0.656 \\
& \mathrm{Gr}^{*}=
\end{aligned}
$$

(Assumption: rho, man $=$ rho,room $=$ rho, in)

$\begin{array}{cccc}\frac{x / D}{2.9} & \frac{d P+\text { observ }}{0.130} & \frac{d P+\text { man }}{0.056} & \frac{d P+\text { indic }}{0.186} \\ 8.5 & 0.347 & 0.165 & 0.512 \\ 14.0 & 0.565 & 0.272 & 0.837 \\ 19.7 & 0.784 & 0.383 & 1.167 \\ 25.3 & 1.046 & 0.492 & 1.538\end{array}$


zoratuganonoonn elorrancom añon ytognon-ennmnnm Joonintammmmn'Szó00000000000

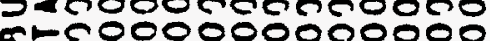
n. . .

0

2 mRoshnassoosh -cm-annmm-cmnoo - anamanonnontrn

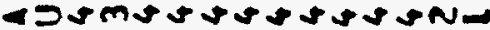
wĹ0000000000000 Ia0000000000000

n

$\infty$

nin

os

Nim

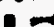

us.

(a)

$\simeq \simeq$

ma

อேn

\$u

$z \stackrel{0}{0}$

2

$\rightarrow$

-us

$u=$

$w z$

nim

n

ư

-

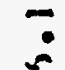

$\frac{1}{2}$

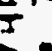

-

nut

os

$-1=$

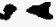

ix

$\rightarrow 2$

I4

cr

4

$\therefore=$

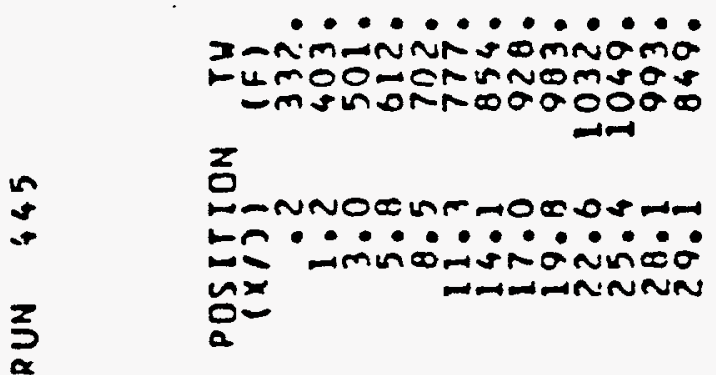

$z \geq 000-00 m+n m+n \infty n$

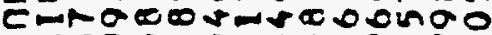

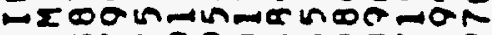
ULCRA.OOOEOOORAO z

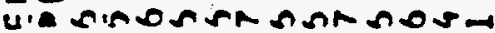
In

-

$-$

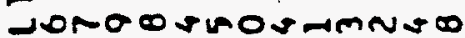
xwommmmonmninno. Jn $\bullet \cdot \bullet \cdot \bullet \cdot \cdots \cdot \bullet$

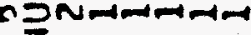

- Monnomoogommn

- Sinregaogogoco

- ?........

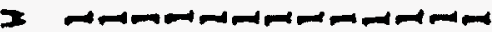

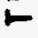

NEONATOROOGOR

थ InOAmRmoOnOOO

- oons consconino

- no0000m-4mNn

- 000000000000

n

亿

Y Jinnarinonaronom jenoor maraoguon JzNnme eringmmñons otmmmmmmmmmm แั

bunampenaringermeam

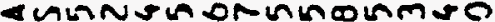
UEO-000090000in I

- into ormo m-nNodnhmoenonm La... a

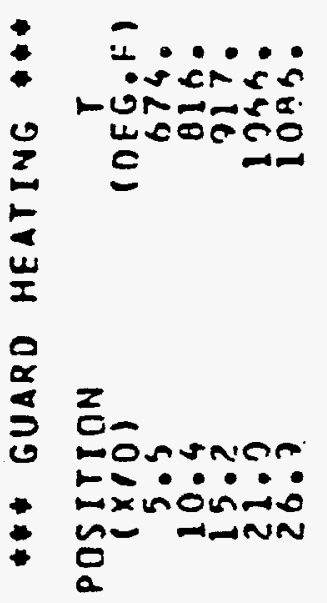




\section{ADIABATIC VELOCITY PROFILE}

$$
\operatorname{Re}_{i}=4180 ; \dot{m}=13.201 \mathrm{~b} / \mathrm{hr} ; x / D=.3 .17 ; \mathrm{T}_{i}=535^{\circ} \mathrm{R}
$$

$\begin{array}{lrlrrr}\begin{array}{c}\text { Distance From } \\ \text { Wa11, in. }\end{array} & \begin{array}{c}\bar{U} \mathrm{~J} / \mathrm{sec} \\ \end{array} & \mathrm{y} / \mathrm{r}_{\mathrm{w}} & \bar{U} / \mathrm{U}_{\mathrm{B}} & \mathrm{y}^{+} & \mathrm{u}^{+} \\ 0.018 & 3.060 & 0.0333 & 0.3657 & 4.9024 & 5.2201 \\ 0.020 & 3.060 & 0.0370 & 0.3657 & 5.4472 & 5.2203 \\ 0.023 & 3.386 & 0.0426 & 0.4047 & 6.2642 & 5.7760 \\ 0.026 & 3.810 & 0.0482 & 0.4554 & 7.0813 & 6.4995 \\ 0.029 & 4.014 & 0.0537 & 0.4797 & 7.8984 & 6.8477 \\ 0.033 & 4.476 & 0.0611 & 0.5349 & 8.9878 & 7.6367 \\ 0.038 & 5.003 & 0.0704 & 0.5980 & 10.3500 & 8.5375 \\ 0.043 & 5.603 & 0.0796 & 0.6697 & 11.7110 & 9.5634 \\ 0.048 & 6.020 & 0.0889 & 0.7195 & 13.0730 & 10.2770 \\ 0.058 & 6.735 & 0.1074 & 0.8050 & 15.7970 & 11.5000 \\ 0.068 & 7.352 & 0.1259 & 0.8786 & 18.5200 & 12.5530 \\ 0.078 & 7.802 & 0.1445 & 0.9324 & 21.2440 & 13.3230 \\ 0.093 & 8.320 & 0.1722 & 0.9944 & 25.3290 & 14.2090 \\ 0.108 & 8.596 & 0.2000 & 1.0273 & 29.4150 & 14.6810 \\ 0.123 & 8.922 & 0.2278 & 1.0663 & 33.5000 & 15.2380 \\ 0.143 & 9.182 & 0.2648 & 1.0974 & 38.9470 & 15.6830 \\ 0.168 & 9.472 & 0.3111 & 1.1321 & 45.7560 & 16.1790 \\ 0.193 & 9.718 & 0.3574 & 1.1614 & 52.5650 & 16.5980 \\ 0.218 & 10.000 & 0.4037 & 1.1951 & 59.3740 & 17.0800 \\ 0.243 & 10.150 & 0.4500 & 1.2131 & 66.1830 & 17.3370 \\ 0.268 & 10.315 & 0.4963 & 1.2328 & 72.9920 & 17.6180 \\ 0.293 & 10.467 & 0.5426 & 1.2509 & 79.8010 & 17.8770 \\ 0.328 & 10.684 & 0.6074 & 1.2769 & 89.3330 & 18.2480 \\ 0.368 & 10.890 & 0.6815 & 1.3015 & 100.2300 & 18.6000 \\ 0.418 & 11.101 & 0.7741 & 1.3267 & 113.8500 & 18.9600 \\ 0.468 & 11.255 & 0.8667 & 1.3451 & 127.4600 & 19.2240 \\ 0.518 & 11.345 & 0.9593 & 1.3558 & 141.0800 & 19.3770 \\ 0.533 & 11.353 & 0.9871 & 1.3569 & 145.1700 & 19.3910\end{array}$


TUBE WALL TEMPERATURE PROFILE UPSTREAM FROM THE START OF HEATING

Run $44500 ; m=13.419 \mathrm{lbm} / \mathrm{hr} ; T_{i}=76.1^{\circ} \mathrm{F} ; P_{i}=13.45$ p.s.i.a.

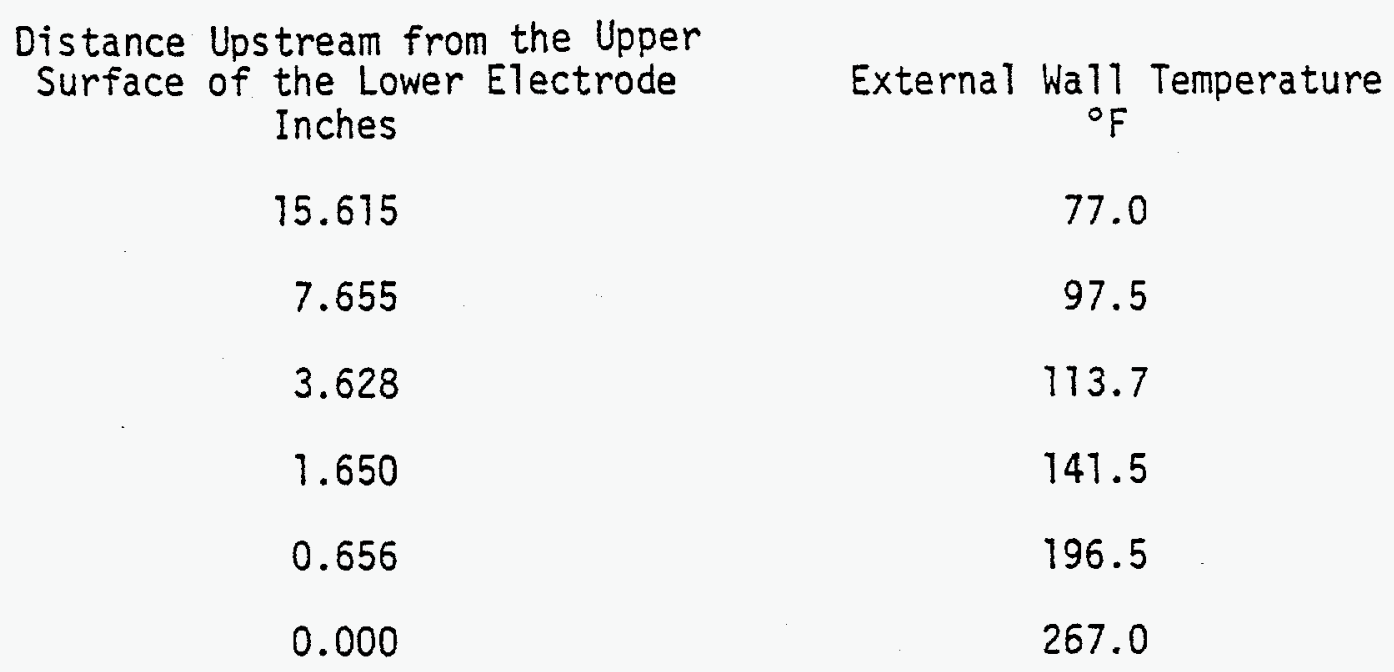




\section{Non-dimensional pressure distributions from the data of Shehata [1984]}

\section{Run 445}

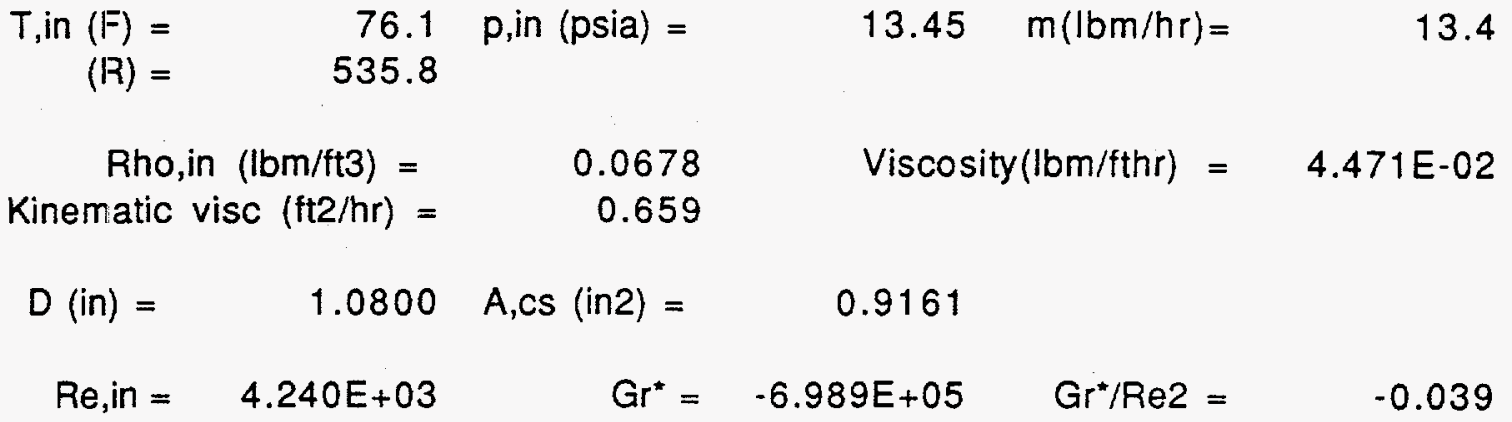

(Assumption: rho, $\operatorname{man}=$ rho,room $=$ rho, in)

$\begin{array}{cccc}\frac{x / D}{2.9} & \frac{d P_{+} .0 \text { bserv }}{0.144} & \frac{d P_{+} \text {man }}{0.113} & \frac{d P_{+} \text {.indic }}{0.257} \\ 8.5 & 0.424 & 0.330 & 0.754 \\ 14.0 & 0.687 & 0.544 & 1.231 \\ 19.7 & 0.953 & 0.766 & 1.719 \\ 25.3 & 1.300 & 0.984 & 2.284\end{array}$




\section{Appendix B}

\section{Mean velocity and temperature profiles}

This appendix revises slightly the deduced non-dimensional profiles of Shehata [his Appendix F, 1984], primarily affecting those defined in terms of wall variables. The basic input is the same and the dimensional profiles, $U\{y, x\}$ and $\mathrm{T}_{\mathrm{g}}\{\mathrm{y}, \mathrm{x}\}$, are taken directly from Shehata's tabulated values. As explained in section 4.6 , due to the property variation and gas acceleration, it was not feasible to determine the friction velocity $u_{\tau}$ directly from the data for its original deduction; instead, correlations by Taylor [1967] were employed. However, now that the numerical approach has been used as a diagnostic technique (section 4.7), the adjusted model predictions provide improved estimates of $f_{S}$ from which $u_{\tau}$ is deduced. Essentially, the predicted velocity and temperature distributions have been fitted to the near wall data over the length of the tube; once that has been done the predictions provide (indirect) measurements of $f_{S}\{x / D\}$.

The perfect gas approximation has been used in calculating the properties. A slightly different treatment of the power law approximation for the enthalpy was employed here to deduce $\mathrm{H}\{\mathrm{T}\}$ for calculating $\mathrm{T}_{\mathrm{b}}$ from the measured profiles. Although the difference from Shehata's results for $T_{b}$ is only a maximum of four per cent, this revision has been carried throughout the new spread sheet calculation for consistency.

This appendix first presents the details of the data reduction procedure which deduces revised profiles of $u^{+}\left\{y^{+}, x / D\right\}$ from Shehata's values of $U\{y, x / D\}$ and $T_{g}\{y, x / D\}$. Then the new deduced results are presented, run by run, from the spread sheet summaries. Here each five digit run designation corresponds to a given pair of profiles; the first three digits identify the nominal values of $\mathrm{Re}_{\mathrm{in}}$ and $\mathrm{q}^{+}$as before and the last two give the approximate axial location. For example, run 44525 indicates profiles for nominal $\mathrm{Re}_{\mathrm{in}} \approx 4000$ and $\mathrm{q}^{+} \approx 0.0045$ at 24.5 diameters. The spread sheet nomenclature is translated later in this appendix.

Since one can integrate the profiles to provide a measurement of $\dot{\mathrm{m}}$, the independently measured mass flow rate (called $\mathrm{m}$ on the spread sheet) can be compared to check consistency. For flows with constant properties, such comparisons would test the overall validity of the velocity profiles. However, for a near-perfect gas and significant heating, the mass flow rate is - instead - primarily a measure of the distribution of the quantity $\mathrm{U}\{\mathrm{y}\} / \mathrm{T}\{\mathrm{y}\}$, as explained later with the details of the integration. 


\section{B. 1 Calculation procedure}

This section explains the process of data reduction sequentially and, in the process, should identify the meanings and sources of the quantities presented on the spread sheet.

Several quantities are taken directly from the tabulations of profile data by Shehata [1984] in his Appendix F:

Axial location, $x / D$

Measured air mass flow rate, with $\mathrm{m}$ representing $\dot{\mathrm{m}}(\mathrm{lbm} / \mathrm{hr})$

Test section current and voltage during the profile measurements

Sensor distances from the wall, y

Deduced mean velocities and temperatures, $\mathrm{U}\{\mathrm{y}\}$ and $\mathrm{T}\{\mathrm{y}\}$

A few quantities have been taken from the tabulations of integral quantities in Appendix A:

Inlet pressure, pin

Nominal test section current, voltage and air mass flow rate $\mathrm{m}$ for the series of profile runs

Heat loss ratios at adjacent wall thermocouples and their locations

The inlet and local wall temperatures which existed during the profile measurement are determined from the tabulated output and data reduction steps in the program by Shehata [Appendix $E$ and F, 1984]. Inlet temperature is deduced from his gas temperature and the quantity $\mathrm{TG} / \mathrm{TI}=\left(\mathrm{Tg} / \mathrm{T}_{\mathrm{in}}\right)$ at the first position away from the wall (his "PT \#1"), i.e.,

$$
\mathrm{T}_{\mathrm{in}}=\mathrm{TEMPERATURE} /(\mathrm{TG} / \mathrm{TI})=\mathrm{T}_{\mathrm{g}} /\left(\mathrm{T}_{\mathrm{g}} / \mathrm{T}_{\mathrm{in}}\right)
$$

(The quantities printed in capital letters are ones which appear in Shehata's program or output.) Shehata prints REWALL $=\operatorname{Re}_{W}=\mathrm{GD} / \mu\left\{\mathrm{T}_{\mathrm{W}}\right\}$ which he calculates as REWALL $=$ REMEAN $*$ XMUB $/ \mathrm{XMUWL}$ or

$$
\operatorname{Re}_{\mathrm{W}}=\left(\mathrm{GD} / \mu\left\{\mathrm{T}_{\mathrm{b}}\right\}\right) \cdot\left(\mu\left\{\mathrm{Tb}_{\mathrm{b}}\right\} / \mu\left\{\mathrm{T}_{\mathrm{W}}\right\}\right)
$$

In addition, the modified wall Reynolds number, $\mathrm{VbD}_{\mathrm{b}} \mathrm{v}\left\{\mathrm{T}_{\mathrm{W}}\right\}$, is printed as MOD.W.RE and is calculated as

$$
\operatorname{Re}_{\mathrm{W}, \bmod }=\mathrm{RESTAR}=\mathrm{REWALL} * \mathrm{~TB} / \mathrm{TW} 5
$$

where TW5 is the local inner wall temperature and TB is printed under the title COMPUTED BULK TEMPERATURE. This representation follows from the perfect gas approximation for density as 


$$
\operatorname{Re}_{w, \bmod }=\frac{V_{b} D}{v\left\{T_{w}\right\}}=\frac{G}{\rho\left\{T_{b}\right\}} \frac{D}{\left(\mu\left\{T_{w}\right\} / \rho\left\{T_{w}\right\}\right)}
$$

Thus, one may determine Shehata's wall temperature as

$$
\mathrm{T}_{\text {Wall }}=\mathrm{TW5}=\text { REWALL } * \mathrm{~TB} / \text { RESTAR }
$$

from the printed output.

Once one has the profiles, pressure and wall temperature available one can use any property relations preferred to calculate the bulk properties and other desired quantities. For convenience, the present spread sheet employs the perfect gas approximation and power law representations [Perkins, 1975; Shehata, 1984]

$$
\begin{aligned}
& \rho \approx \rho_{\text {ref }}\left(p / p_{\text {ref }}\right)\left(T_{\text {ref }} / T\right) \\
& \mu \approx \mu_{\text {ref }}\left(T / T_{\text {ref }}\right)^{0.67} \\
& c_{p} \approx c_{p} \text {,ref }\left(T / T_{\text {ref }}\right)^{0.095} \\
& H-H_{\text {ref }} \approx\left(c_{p, r e f} T_{\text {ref }} / 1.095\right)\left[\left(T / T_{\text {ref }}\right)^{1.095}-1\right]
\end{aligned}
$$

where $T_{\text {ref }}=534 \mathrm{R}$ and pref $=14.696$ psia. The coefficients are $\rho_{\text {ref }}=0.074321$ $\mathrm{lbm} / \mathrm{ft}^{3}, \mu_{\text {ref }}=1.2391 \times 10^{-5} \mathrm{lbm} / \mathrm{ftsec}, \mathrm{c}$, ref $=0.24 \mathrm{Btu} / \mathrm{lbmF}$ and $\mathrm{H}_{\mathrm{ref}}=0 \mathrm{Btu} / \mathrm{lbm}$, respectively. These property relations are consistent with the nomenclature in the predictive program by Bankston and McEligot [1970].

In the body of this report, numerical predictions are based on the boundary and inlet conditions of the experimental runs taken without the probe installed in the test section, for example, run 445 (Appendix A) rather than run 44525 (this appendix). On the spread sheet these conditions are referred to as "nominal." The nominal total electrical power (NomP) is calculated as the nominal current times the nominal voltage drop and the "actual" power is done likewise; the ratio $\mathrm{P} / \mathrm{NomP}$ then is a measure of the difference between the conditions of the two runs, as is the difference between $\mathrm{m}$ and Nom $\mathrm{m}$. These small differences are accepted among the experimental uncertainties in the comparisons between the predicted and measured profiles. Conceptually, more precise comparisons could be obtained by recalculating the prediction for each set of profiles.

The diameter and cross sectional area are calculated, including consideration of thermal expansion using the wall temperature and 


$$
\alpha(\text { in } / \text { inF })=7.26 \times 10^{-6}+1.20 \times 10^{-9}[t(F)-70.0]
$$

from Taylor [1982]. The expansion is $\Delta \mathrm{D} / \mathrm{D}_{\mathrm{O}}=\alpha \cdot\left(\mathrm{t}_{\mathrm{W}}-70.0\right)$. Also Perkins's calibration of the unit electrical resistance of the test section [his eqn. (7), p.26, 1975],

$$
R^{\prime}(\mathrm{ohms} / \mathrm{ft})=0.00587+4.64 \times 10^{-7}\left[\mathrm{t}_{\mathrm{W}}(\mathrm{F})-300.0\right]
$$

is employed in determining the heat flux at the profile location. The heat loss ratio (HtLs/q,gen) is interpolated from the tabulations of the nominal run in Appendix A at the adjacent thermocouple locations. Thus, the lineal heat transfer rate to the gas becomes

$$
q^{\prime} w=i^{2} R^{\prime}[1-(q h 1 / q g e n)]
$$

where $i$ is the electrical current and the heat flux to the gas becomes $q^{\prime \prime} w=q^{\prime} w / \Pi D$.

The sensor location $y$ is based on the expanded radius of the tube wall, $\mathrm{r}_{\mathrm{W}}$.

The tabulations of the non-dimensional temperature profiles are calculated directly from $\mathrm{T}\{\mathrm{y}\}$ and the deduced values of $\mathrm{T}_{\mathrm{in}}$. For other profiles the bulk velocity and bulk temperature are used in their normalization. At each sensor location $y$ the pointwise density and enthalpy are determined from the property approximations. Trapezoidal integration is then used to calculate the mass flow rate and the enthalpy flow rate from the profile. Thus, the mass flow rate is

$$
\dot{\mathrm{m}}=\Sigma(\rho\{\mathrm{y}\} \cdot \mathrm{U}\{\mathrm{y}\}) \mathrm{j}+1 / 2 \cdot \Delta \mathrm{A}_{\mathrm{cs}, \mathrm{j}+1 / 2}
$$

and the total enthalpy flow rate at the cross section is

$$
\dot{\mathrm{E}}=\sum(\rho\{\mathrm{y}\} \cdot \mathrm{U}\{\mathrm{y}\} \cdot \mathrm{H}\{\mathrm{y}\}) \mathrm{j}+1 / 2 \cdot \Delta \mathrm{A}_{\mathrm{cs}, \mathrm{j}+1 / 2}
$$

The bulk enthalpy is simply $\mathrm{H}_{\mathrm{b}}=\dot{\mathrm{E}} / \dot{\mathrm{m}}$.

Bulk properties are evaluated at the bulk enthalpy, e.g., $\mathrm{Tb}=\mathrm{T}\{\mathrm{Hb}, \mathrm{p}\} \approx \mathrm{T}\left\{\mathrm{H}_{\mathrm{b}}\right\}$. Specifically, the bulk temperature is given as

$$
\left(\mathrm{T}_{\mathrm{b}} / \mathrm{T}_{\mathrm{ref}}\right)=[(\mathrm{d}+1) \overline{\mathrm{H}}+1]^{1 /(1+\mathrm{d})}
$$

where $\overline{\mathrm{H}}$ is defined as $\left(\mathrm{H}-\mathrm{H}_{\text {ref }} /\left(\mathrm{c}_{\mathrm{p}}\right.\right.$,ref $\left.\mathrm{T}_{\text {ref }}\right)$ and $\mathrm{d}$ is the exponent in the power law approximation of the specific heat at constant pressure (taken as 0.095).

The inference was made above that comparison of the mass flow rate from profile integration to the rate measured with the inlet flowmeter is not a measure of 
the accuracy of the velocity data alone. The total enthalpy rate is more so. With the perfect gas approximation, the mass flow rate calculation may be re-phrased as

$$
\dot{\mathrm{m}}=\frac{\rho_{\text {ref }} \mathrm{T}_{\text {ref }} \mathrm{p}}{\mathrm{p}_{\text {ref }}} \sum\left(\frac{1}{\mathrm{~T}\{\mathrm{y}\}} \mathrm{U}\{\mathrm{y}\}\right)_{\mathrm{j}+1 / 2} \Delta \mathrm{A}_{\mathrm{cs}, j+1 / 2}
$$

so both $\mathrm{U}$ and $\mathrm{T}$ are directly involved - or, more precisely, their quotient. On the other hand, the enthalpy flow rate is essentially

$$
\dot{\mathrm{E}}=\frac{\rho_{\text {ref }} \mathrm{c}_{\mathrm{p}, \text { ref }} \mathrm{T}_{\text {ref }}^{1-\mathrm{d}} \mathrm{p}}{(\mathrm{d}+1) \mathrm{p}_{\text {ref }}} \sum\left(\frac{1}{\mathrm{~T}\{\mathrm{y}\}} \mathrm{U}\{\mathrm{y}\}[\mathrm{T}\{\mathrm{y}\}]^{1+\mathrm{d}}\right)_{j+1 / 2} \Delta \mathrm{A}{ }_{\mathrm{cs}, j+1 / 2}
$$

with $\mathrm{H}_{\text {ref }}$ taken as zero at $\mathrm{T}_{\text {ref. }}$ For air the exponent $\mathrm{d}$ is relatively small; therefore, the effects of air property variation cause $\dot{E}$ to vary as

$$
\dot{\mathrm{E}} \sim \sum\left(\mathrm{U}\{\mathrm{y}\} \cdot[\mathrm{T}\{\mathrm{y}\}]^{\mathrm{d}}\right)_{\mathrm{j}+1 / 2} \cdot \Delta \mathrm{A}_{\mathrm{Cs}, \mathrm{j}+1 / 2} \approx \sum \mathrm{U}\{\mathrm{y}\}_{j+1 / 2} \cdot \Delta \mathrm{A}_{\mathrm{Cs}, \mathrm{j}+1 / 2}
$$

Consequently, an energy balance (or ultimately a bulk temperature comparison) is a more direct representation of the level of accuracy of the measured velocities than a mass balance is.

The bulk density is calculated from the perfect gas approximation $\rho_{b}=\rho\left\{T_{b}, p\right\}$ and the bulk velocity follows as $V_{b}=\dot{m} /\left(\rho b A_{c s}\right)$ or $V_{b}=G / \rho b$. Normalized profiles may then be calculated as $\mathrm{U} / \mathrm{Vb}_{\mathrm{b}}$ and $\left(\mathrm{T}_{\mathrm{W}}-\mathrm{T}\{\mathrm{y}\}\right) /\left(\mathrm{T}_{\mathrm{W}}-\mathrm{T}_{\mathrm{b}}\right)$. In addition, the bulk Reynolds number of the profiles is formed as $\operatorname{Re}_{b}=4 \dot{\mathrm{m}} /\left(\Pi D \mu_{b}\right)$, where $\mu_{b}=\mu\left\{T_{b}\right\}$, for later evaluation of the reference friction factor.

To present profiles in terms of well-defined wall coordinates,

$$
\mathrm{y}^{+}{ }_{\mathrm{w}}=\mathrm{y} \mathrm{u}_{\tau} / \mathrm{v}_{\mathrm{w}}, \mathrm{u}^{+}{ }_{\mathrm{w}}=\mathrm{U} / \mathrm{u}_{\tau} \text { and } \mathrm{t}^{+}{ }_{\mathrm{w}}=\left(\mathrm{T}_{\mathrm{W}}-\mathrm{T}\right) \rho_{\mathrm{w}} \mathrm{u}_{\tau, \mathrm{w}} \mathrm{cp}_{\mathrm{w}} / \mathrm{q}^{\prime \prime} \mathrm{w}
$$

one needs a reasonable value of the friction velocity, $u_{\tau, w}=\left[g_{c} \tau_{w} / \rho_{W}\right]^{1 / 2}$. As explained in section 4.6, conventional approaches and correlations will not provide reliable values. However, after the turbulence model has been adjusted so that the predicted profiles of $U\{y, x\}$ and $T\{y, x\}$ in the viscous layer agree with their measured values across and along the test section (section 4.7), then the values of $\tau_{W}$ from the program output can be taken as indirectly deduced data. 
The pertinent code result is $f_{S} / f_{D K M}$ where $f_{S}$ is the friction factor defined unambiguously in terms of bulk properties, as

$$
f_{S}=\tau_{w} /\left(G^{2} / 2 \rho b g_{C}\right)
$$

and it is referenced to the Drew, Koo and McAdams correlation [1932]

$$
\text { fDKM }=0.0014+0.125 \operatorname{Reb}^{-0.32}
$$

here evaluated at the bulk Reynolds number (as in the code). The wall coordinates are defined in terms of fluid properties evaluated at the wall temperature, $\mu_{\mathrm{W}}=$ $\mu\left\{T_{W}\right\}, c_{p, w}=c_{p}\left\{T_{W}\right\}$ and so forth, as by Bankston and McEligot [1970]. Once these properties are evaluated and $\tau_{W}$ is determined via $f_{S}=\left(f_{S} / f_{D K M}\right) \cdot f_{D K M}$, calculation of $\mathrm{u}_{\tau}, \mathrm{y}^{+}{ }_{\mathrm{w}}, \mathrm{u}^{+} \mathrm{w}$ and $\mathrm{t}^{+} \mathrm{w}$ from their definitions is straight forward.

For comparison purposes, numerical predictions should utilize these same definitions of the quantities (or employ the dimensional measured quantities directly).

\section{B. 2 Nomenclature}

The terms and headings used in the spread sheets may be decoded as follows. Units are indicated in parentheses on the spread sheets; English engineering units are employed for historical reasons. The items are listed in the order in which they appear and generally are not repeated if they appear again. "Self-explanatory" items are not included.

Program

Symbol

$x / D$

p,in

$\mathrm{m}$

Nom. volt

Nom $P$
$\Delta \mathrm{v}$

P

Usual

Nomenclature

$\mathrm{x} / \mathrm{D}$

$\mathrm{p}_{\text {in }}$

$\dot{\mathrm{m}}$

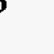

\section{Definition, description, comment}

Dimensionless axial location measured from the start of heating

Static pressure at inlet

Measured air mass flow rate

"Nominal" voltage drop across test section during related experimental run without probe (e.g., run 618)

"Nominal" electrical power dissipated in test section 
Program

Symbol

Nom $m$

$\mathrm{P} /$ NomP

$T$,in

$\mathrm{T}, \mathrm{w}$

D

$\mathrm{A}, \mathrm{cs}$

ThExp

deltaD/Do

$r, w$

$\mathrm{R}^{\prime}$

q'gen

HtLs/q,gen

$q^{\prime} w$
Usual

Nomenclature

"Nominal" mass flow rate

Comparison of power during profile measurements to power during "nominal" run

Air inlet temperature

Local temperature at inner surface of test section

Internal diameter of test section, accounting for thermal expansion

Cross-sectional flow area, accounting for thermal expansion

Coefficient of linear thermal expansion

Fractional expansion of diameter, $\alpha \bullet\left(t_{w}-70\right)$, relative to diameter of unheated tube

Radius of inner surface of tube, accounting for thermal expansion

Electrical resistance of test section per unit length

Lineal thermal energy generation rate

Heat loss rate relative to energy generation rate

Linear heat transfer rate to gas,

$$
\mathrm{i}^{2} \mathrm{R}^{\prime}\left[1-\left(\frac{\mathrm{q}_{\mathrm{hl}}}{\mathrm{q}_{\text {gen }}}\right)\right]
$$


Program

Symbol

$\mathrm{f}, \mathrm{s} / \mathrm{f}, \mathrm{DKM}$

$\mathrm{m} /$ Nom $\mathrm{m}$

q"w

y

$\mathrm{U}$

$\mathrm{T}$

$\mathrm{U} / \mathrm{V}, \mathrm{b}$

$\mathrm{T} / \mathrm{T}$, in

$(\mathrm{Tw}-\mathrm{T}) /(\mathrm{Tw}-\mathrm{Tb})$

$y+w$

$\mathrm{u}+, \mathrm{w}$
Usual

Nomenclature

$\mathrm{f}_{\mathrm{S}} / \mathrm{fDKM}$

$q^{\prime \prime}$

y

$\mathrm{U}$ or $\mathrm{u}$

$\mathrm{T}$

$\mathrm{U} / \mathrm{V}_{\mathrm{b}}$ or $\mathrm{U} / \mathrm{V}_{\mathrm{m}}$

$\mathrm{T} / \mathrm{T}$ in

$\left(\mathrm{T}_{\mathrm{W}}-\mathrm{T}\right) /\left(\mathrm{T}_{\mathrm{W}}-\mathrm{T}_{\mathrm{b}}\right)$

$\mathrm{y}^{+}{ }_{\mathrm{w}}$

$u^{+} w$
Definition, description, comment

Predicted friction factor (based on velocity gradient) normalized by Drew, Koo and McAdams correlation; a result from the prediction program of Bankston and McEligot

Comparison of mass flow rate during profile measurements to mass flow rate during "nominal" run

Convective heat flux to gas, $\mathrm{q}_{\mathrm{W}}^{\prime} / \pi \mathrm{D}$

Sensor distance from the wall, accounting for thermal expansion

Pointwise, streamwise mean velocity

Pointwise time-mean gas temperature

Pointwise, streamwise mean velocity normalized by bulk or mixed mean velocity

Pointwise time-mean gas temperature normalized by inlet temperature

Pointwise time-mean gas temperature normalized by local temperature difference

Non-dimensional distance from wall, $\mathrm{y} \mathrm{u}_{\tau} / \mathrm{v}_{\mathrm{w}}$

Non-dimensional mean streamwise velocity, $\mathrm{U} / \mathrm{u}_{\tau}$ 
Program

Symbol

$\mathrm{t}+, \mathrm{w}$

Int. mdot

$\mathrm{H}, \mathrm{b}$

$\mathrm{T}, \mathrm{b}$

Mdot,prof/meas

Rho,b,prof

G,prof

$\mathrm{V}, \mathrm{b}$, prof

$\mathrm{Re}, \mathrm{b}$
Usual

Nomenclature

$t^{+} w$

$\dot{\mathrm{m}}$

$\mathrm{H}_{\mathrm{b}}$

$\mathrm{T}_{\mathrm{b}}$

$\dot{\mathrm{m}}$ prof $/ \dot{\mathrm{m}}$ meas

$\rho b$ or $\rho_{m}$

G

$\mathrm{Vb}$

$\operatorname{Re}_{b}$
Definition, description, comment

Pointwise time-mean gas

temperature expressed in wall coordinates,

$$
\left(\mathrm{T}_{\mathrm{w}}-\mathrm{T}\right) \rho_{\mathrm{w}} \mathrm{u}_{\tau, \mathrm{w}} \mathrm{c}_{\mathrm{p}, \mathrm{w}} / \mathrm{q}{ }_{\mathrm{w}}
$$

Air mass flow rate, determined by integration of measured velocity profile

Bulk enthalpy, determined by integration of the enthalpy distribution corresponding to the measured temperature profile, $\dot{\mathrm{E}} / \dot{\mathrm{m}}$

Absolute temperature corresponding to bulk enthalpy, i.e. bulk or mixed-mean temperature

Mass flow rate deduced from profile integration, compared to measured mass flow rate

Density corresponding to bulk temperature

Mean streamwise mass flux deduced by integration of mass flux profile

Bulk velocity, deduced from $G$,prof and Rho,b,prof

Local bulk Reynolds number based on mass flow rate from

profile integration, $\frac{4 \dot{\mathrm{m}}}{\pi \mathrm{D} \mu_{\mathrm{b}}}$ 
Program

Symbol

f,DKM

$\mathrm{f}, \mathrm{s}$,pred

$\mathrm{u}, \mathrm{tau}, \mathrm{w}$
Usual

Nomenclature

${ }^{\mathrm{f}} \mathrm{DKM}$

$f_{S}$

$\mathrm{u}_{\tau, \mathrm{w}}$
Definition, description, comment

Fanning friction factor from Drew, Koo and McAdams correlation [1932] evaluated at local bulk Reynolds number,

$0.0014+0.125 \operatorname{Re}_{\mathrm{b}}{ }^{-0.32}$

Fanning friction factor corresponding to mass flow rate from profile integration, $2 \mathrm{~g}_{\mathrm{C}} \rho_{\mathrm{b}} \tau_{\mathrm{W}} / \mathrm{G}^{2}$

Friction velocity evaluated at wall conditions, $\left[g_{\mathrm{C}} \tau_{\mathrm{W}} / \rho_{\mathrm{W}}\right]^{1 / 2}$

\section{B. 3 Mean profiles}

The mean profiles and related quantities are presented on the spread sheet summaries on the following pages. 


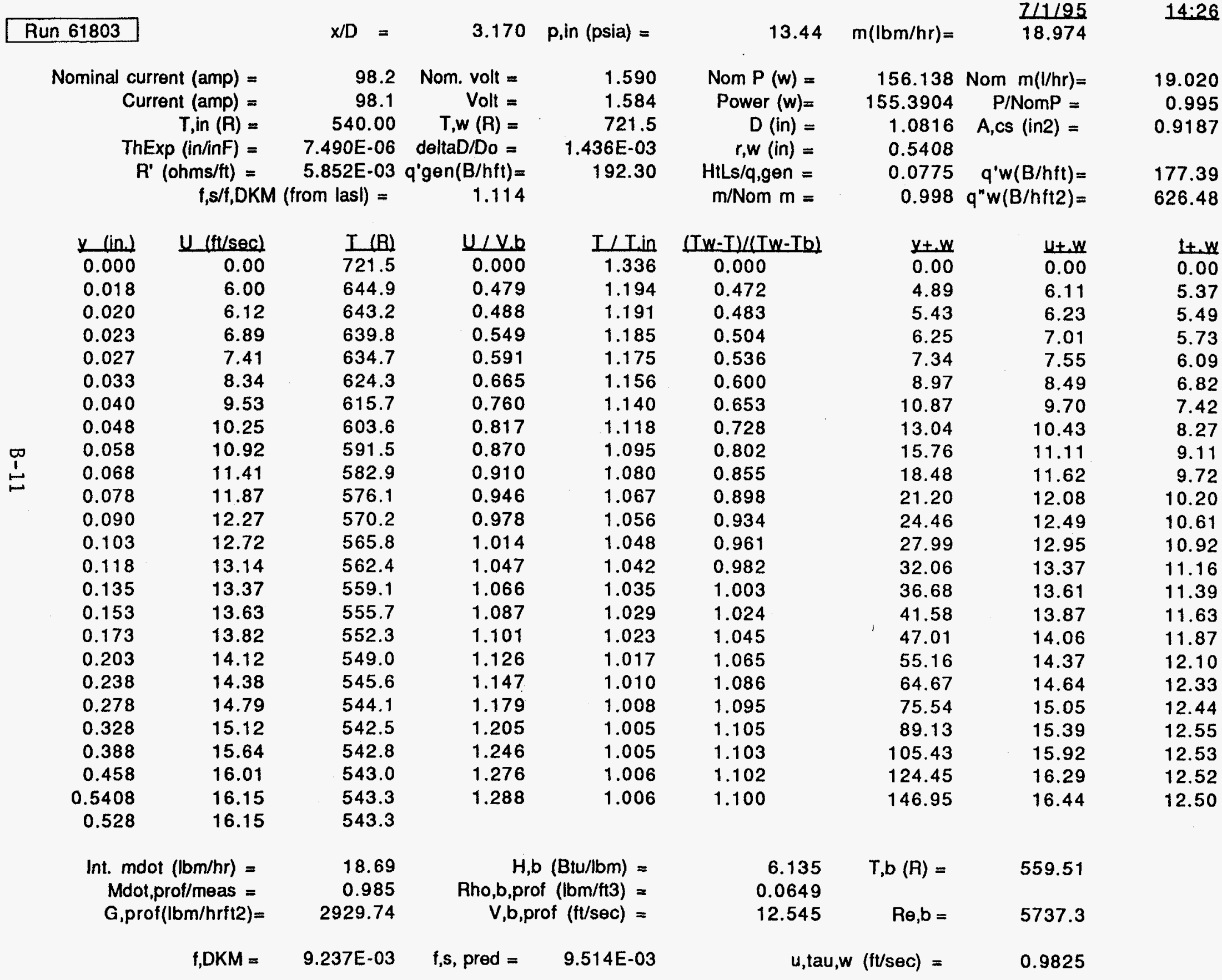




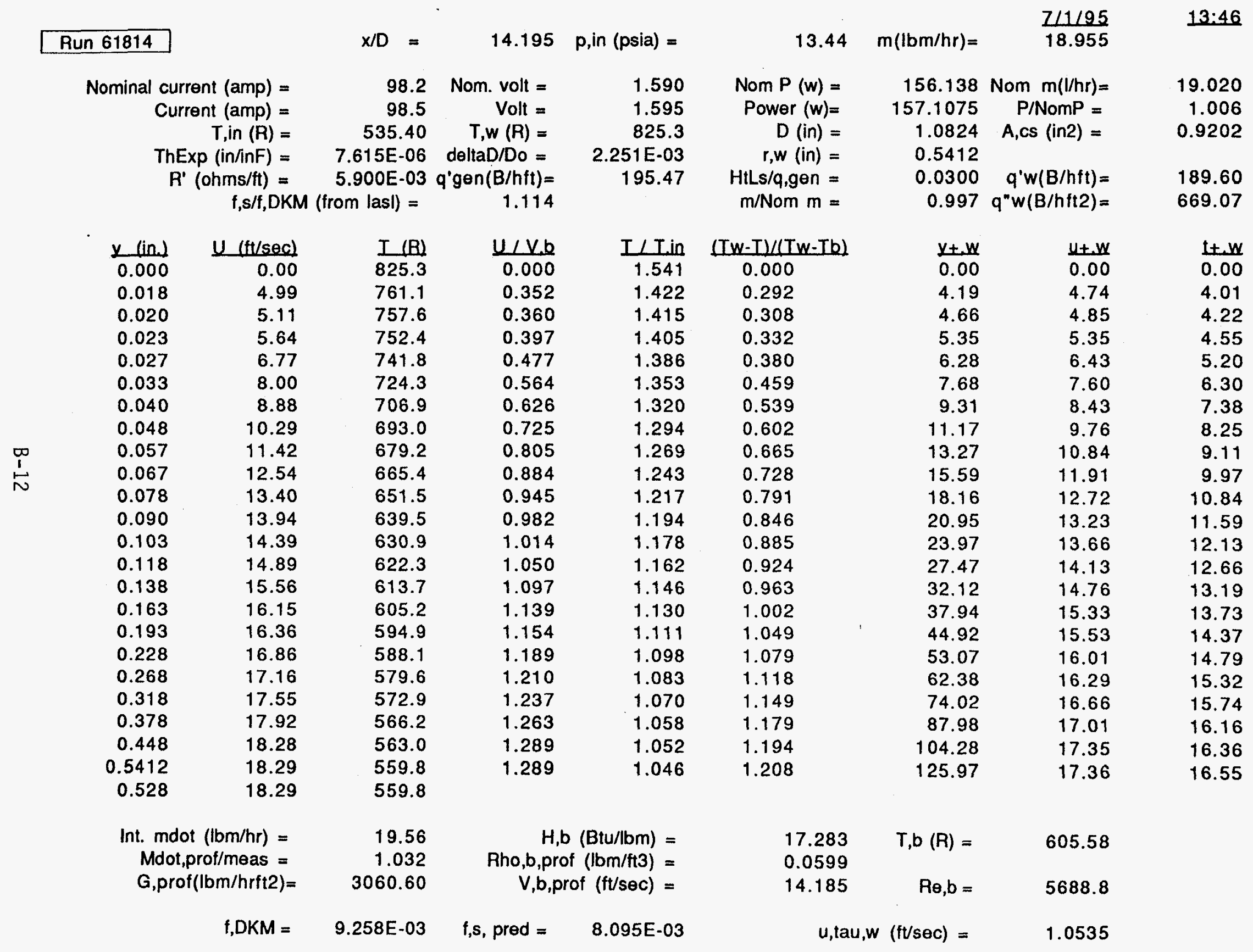


Nominal current $(\mathrm{amp})=$

Current (amp) $=$ $T$, in $(R)=$

ThExp (in/inF $)=$

$R^{\prime}($ ohms/tt) $=$

$$
f, s / f, D K M \text { (from lasl) }=
$$

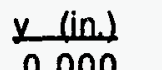

0.023

0.028

0.033

0.038

0.043

0.048

0.055

$\stackrel{p}{\stackrel{\omega}{\omega}}$ $\begin{array}{r}0.533 \\ \hline\end{array}$

Int. $\mathrm{mdot}(\mathrm{lbm} / \mathrm{hr})=$

Mdot,prof/meas =

G,prof $(1 \mathrm{bm} / \mathrm{hrft} 2)=$

$f, D K M=$
98.2 Nom. volt $=\quad 1.590$

$98.4 \quad$ Volt $=\quad 1.595$

$535.00 \quad T, w(R)=\quad 891.2$

7.694E-06 deltaD/Do $=2.782 \mathrm{E}-03$

5.931E-03 q'gen(B/hft)=

1.114

196.08

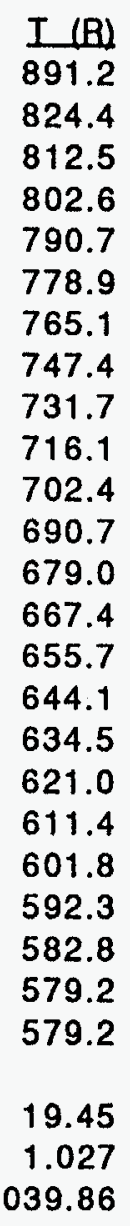

$\frac{u / V .6}{0.000}$

0.358

0.429

0.497

0.569

0.632

0.689

0.744

0.788

0.854

0.918

0.982

1.018

1.052

1.088

1.133

1.167

1.239

1.262

1.280

1.303

$$
1.337
$$

1.344

I I Tin

1.666

1.541

1.519

1.500

1.478

1.456

1.430

1.397

1.368

1.338

1.313

1.291

1.269

1.247

1.226

1.204

1.186

1.161

1.143

1.125

1.107

1.089

1.083

Nom $P(w)=$ Power $(w)=$

$D$ (in) $=$ $r, w($ in) $=$

HtLs/q,gen =

$\mathrm{m} / \mathrm{Nom} \mathrm{m}=$

\section{$(I w-T) /(T w-T b)$}

0.000

0.269

0.317

0.357

0.405

0.453

0.508

0.579

0.643

0.706

0.761

0.808

0.855

0.902

0.949

0.996

1.034

1.089

1.127

1.166

1.204

1.242

1.257

$\mathrm{H}, \mathrm{b}(\mathrm{Btu} / \mathrm{lbm})=$ Aho,b,prof $(\mathrm{lbm} / \mathrm{tt} 3)=$

$V, b$, prof $(f t / s e c)=$

$9.375 \mathrm{E}-03$

$f, s$, pred $=\quad 7.939 E-03$
156.138 Nom $\mathrm{m}(1 / \mathrm{hr})=$ 156.948 P/NomP =

$1.0830 \quad A, \operatorname{cs}($ in2 $)=$

0.5415

$0.0059 \quad q^{\prime} w(B / h f t)=$

$0.995 q^{n} w(B / h f t 2)=$

19.020

1.005

0.9212

194.92

687.49

$\not+. w$
0.00
4.96
6.04
7.12
8.19
9.27
10.35

$\underline{u+w}$

0.00

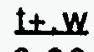

0.00

3.98

4.70

5.29

5.99

6.70

7.52

11.86

13.37

15.52

17.90

20.48

23.29

26.52

30.83

36.22

42.69

50.24

58.86

69.65

82.58

97.68

116.76

6.70

7.67

8.52

9.29

10.03

10.62

11.51

12.38

13.24

13.73

14.18

14.67

15.27

15.73

16.71

17.01

17.26

17.57

18.02

18.12

8.58

9.51

10.45

11.26

11.96

12.65

13.35

14.04

14.74

15.31

16.12

16.69

17.26

17.82

18.39

18.61

$\begin{array}{rrr}26.396 & T, b(R)= & 642.99 \\ 0.0564 & & \\ 14.959 & R \theta, b= & 5430.6\end{array}$




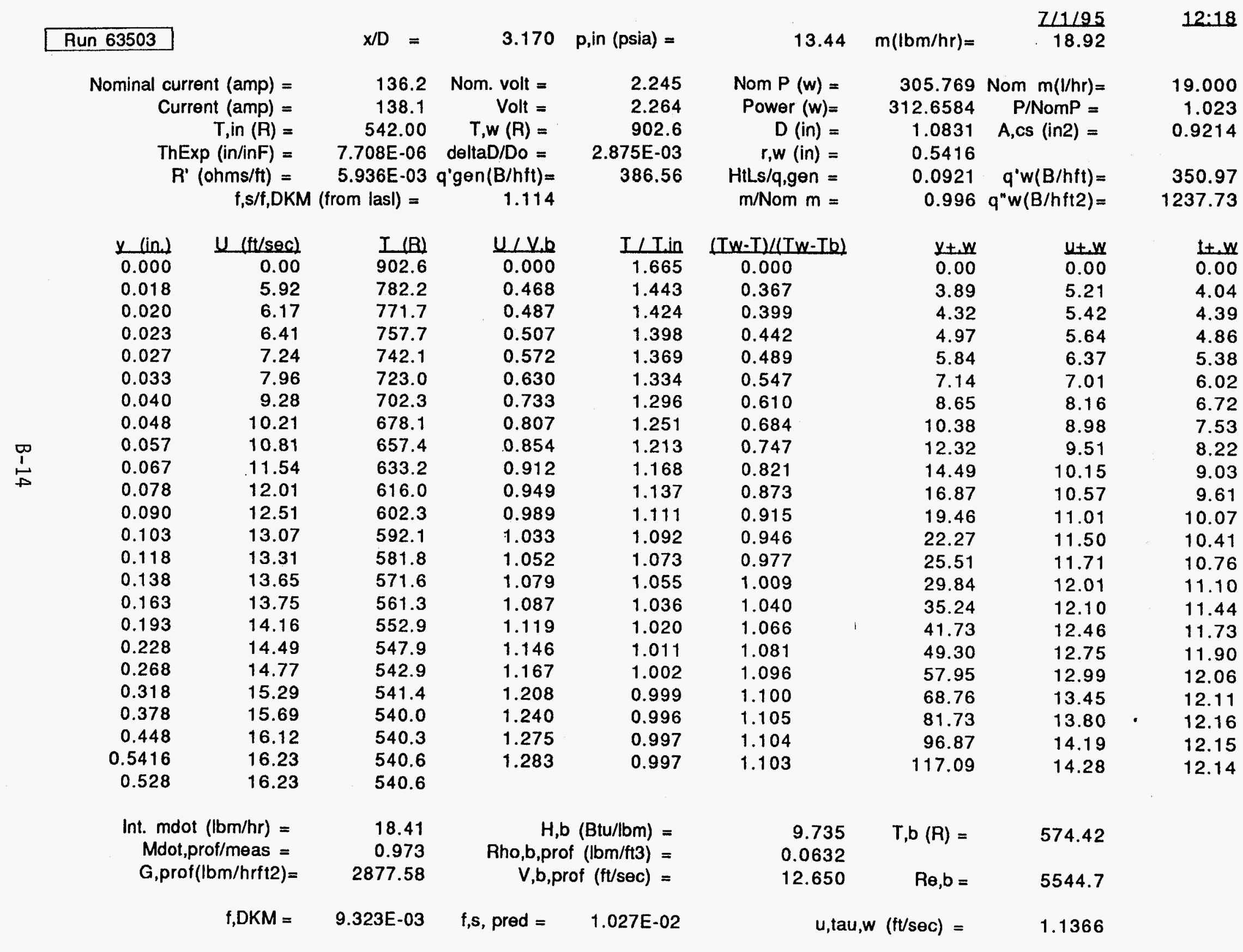




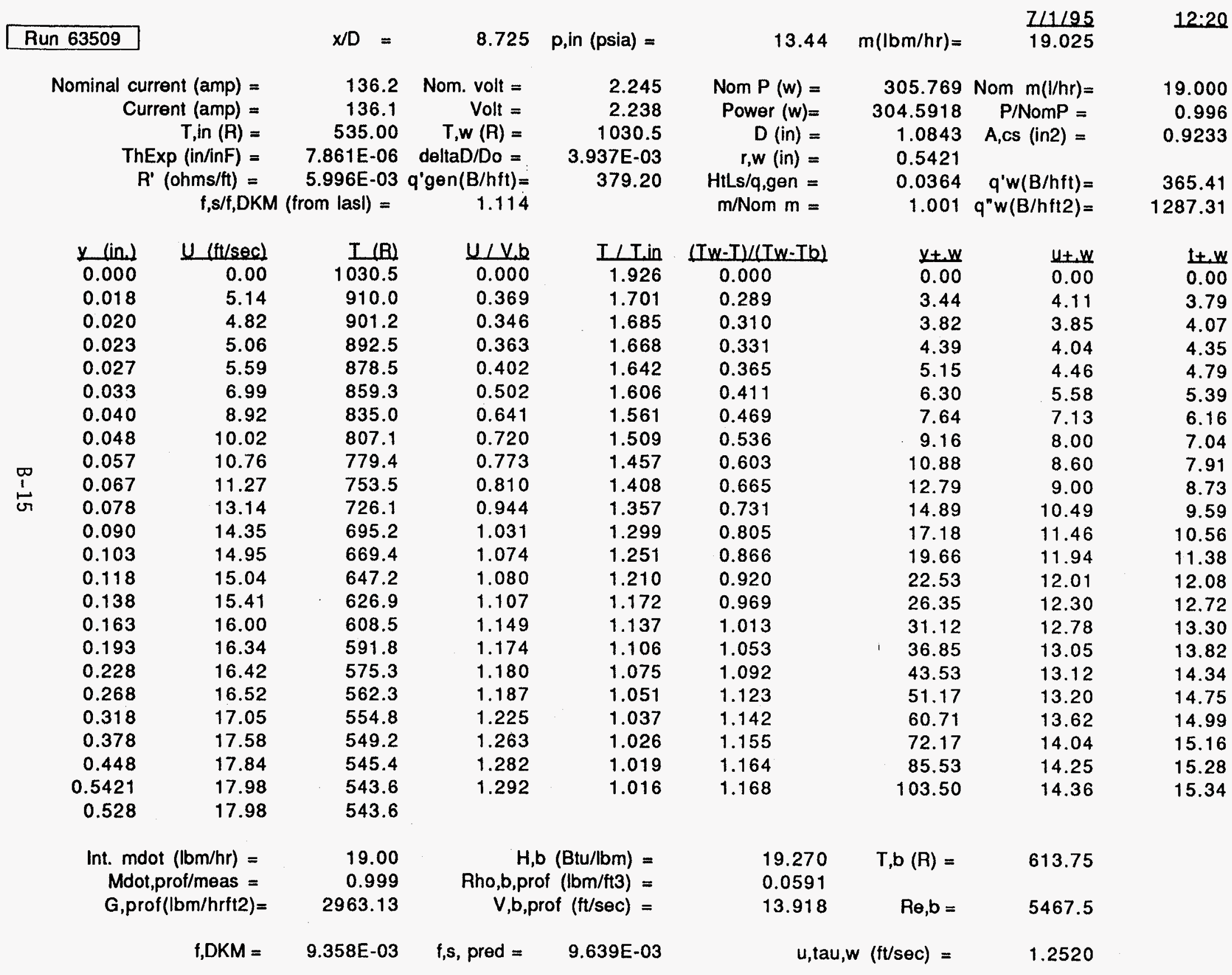




\begin{tabular}{|c|c|c|c|c|c|c|c|c|}
\hline Run 63514 & \multicolumn{2}{|r|}{$x / D=$} & \multicolumn{2}{|c|}{14.195 p,in (psia) $=$} & 13.44 & $\mathrm{~m}(\mathrm{lbm} / \mathrm{hr})=$ & \multicolumn{2}{|l|}{$\frac{711 / 95}{18.958}$} \\
\hline \multicolumn{2}{|c|}{ Nominal current $(\mathrm{amp})=$} & 136.2 & Nom. volt $=$ & 2.245 & Nom $P(w)=$ & 305.769 & Nom $m(1 / h r)=$ & 19.000 \\
\hline \multicolumn{2}{|c|}{ Current (amp) $=$} & 136.2 & Volt $=$ & 2.240 & Power $(w)=$ & 305.088 & $\mathrm{P} / \mathrm{NomP}=$ & 0.998 \\
\hline \multirow{2}{*}{\multicolumn{2}{|c|}{$\begin{aligned} T, \text { in }(\overline{\mathrm{H}}) & = \\
T h E \times 0(\text { in/in } F) & =\end{aligned}$}} & 537.00 & $T, w(R)=$ & 1155.2 & $D($ in $)=$ & 1.0854 & $A, c s(i n 2)=$ & 0.9253 \\
\hline \multirow{2}{*}{\multicolumn{2}{|c|}{$\begin{aligned} \text { ThExp }(\mathrm{in} / \mathrm{inF}) & = \\
\mathrm{R}^{\prime}(\mathrm{ohms} / \mathrm{ft}) & =\end{aligned}$}} & 8.011E-06 & deltaD/Do = & $5.011 \mathrm{E}-03$ & $r, w($ in $)=$ & 0.5427 & & \\
\hline & & $6.054 \mathrm{E}-03$ & $q^{\prime} g e n(B / h f t)=$ & 383.42 & HtLs/q,gen = & 0.0315 & $q^{\prime} w(B / h f t)=$ & $371 .:$ \\
\hline \multicolumn{3}{|c|}{$f, s / f, D K M($ from lasl) $=$} & 1.114 & & $\mathrm{~m} /$ Nom $\mathrm{m}=$ & 0.998 & $q^{\prime \prime} w(B / h f t 2)=$ & 1306.76 \\
\hline$y \quad$ (in) & $U(\mathrm{ft} / \mathrm{sec})$ & $I(B)$ & $U / V, b$ & $I /$ I.in & $(T w-T)(T w-T b)$ & $x \pm w$ & $u+w$ & $1 \pm$ \\
\hline 0.000 & 0.00 & 1155.2 & 0.000 & 2.151 & 0.000 & 0.00 & 0.00 & 0.0 \\
\hline 0.023 & 6.20 & 1002.8 & 0.400 & 1.867 & 0.309 & 3.94 & 4.57 & 4.63 \\
\hline 0.025 & 6.07 & 999.4 & 0.392 & 1.861 & 0.316 & 4.28 & 4.47 & 4.73 \\
\hline 0.028 & 6.62 & 986.9 & 0.428 & 1.838 & 0.341 & 4.79 & 4.88 & 5.11 \\
\hline 0.032 & 8.03 & 967.4 & 0.518 & 1.802 & 0.381 & 5.47 & 5.91 & 5.7 \\
\hline 0.038 & 9.15 & 948.1 & 0.591 & 1.766 & 0.420 & 6.50 & 6.74 & 6.29 \\
\hline 0.045 & 10.38 & 920.0 & 0.670 & 1.713 & 0.477 & 7.70 & 7.65 & 7.14 \\
\hline 0.053 & 11.90 & 892.0 & 0.768 & 1.661 & 0.534 & 9.07 & 8.76 & 7.99 \\
\hline 0.062 & 13.00 & 860.6 & 0.839 & 1.603 & 0.597 & 10.61 & 9.57 & 8.94 \\
\hline 0.072 & 13.57 & 825.7 & 0.876 & 1.538 & 0.668 & 12.32 & 10.00 & 10.0 \\
\hline 0.083 & 14.83 & 794.5 & 0.958 & 1.480 & 0.731 & 14.20 & 10.92 & 10.95 \\
\hline 0.095 & 15.45 & 763.3 & 0.997 & 1.421 & 0.794 & 16.25 & 11.38 & 11.90 \\
\hline 0.108 & 16.39 & 737.5 & 1.058 & 1.373 & 0.847 & 18.48 & 12.07 & 12.68 \\
\hline 0.123 & 16.83 & 713.4 & 1.086 & 1.328 & 0.896 & 21.04 & 12.39 & 13.41 \\
\hline 0.143 & 17.33 & 684.1 & 1.118 & 1.274 & 0.955 & 24.47 & 12.76 & 14.30 \\
\hline 0.168 & 17.76 & 658.4 & 1.146 & 1.226 & 1.007 & 28.74 & 13.08 & 15.0 \\
\hline 0.198 & 18.19 & 634.5 & 1.174 & 1.182 & 1.056 & 33.88 & 13.40 & 15.8 \\
\hline 0.233 & 18.51 & 615.8 & 1.195 & 1.147 & 1.093 & 39.86 & 13.63 & 16.37 \\
\hline 0.273 & 18.86 & 598.9 & 1.217 & 1.115 & 1.128 & 46.71 & 13.89 & 16.8 \\
\hline 0.323 & 19.17 & 585.6 & 1.237 & 1.090 & 1.155 & 55.26 & 14.12 & 17.29 \\
\hline 0.383 & 19.54 & 574.0 & 1.261 & 1.069 & 1.178 & 65.53 & 14.39 & 17.6 \\
\hline 0.453 & 19.93 & 565.9 & 1.287 & 1.054 & 1.195 & 77.50 & 14.68 & 17.89 \\
\hline 0.5427 & 19.62 & 559.4 & 1.267 & 1.042 & 1.208 & 92.85 & 14.45 & 18.08 \\
\hline 0.533 & 19.62 & 559.4 & & & & & & \\
\hline \multirow{2}{*}{\multicolumn{2}{|c|}{$\begin{aligned} \text { Int. mdot }(\mathrm{lbm} / \mathrm{hr}) & = \\
\mathrm{Mdot}, \mathrm{prof} / \mathrm{meas} & = \\
\mathrm{G}, \operatorname{prof}(\mathrm{lbm} / \mathrm{hrft} 2) & =\end{aligned}$}} & $\begin{array}{l}19.65 \\
1.037\end{array}$ & \multicolumn{2}{|c|}{$\begin{array}{r}\text { H,b (Btu/lbm) }= \\
\text { Rho,b,prof (lbm/tt3) }=\end{array}$} & $\begin{array}{l}31.030 \\
0.0548\end{array}$ & $T, b(R)=$ & 661.93 & \\
\hline & & 3058.27 & \multicolumn{2}{|c|}{$V, b$, prof $(\mathrm{ft} / \mathrm{sec})=$} & 15.493 & $R e, b=$ & 5370.2 & \\
\hline & $f, D K M=$ & $9.404 E-03$ & $f, s$, pred $=$ & 8.803E-03 & $\mathrm{u}, \mathrm{t}$ ć & $w(f t / s \theta c)=$ & 1.3579 & \\
\hline
\end{tabular}




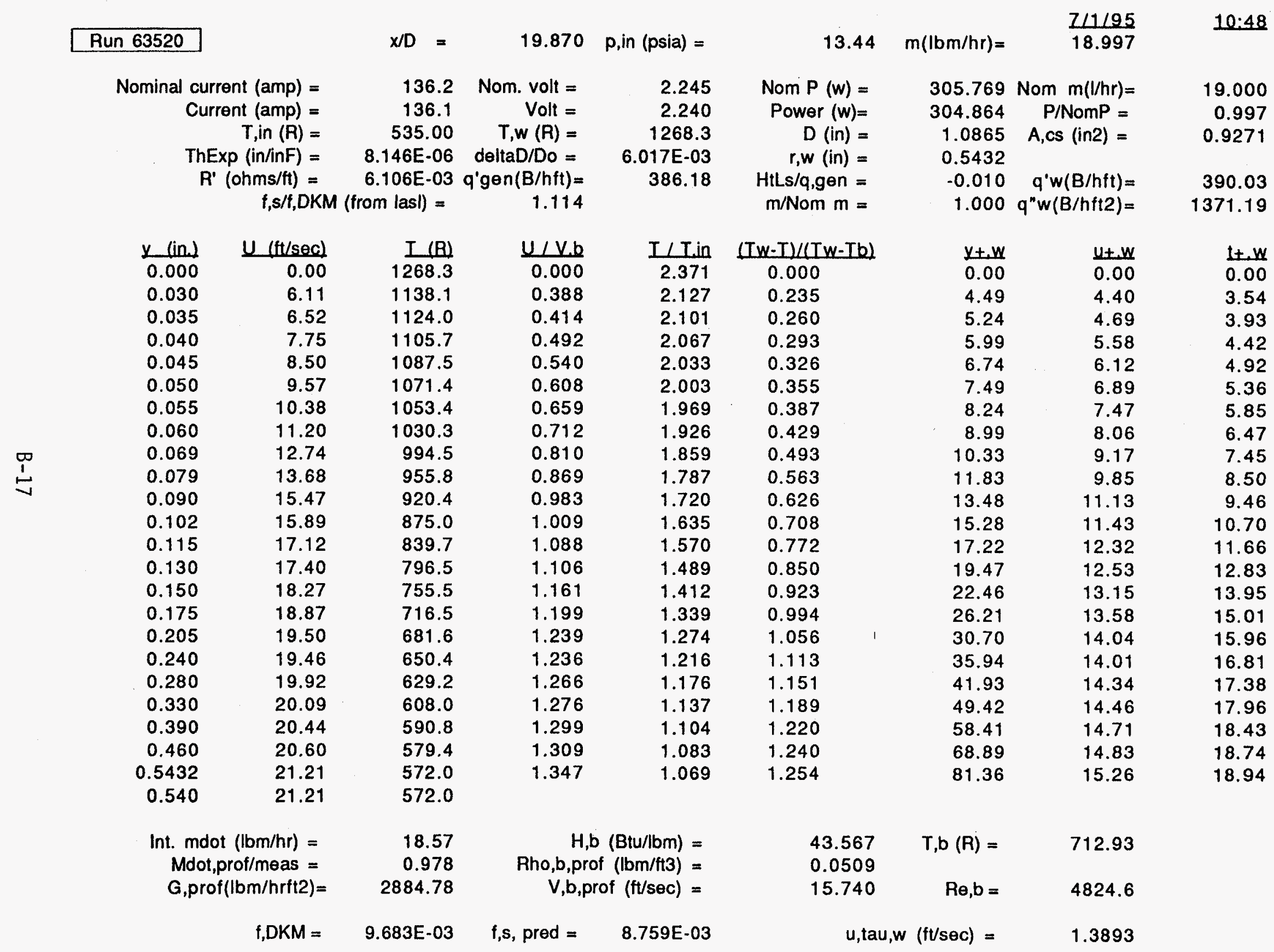




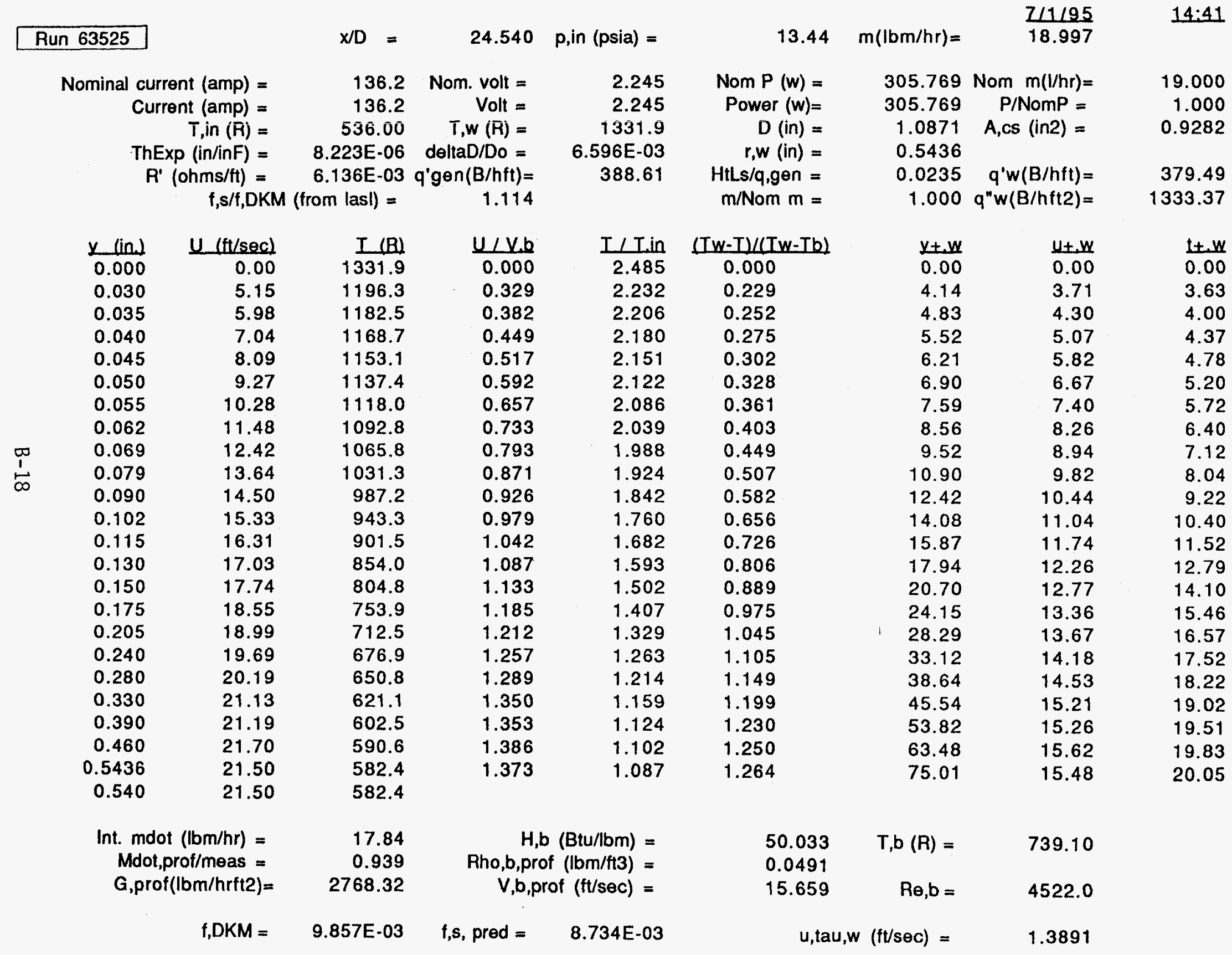




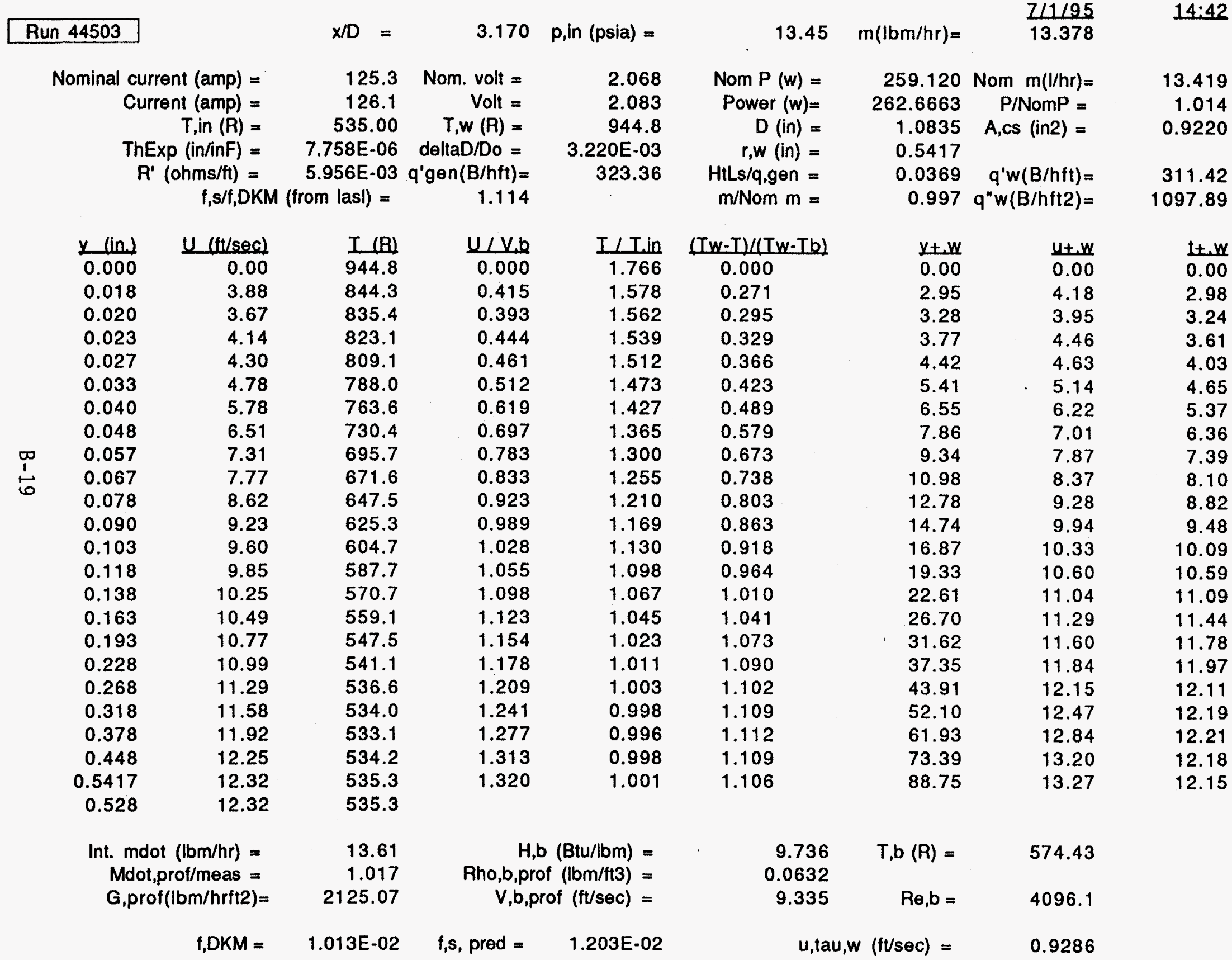




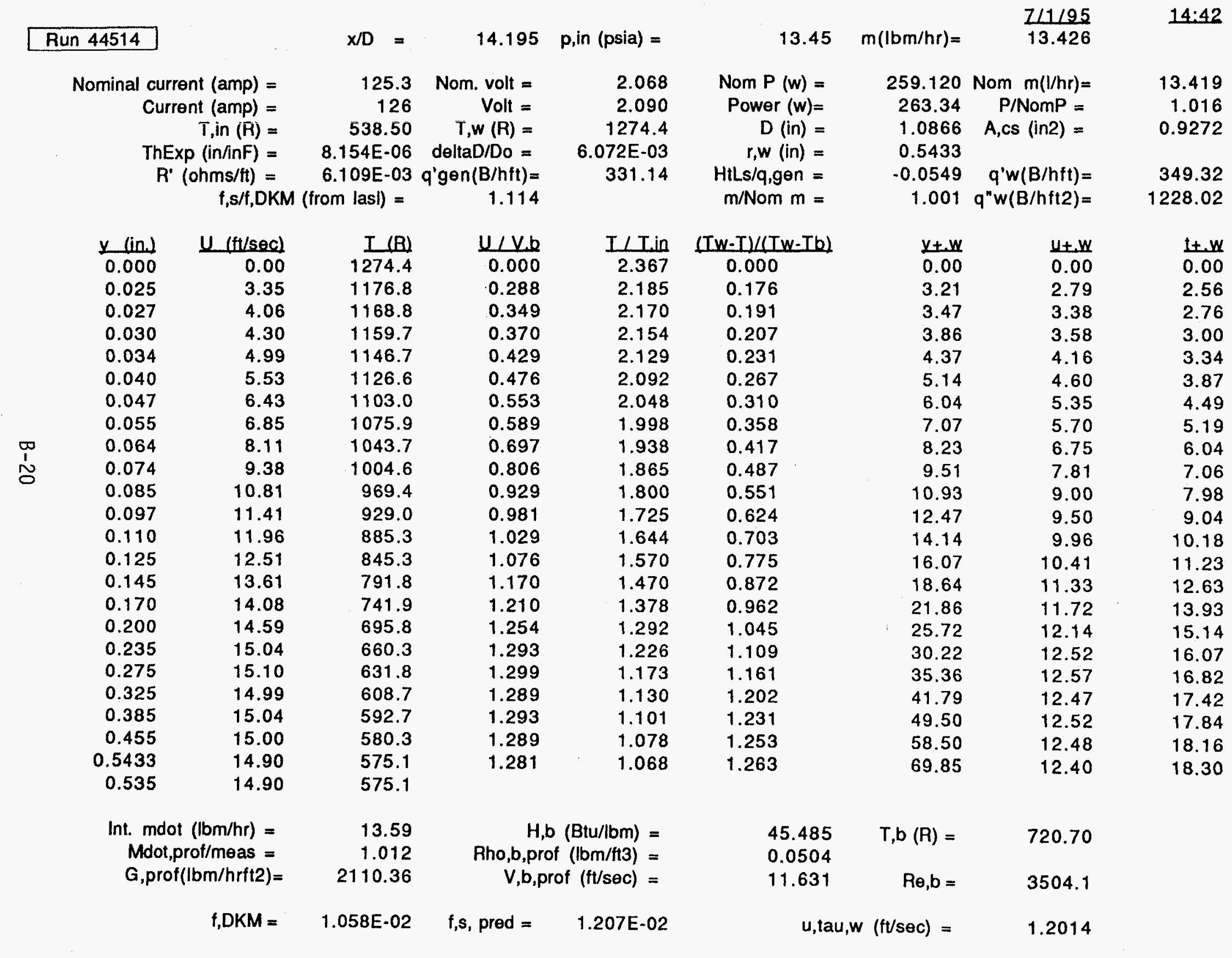




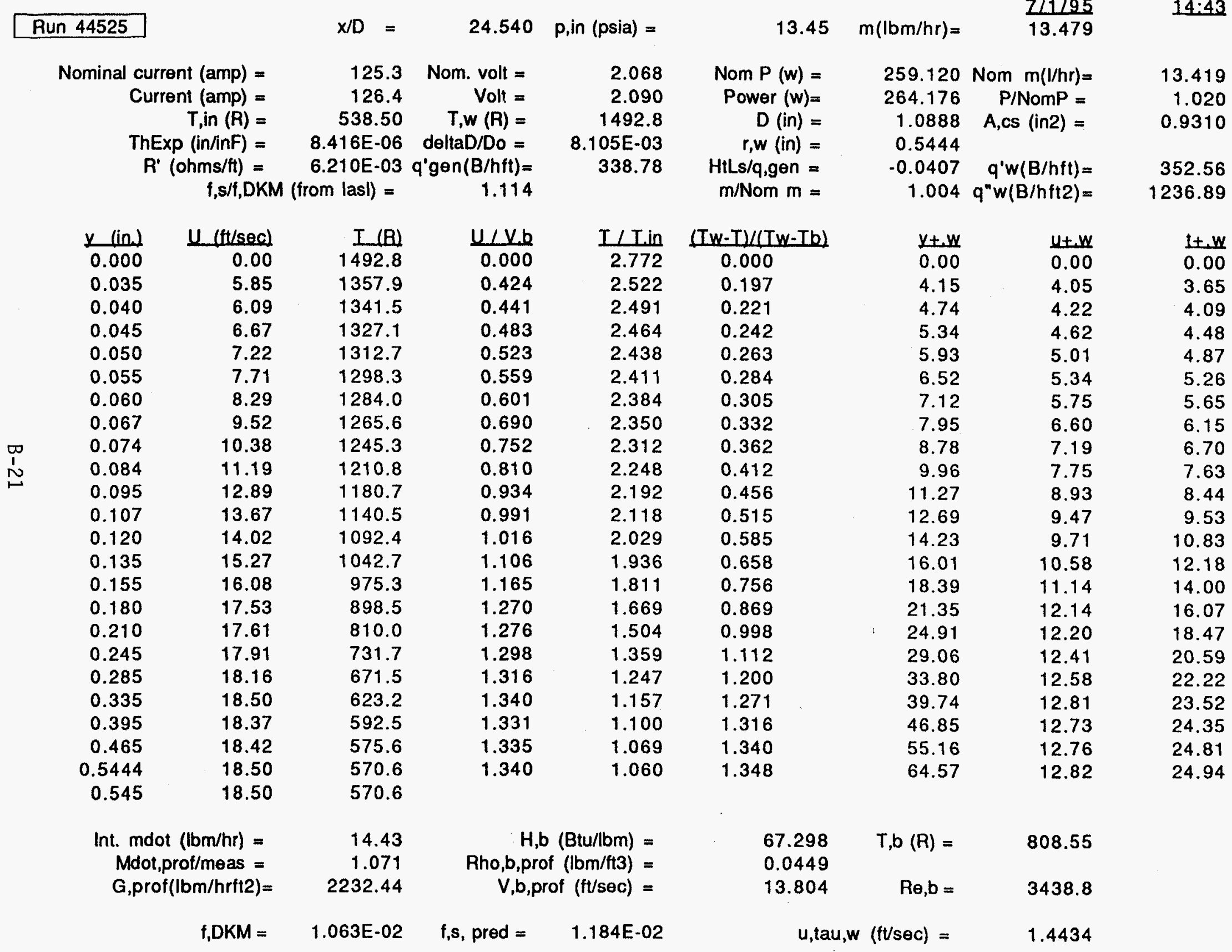




\section{FIGURE CAPTIONS}

1. Schematic diagram of experimental apparatus.

2. Details of miniature boundary layer hot wire probe.

3. Schematic drawing and details of articulating probe support.

4. Adiabatic mean axial velocity profiles at entry to heated section.

5. Axial distributions of integral parameters.

6. Axial development of mean temperature and mean axial velocity fields for "turbulent" run, $\mathrm{q}^{+} \approx 0.0018$ and $\mathrm{Re}_{\text {in }} \approx 6080$.

7. Axial development of mean temperature and mean axial velocity fields for "subturbulent" run, $\mathrm{q}^{+} \approx 0.0035$ and $\operatorname{Re}_{\text {in }} \approx 6050$.

8. Axial development of mean temperature and mean axial velocity fields for "laminarizing" run, $\mathrm{q}^{+} \approx 0.0045$ and $\mathrm{Re}_{\mathrm{in}} \approx 4260$.

9. Comparison of mean profiles downstream, in terms of wall coordinates.

10. Comparison of viscous layer data to numerical solution with turbulence model modified for agreement.

11. Axial behavior of deduced mixing length profiles.

12. Axial behavior of deduced eddy diffusivity profiles.

13. Axial behavior of deduced Reynolds shear stress profiles.

14. Axial behavior of deduced turbulent heat flux profiles. 


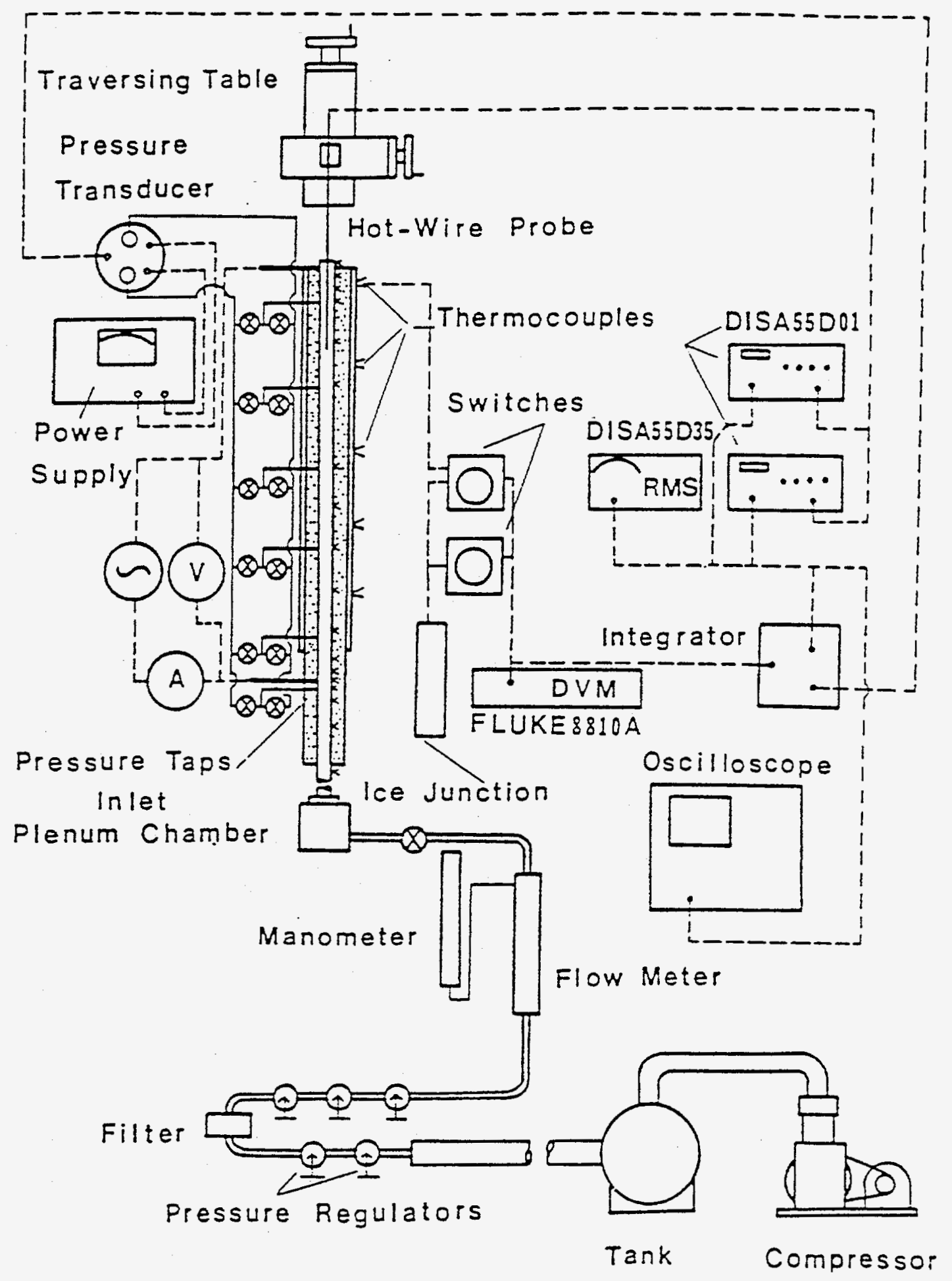

Fig. 1. Schematic diagram of experimental apparatus. 


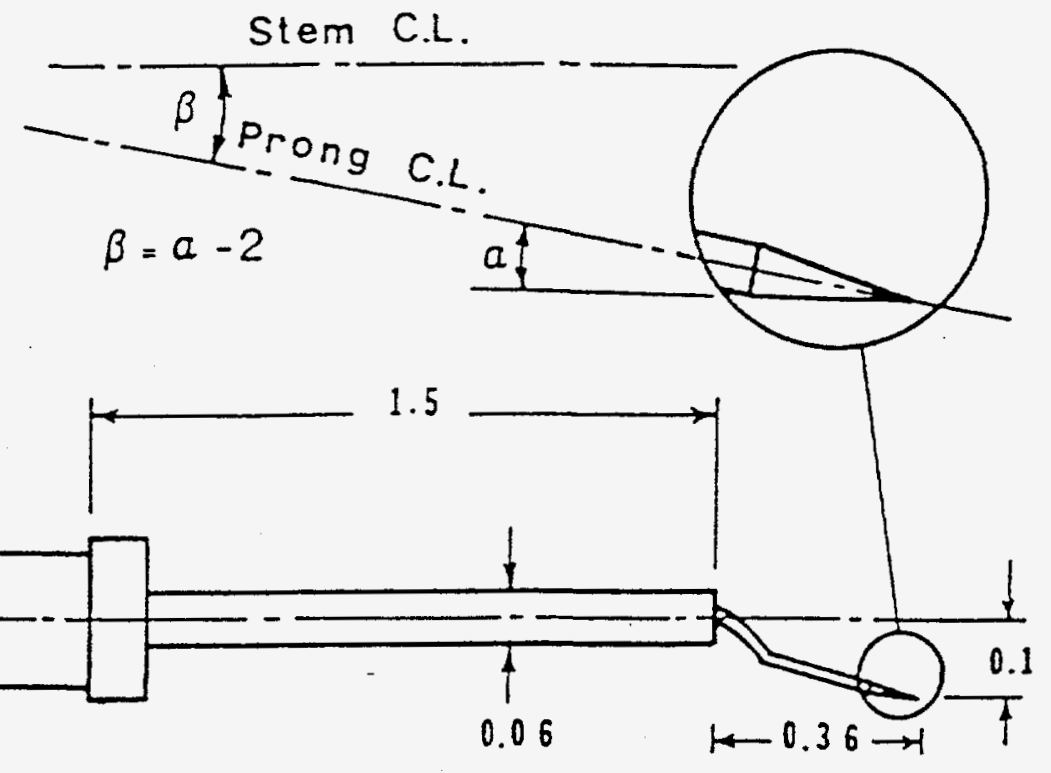

Fig. 2. Details of miniature boundary layer hot wire probe (dimensions in inches): 
Centering and

Aligning

Guard Pins (Number 1 and 2)
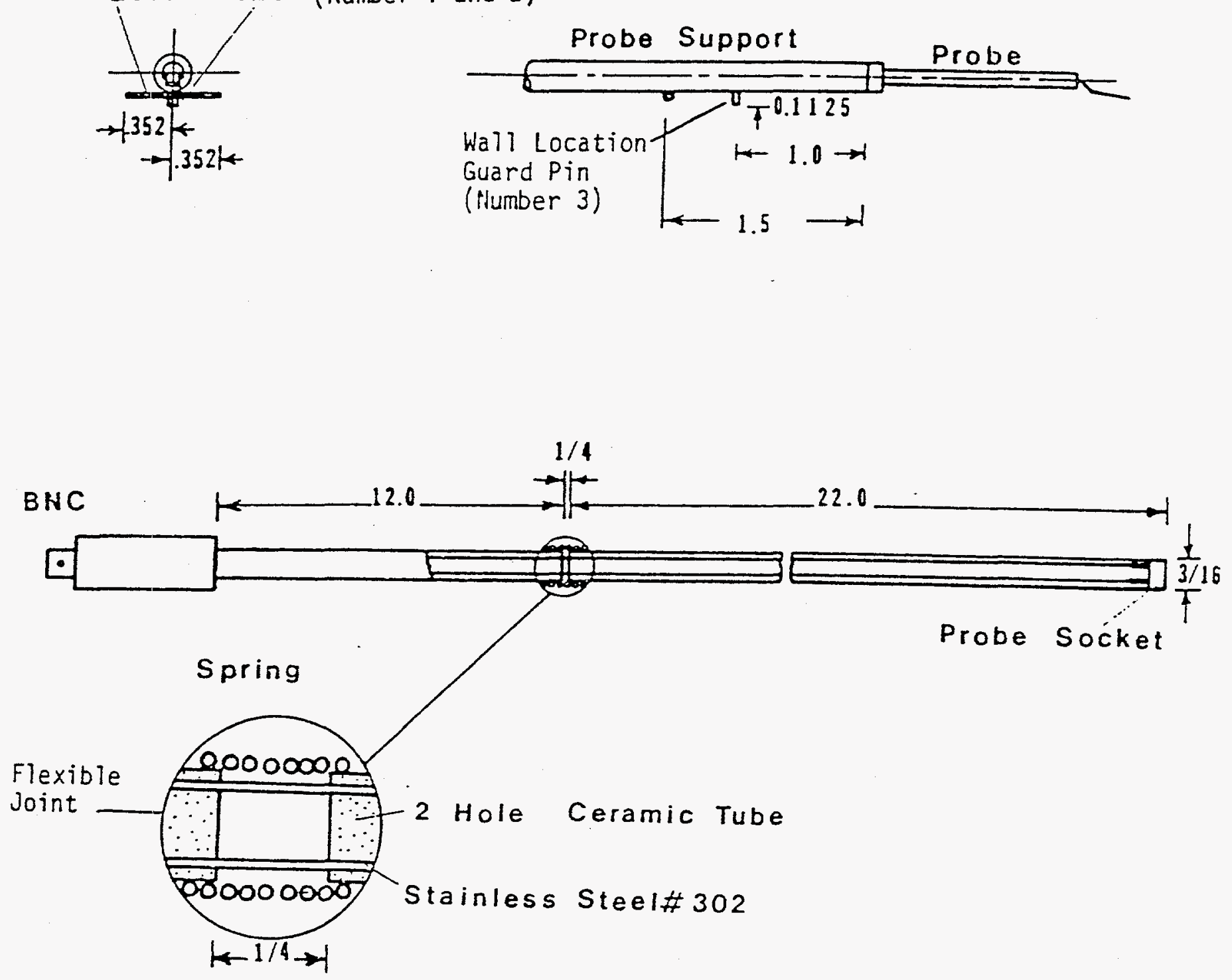

Fig. 3. Schematic drawing and details of articulating probe support (dimensions in inches). 


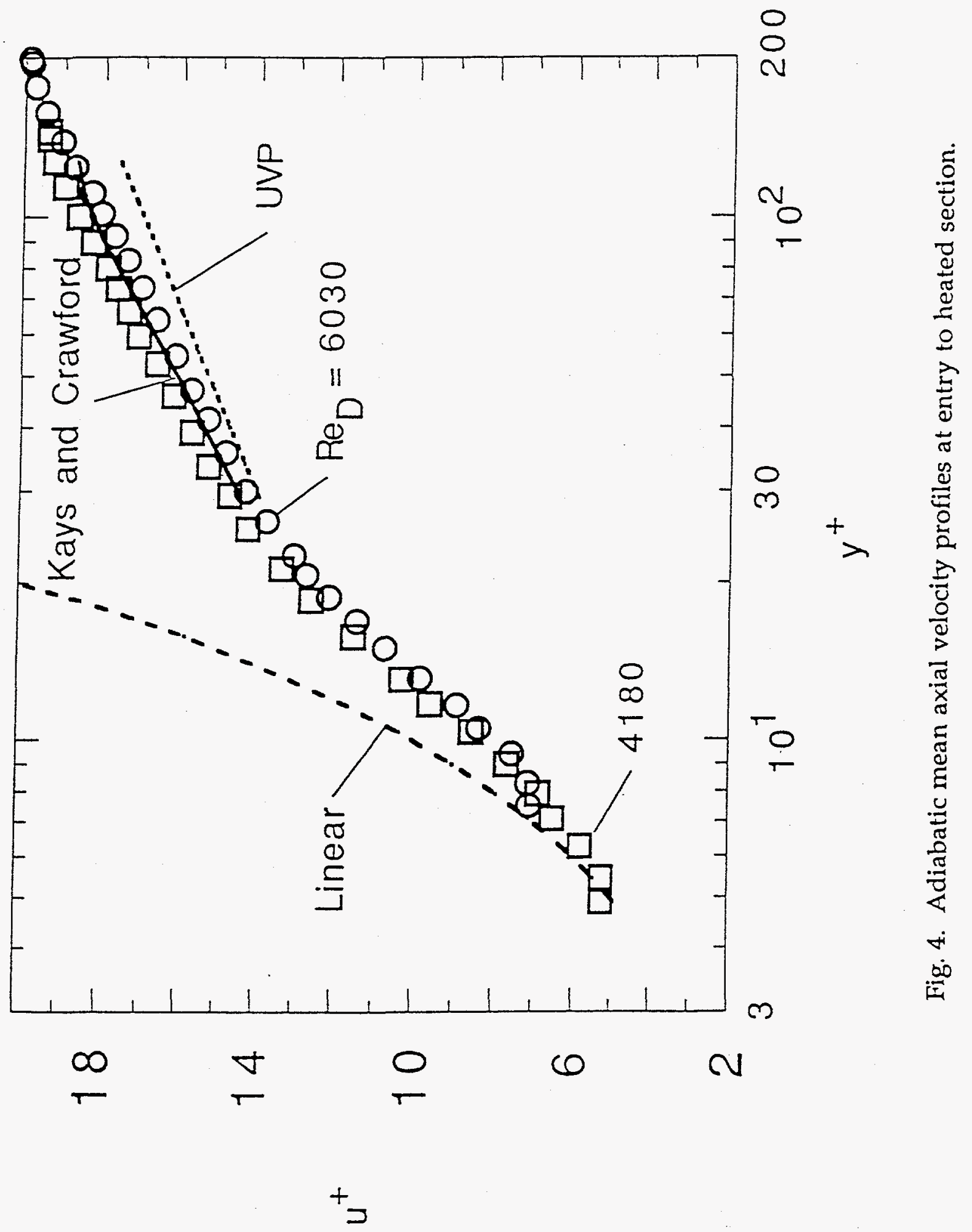



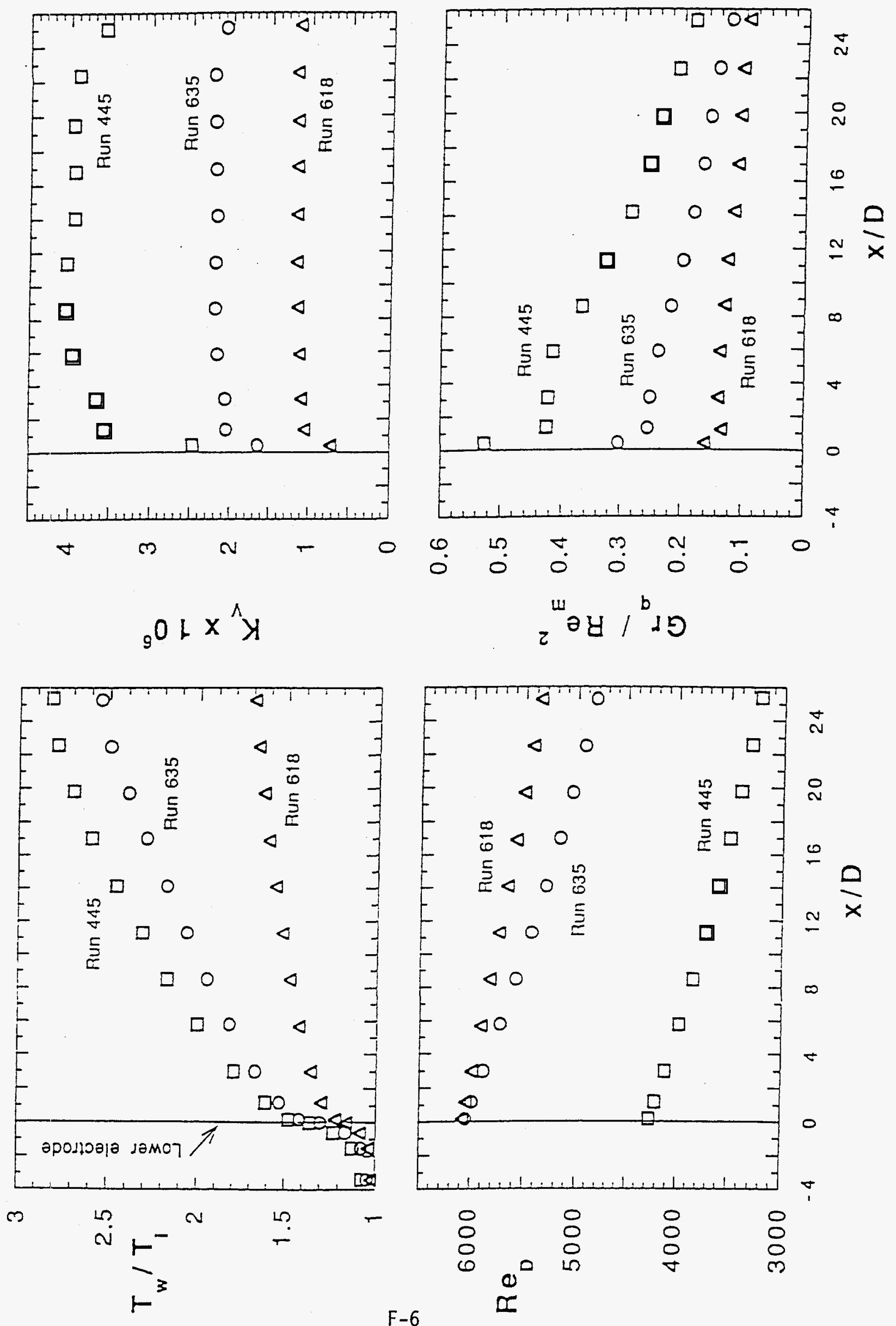

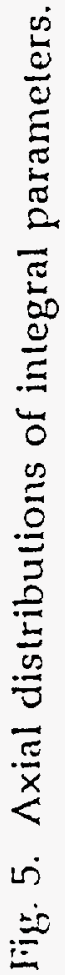

F-6 

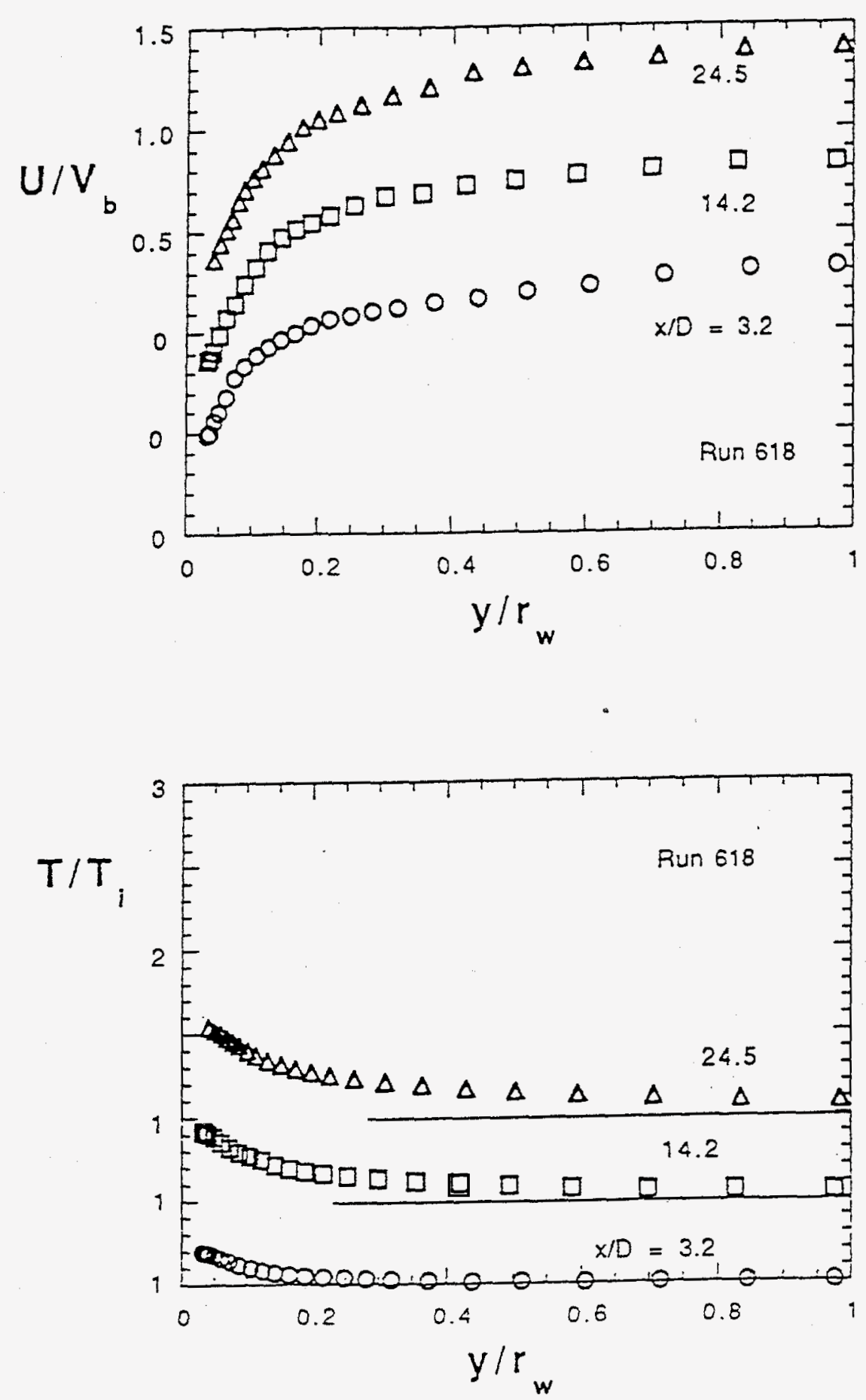

Fig. 6. Axial development of mean temperature and mean axial velocity fields for "turbulent" run, $\mathrm{q}^{+} \approx 0.0018$ and $\operatorname{Re}_{\text {in }}=6080$. 

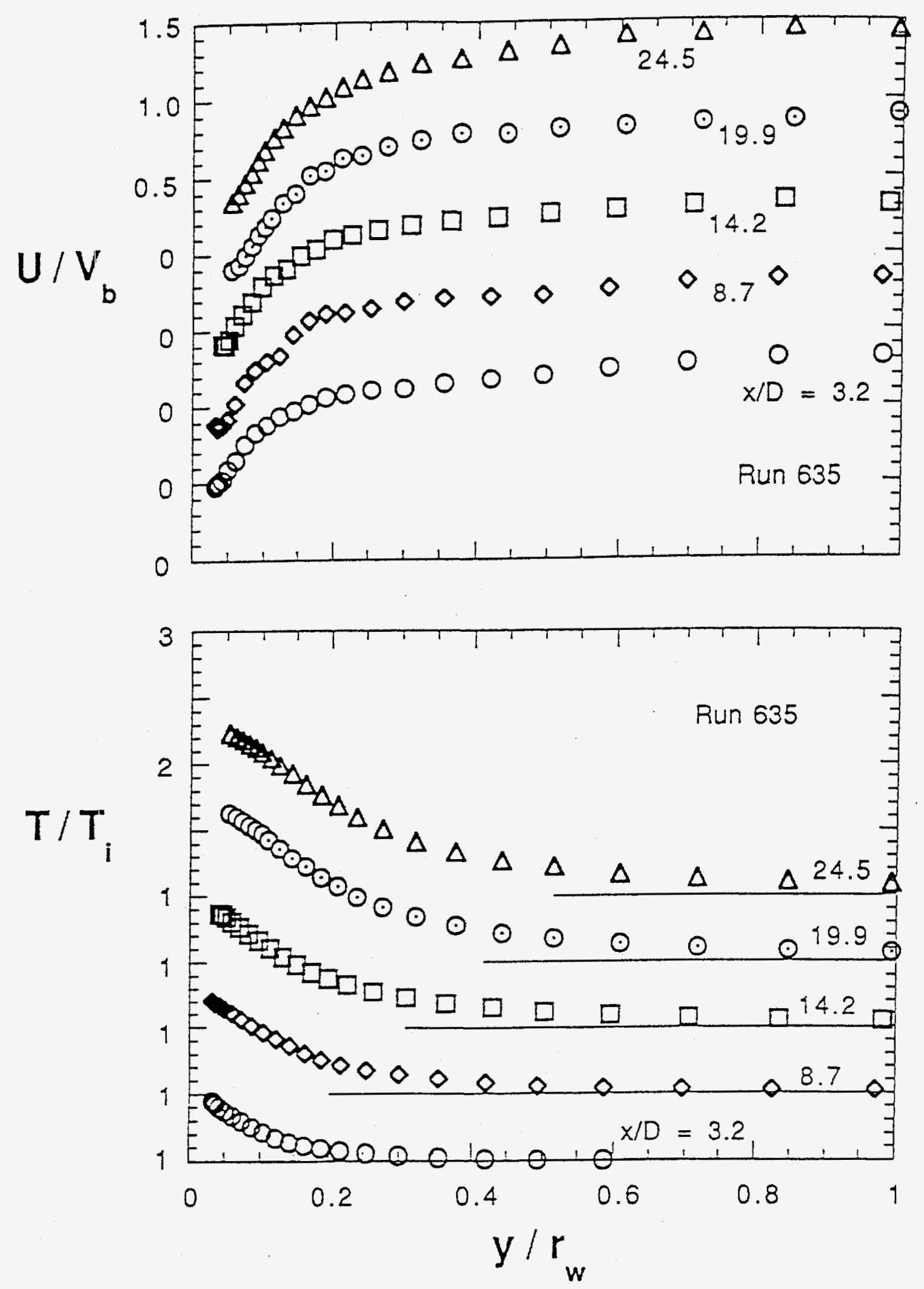

Fig. 7. Axial development of mean temperature and mean axial velocity fields for "subturbulent" run, $\mathrm{q}^{+} \approx 0.0035$ and $\mathrm{Re}_{\text {in }}=6050$. 

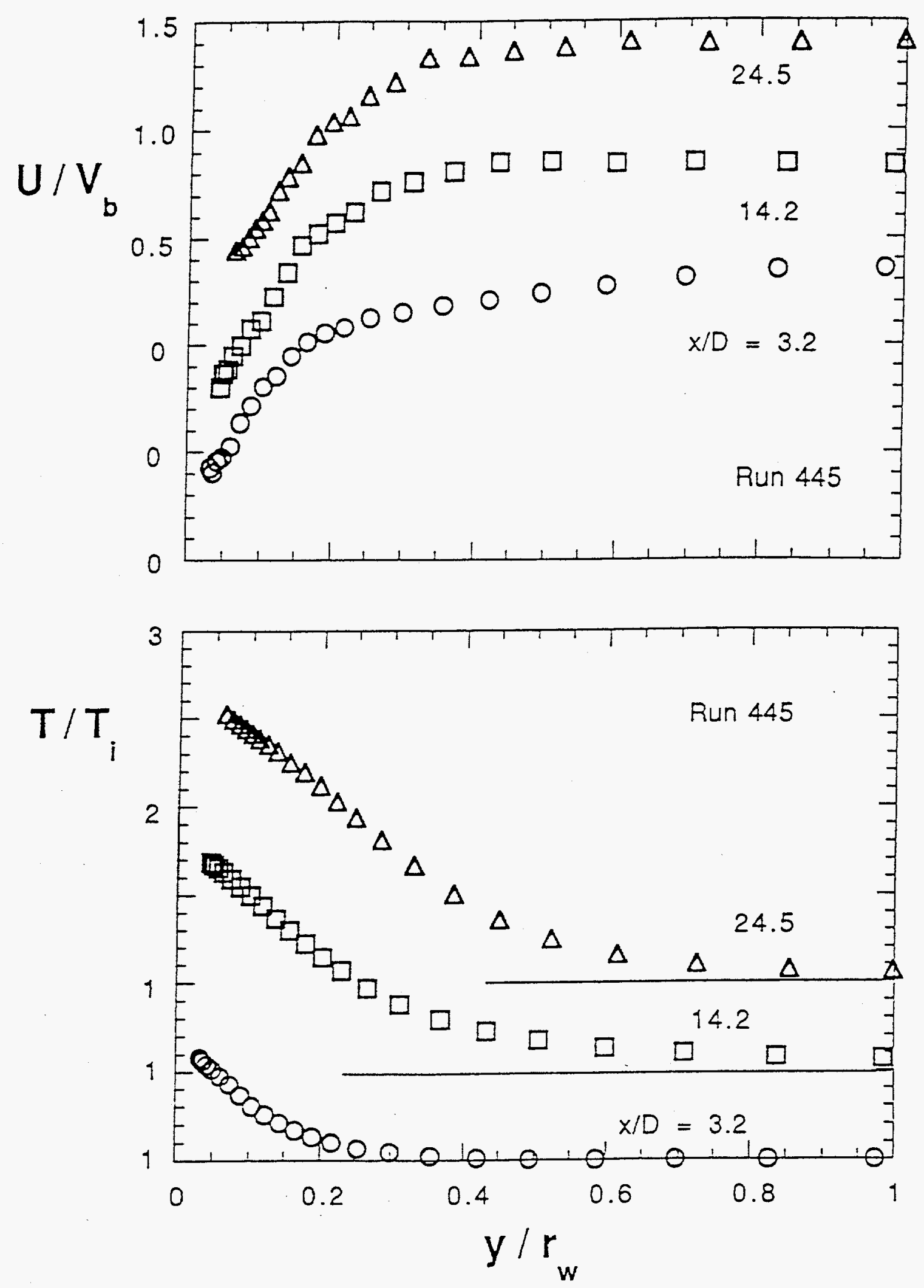

Fig. 8. Axial development of mean temperature and mean axial velocity fields for "laminarizing" run, $\mathrm{q}^{+}=0.0045$ and $\mathrm{Re}_{\text {in }}=4260$. 

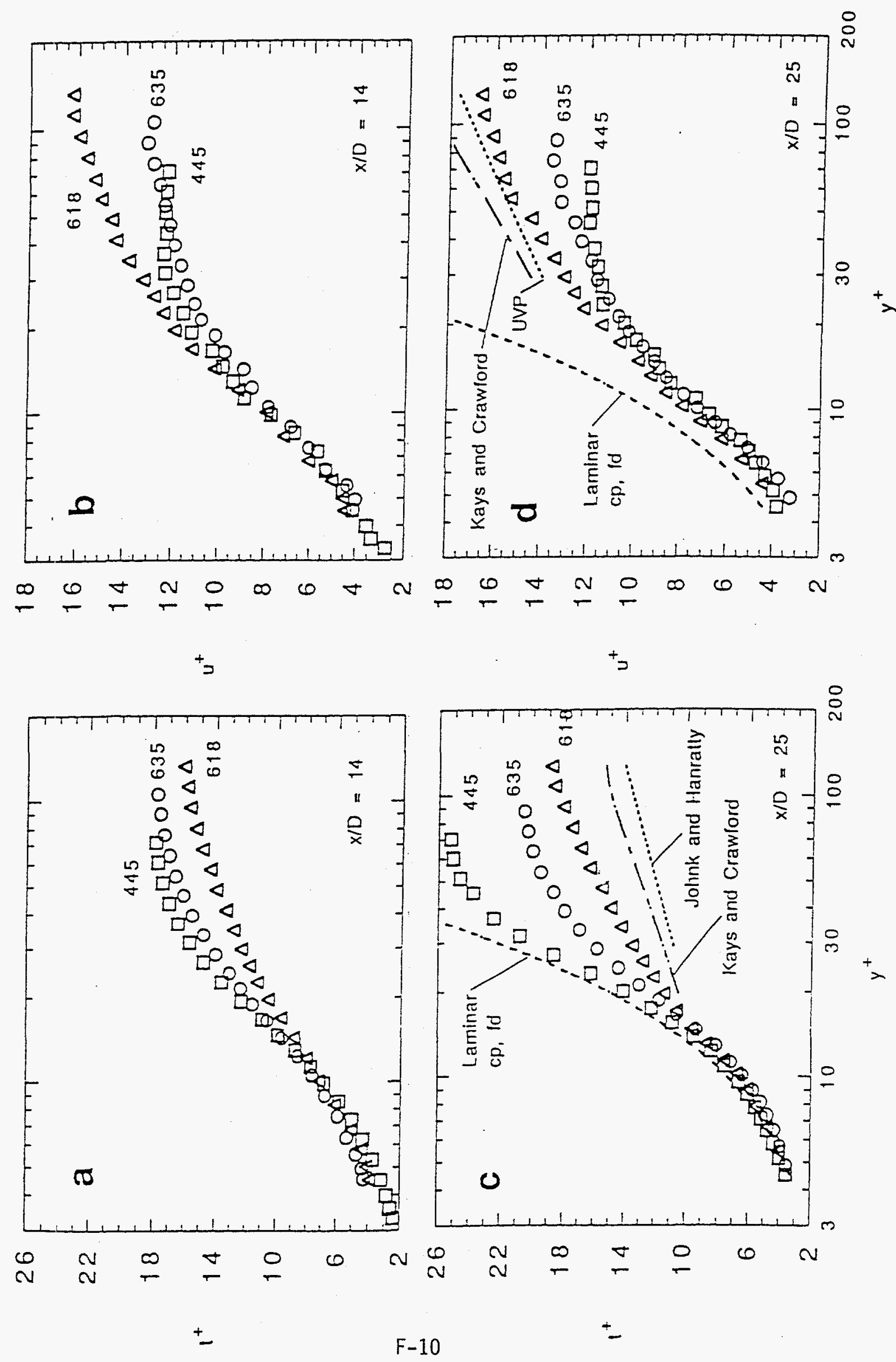


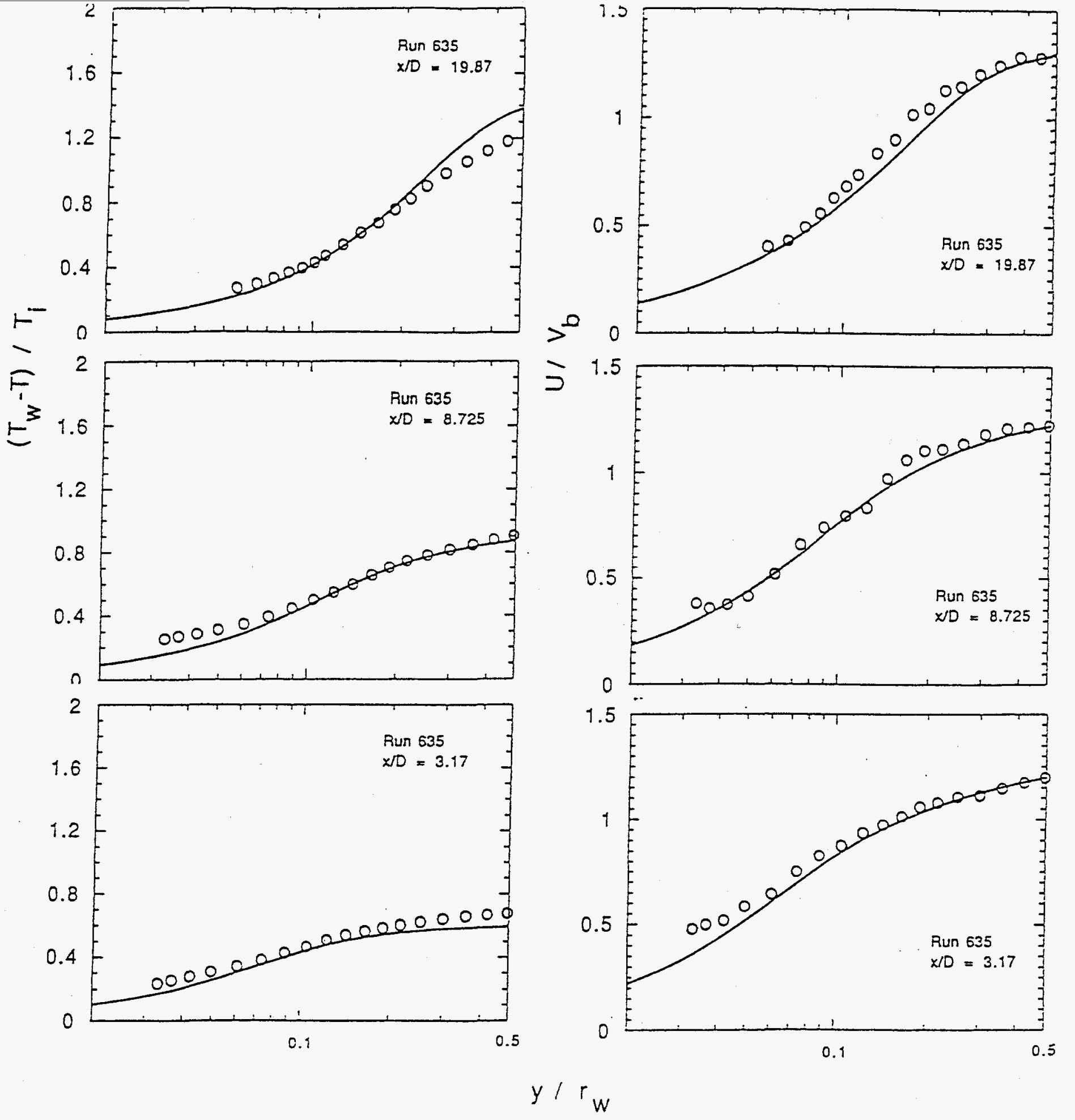

Fig. 10. Comparison of viscous layer data to numerical solution with turbulence model modified for agreement. 

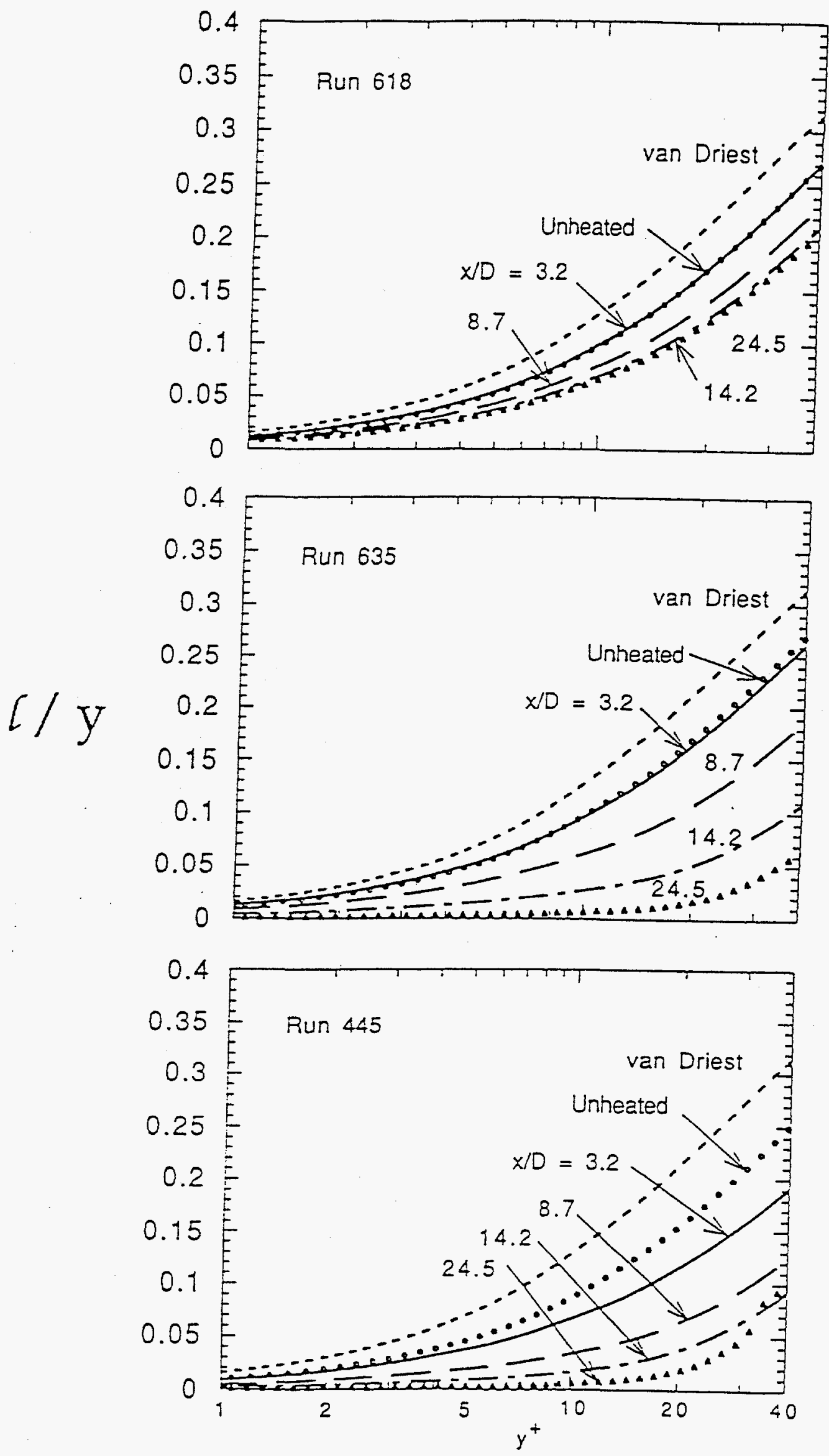

Fig. 11. Axial behavior of deduced mixing length profiles. 

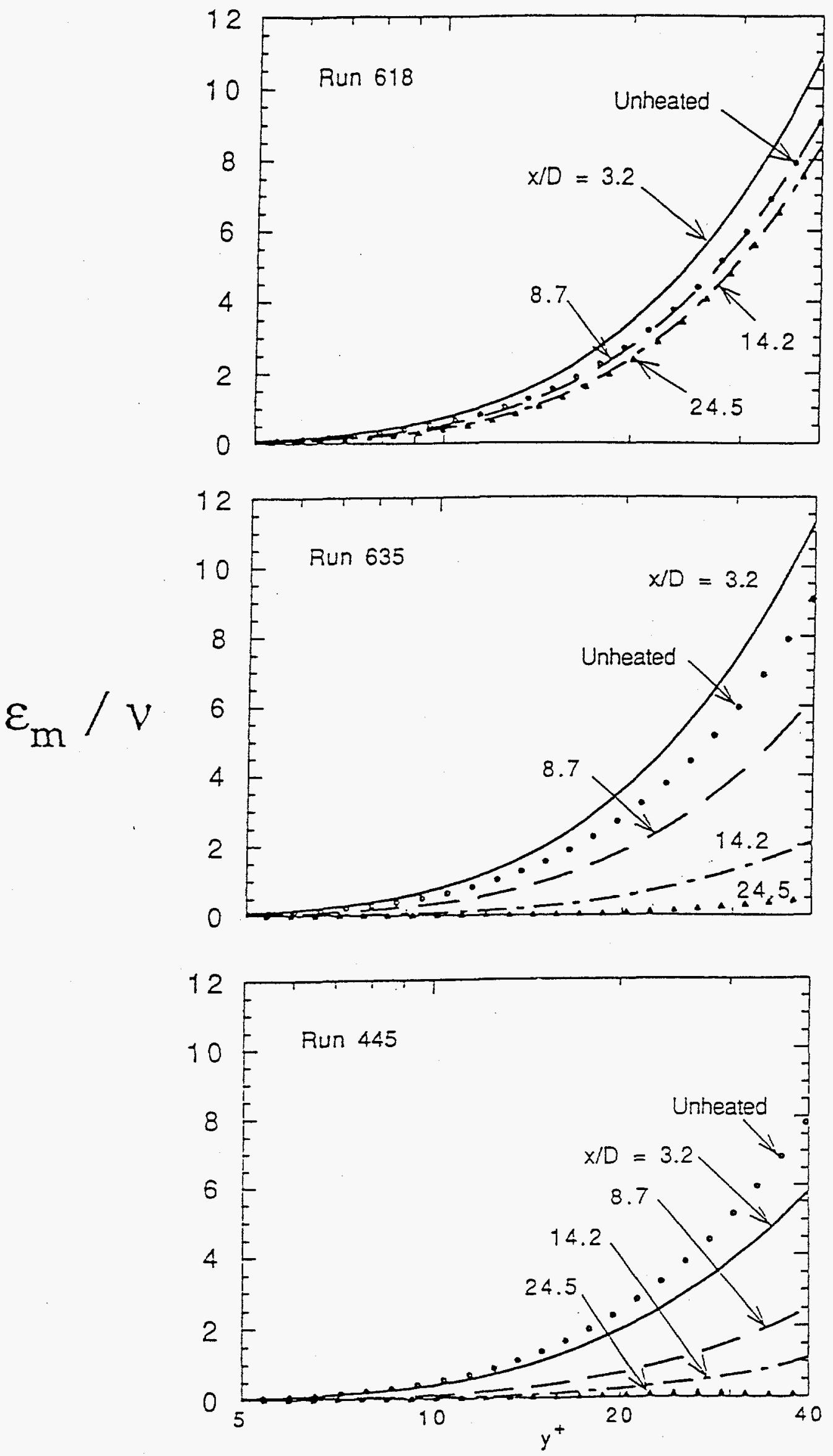

Fig. 12. Axial behavior of deduced eddy diffusivity profiles. 

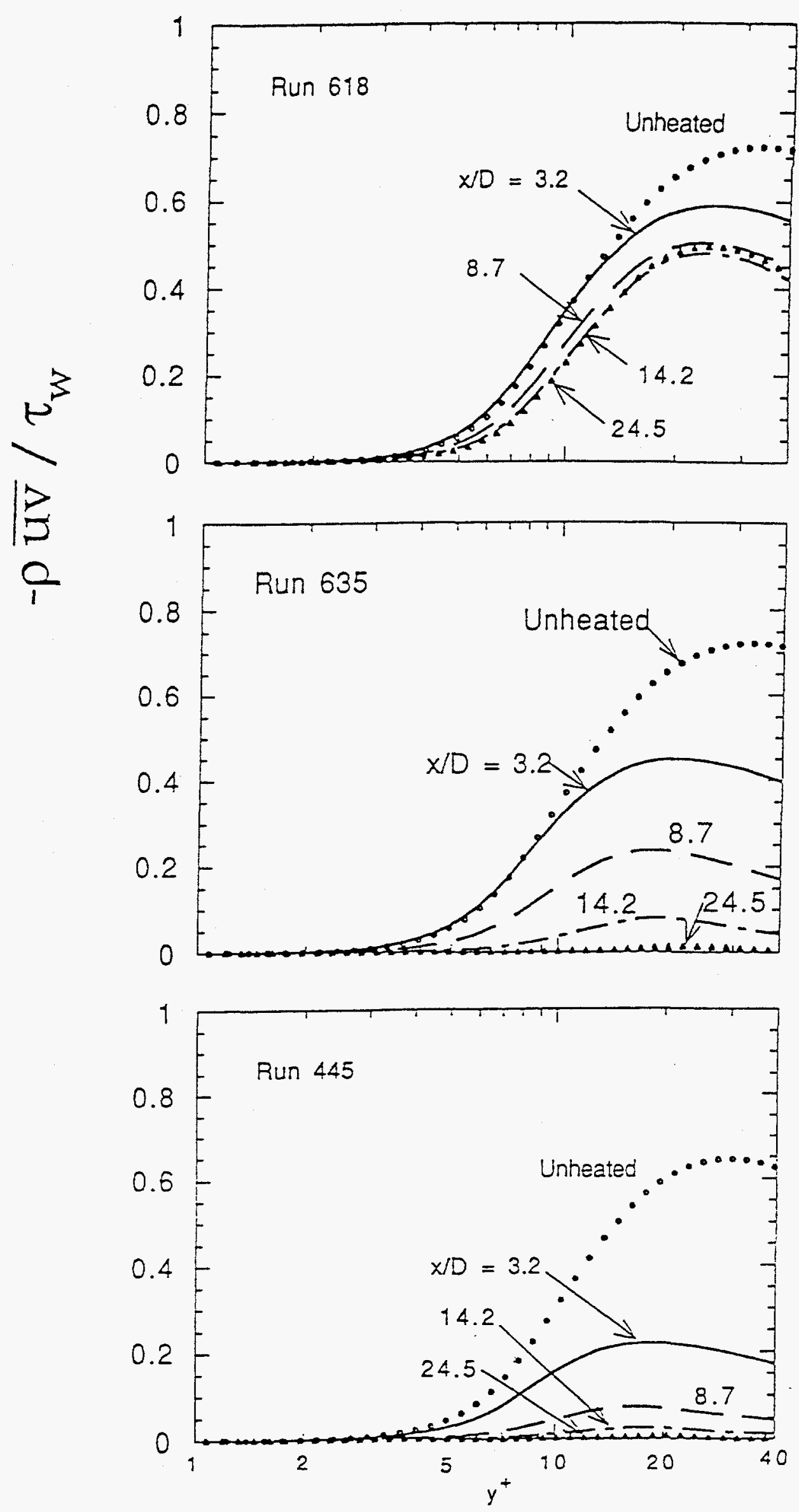

Fig. 13. Axial behavior of deduced Reynolds shear stress profiles. 


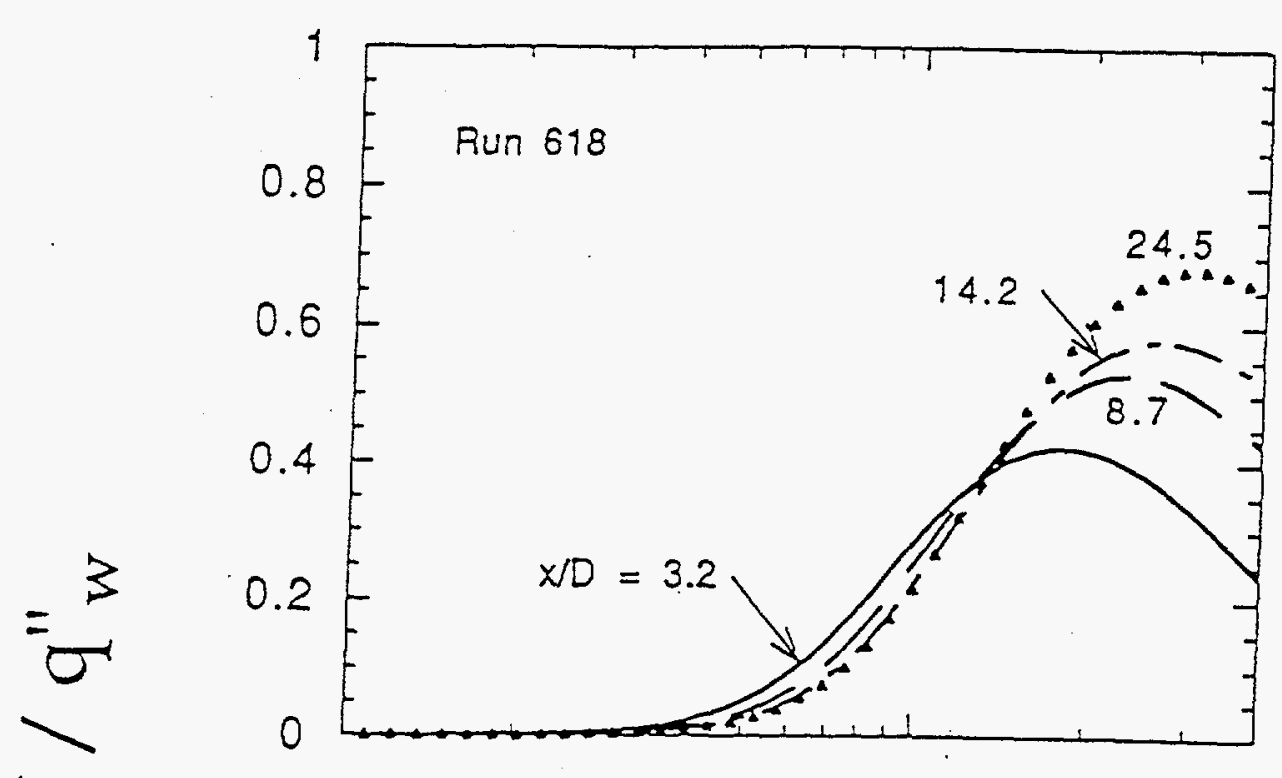

落

U.

a 1
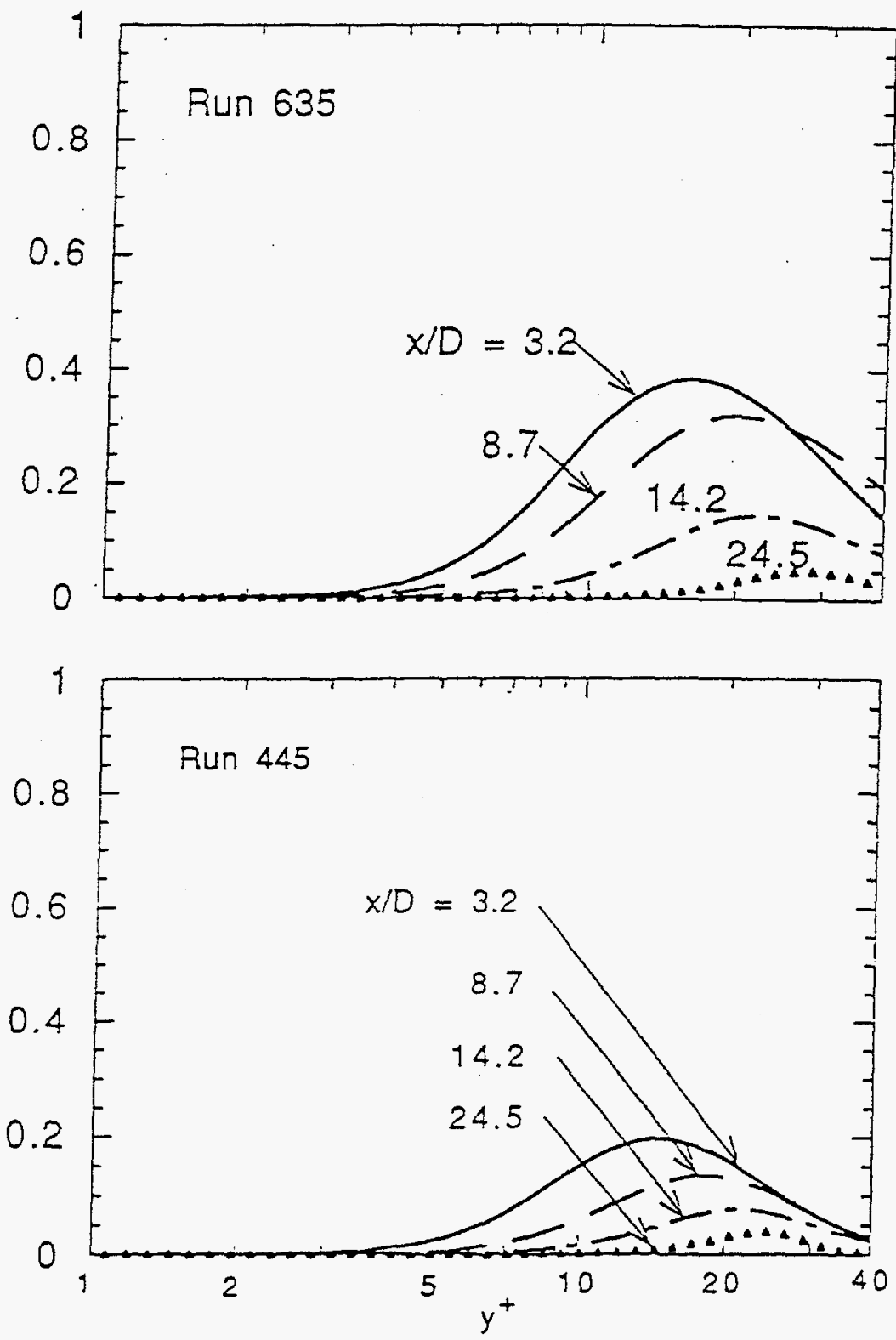

Fig. 14. Axial behavior of deduced turbulent heat flux profiles. 


\section{REFERENCES CITED}

Ahmad, A. M., 1968. Forced convective heat transfer to cooled cylinders at low Reynolds numbers and with large temperature differences. Tech. report CARDE TR 588/68.

Andrews, G. E., D. Bradley and G. F. Hundy, 1972. Hot wire anemometry calibration for measurements of small gas velocities. Int. J. Heat Mass Transfer, 15, pp 1765-1786.

Antonia, R. A., and J. D. Atkinson, 1976. A ramp model for turbulent temperature fluctuations. Phys. Fluids, 19 , pp. 1273-1278.

Bankston, C. A., and D. M. McEligot, 1970. Turbulent and laminar heat transfer to gases with varying properties in the entry region of circular ducts. Int. J. Heat Mass Transfer, 13 , pp 319-344.

Barney, C., 1976. Investigation of laminarizing gas flow using hot wire anemometry techniques. M. S. E. Report, Aero. Mech. Engr., Univ. Arizona.

Blackwelder, R. F., and L. S. G. Kovasznay, 1972. Large scale motion of a turbulent boundary-layer during relaminarization. J. Fluid Mech., $\underline{53}$, pp 6183.

Blackwelder, R.F ., and R. E. Kaplan, 1976. On the wall structure of the turbulent boundary layer. J. Fluid Mech., $\underline{76}$, pp 86-112.

Bradshaw, P. 1971. An introduction to turbulence and its measurement. New York: Pergamon.

Brodkey, R. S., 1975. Personal communication at seminar by D.M. McEligot, Max Planck Inst. für Stromungsf., Gottingen, BRD, March.

Carr, A. D., M. A. Connor and H. O. Buhr, 1973. Velocity, temperature and turbulence measurements in air pipe flow with combined free and forced convection. J. Heat Transfer, 95 pp. 445-452.

Chambers, F. W., H. D. Murphy and D. M. McEligot, 1983. Laterally converging flow. Part 2. Temporal wall shear stress. J. Fluid Mech., 127, pp 403-428.

Chevray, R., and N. R. Tutu, 1972. Simultaneous measurements of temperature and velocity in heated flows. Proc., Symp. Turbulence Measurements in Liquids, Rolla, Mo. 
Cole, J., and A. Roshko, 1954. Heat transfer from wires at Reynolds numbers in the Oseen range. Proc., Heat Transfer and Fluid Mechanics Inst., Univ. California, Berkeley, Cal., pp. 13-23.

Collis, D. C., and M. J. Williams, 1959. Two-dimensional convection from heated wires at low Reynolds numbers. J. Fluid Mech., $\underline{6}$, pp 357-384.

Cornte-Bellot, G., A. Strohl and E. Alcaraz, 1971. On aerodynamic disturbances caused by single hot-wire probes. J. Appl. Mech., 38, pp. 767-774.

Corino, E. R., and R. S. Brodkey, 1969. A visual observation of the wall region in turbulent flow. J. Fluid Mech., 37 , pp 1-30.

Davies, P. O. A. L., and M. J. Fisher, 1964. Heat transfer from electrically heated cylinders. Proc., Royal Soc., 280A pp. 486-527.

Drew, T. B., E. C. Koo and W. M. McAdams, 1932. The friction factor in clean round pipes. Trans., A.I.Ch. E., $\underline{38}$, pp. 56-72.

Inagaki, T., and K. Komori, 1993. Numerical prediction of turbulent heat trasnsfer in combined forced and natural convection 9aiding flow) in a uniformly vertical heated pipe: Two-equations turbulence models for velocity and temperature. Heat transfer - Japanese Research, 22, pp. 213-223.

Iritani, Y., N. Kasagi and M. Hirata, 1983. Heat transfer mechanism and associated turbulence structure in the near-wall region of a turbulent shear flow. Proc., 4th Int. Symp. Turb. Shear Flows, Karlsruhe, BRD.

Johnk, R. E., and T. J. Hanratty, 1962. Temperature profiles for turbulent flow of air in a pipe. Chem. Eng. Sci., 17, pp. 867-892.

Kawamura, H., 1979. Analysis of laminariization of heated turbulent gas using a two-equation model of turbulence. Proc., 2nd Intl. Symp. Turb. Shear Flow, London, pp. 18.16-18.21.

Kays, W. M., and M. E. Crawford, 1980. Convective heat and mass transfer, 2nd ed. New York: McGraw-Hill.

King, L. V., 1914. On the convection of heat from small cylinders in a stream of fluid. Phil. Trans., Royal Soc., London, Ser. A, 214, pp. 373-432.

Kline, S. J., and F. A. McClintock, 1953. Describing uncertainties in singlesample experiments. Mech. Engr., $\underline{75}$, No. 1, pp. 3-8.

Kline, S. J., W. C. Reynolds, F. A. Schraub and P. W. Rundstadler, 1967. The structure of turbulent boundary layers. J. Fluid Mech., 30, pp 741-773. 
Kreith, F., 1973. Principles of heat transfer, 3rd ed. New York: Intext.

Launder, B. E., 1964. Laminarization of the turbulent boundary layer by acceleration. MIT Gas Turbine Lab. Rpt. 77. Also NASA N66-16042.

Launder, B. E., 1987. Personal communication. Univ. Manchester Inst. Sci. Tech.

Loehrke, R. I., and H. M. Nagib, 1976. Control of freestream-turbulence by means of honeycombs: A balance between suppression and generation. J. Fluids Engr., 98, pp. 342-353.

McEligot, D. M, 1986. Convective heat transfer in internal gas flows with temperature-dependent properties. Adv. Transport Processes, $\underline{4}$ pp 113-200.

McEligot, D. M, 1986. Basic thermofluiddynamic problems in high temperature heat exchangers. High Temperature Heat Exchangers (Ed.: Y. Mori et al.), New York: Hemisphere, pp 60-86.

McEligot, D. M., and H. Eckelmann, 1990. Effects of streamwise pressure gradients on turbulence structure in the viscous layer. Tech. rpt. WNSD/HYDRO-90-03. Also DTIC AD No. A225 048.

McEligot, D. M., and H. Eckelmann, 1993. Turbulence structure in the viscous layer of converging flows. Proc., 9th Intl. Symp. Turb. Shear Flows, Kyoto, 1 , pp. 8-5-1 to 8-5-6.

McEligot, D. M., L. W. Ormand and H. C. Perkins, 1966. Internal low Reynolds number turbulent and transitional gas flow with heat transfer. J. Heat Transfer, $\underline{88}$, pp 239-245.

Mikielewicz, D. P., 1994. Comparative studies of turbulence models under conditions of mixed convection with variable properties in heated vertical tubes. Ph.D. thesis, Univ. Manchester.

Moen, W. K., 1960. Surface temperature measurement. Inst. and Control Syst., $\underline{33}$, pp. 70-73.

Murphy, H.D., F.W. Chambers and D.M. McEligot, 1983. Laterally converging flow. Part 1. Mean flow. J. Fluid Mech., 127, pp 379-401.

Narasimha, R., and K.R. Sreenivasan, 1979. Relaminarization of fluid flows. Adv. Appl. Mech., 19, pp 221-309. 
Nash, J. F., and A. G. J. MacDonald, 1967. A calculation method for incompressible turbulent boundary layers including the effect of upstream history on the turbulent shear stress. NPL Aero. Report 1234. Also NASA N68-20516.

Patel, V. C., and M.R. Head, 1968. Reversion of turbulent to laminar flow. J. Fluid Mech., $\underline{34}$, pp. 371-392.

Patel, V. C., and M.R. Head, 1969. Some observations on skin friction and velocity profiles in fully developed pipe and channel flows. Fluid Mech., $\underline{36}$, pp. 181-201.

Pennel, W. T., E. R. G. Eckert and E. M. Sparrow, 1972. Laminarization of turbulent pipe flow by fluid injection. J. Fluid Mech., 52, pp. 451-464.

Perkins, H. C., and P. M. Worsoe-Schmidt, 1965. Turbulent heat and momentum transfer for gases in a circular tube at wall-to-bulk temperature ratios to seven. Int. J. Heat Mass Transfer, $\underline{8}$, pp. 1011-1031.

Perkins, K. R., 1975. Turbulence structure in gas flows laminarizing by heating. Ph.D. thesis, Univ. Arizona.

Perkins, K. R., and D. M. McEligot, 1973. Roughness of heat transfer surfaces. Int. J. Heat Mass Transfer, 16 pp. 679-682.

Perkins, K. R., and D. M. McEligot, 1975. Mean temperature profiles in heated laminarizing air flows. J. Heat Transfer, 97, pp. 589-593.

Pessoni, D. H., and B. T. Chao, 1974. A simple technique for turbulence measurements in nonisothermal air flows. Proc., 5th Intl. Heat Trans. Conf., Tokyo, $\underline{5}$, pp. 278-283.

Reynolds, H. C., 1968. Internal low-Reynolds-number, turbulent heat transfer. Ph.D. thesis, Univ. Arizona. Also DTIC AD-669-254.

Reynolds, H. C., M. E. Davenport and D. M. McEligot, 1968 Velocity profiles and eddy diffusivities for fully developed turbulent, low Reynolds number pipe flow, ASME Paper 68-WA/FE-34.

Scadron, M. D., and I. Warshawsky, 1952. Experimental determination of time constants and Nusselt numbers for bare wire thermocouples in high velocity air streams and analytic approximation of conduction and radiation errors. NACA TN 2599.

Schlichting, H., 1968. Boundary layer theory, 6th ed. New York: McGraw-Hill. 
Shehata, A. M., 1984. Mean turbulence structure in strongly heated air flows. Ph.D. thesis, Univ. Arizona.

Sreenivasan, K. R., 1982. Laminarescent, relaminarizing and retransitional flows. Acta Mechanica, 44, pp.1-48.

Stabile, J. A., and D. M. McEligot, 1978. Effects of heated coherent structures on measurements by laser Doppler anemometry. Proc., AFOSR Workshop on Coherent Structures of Turbulent Boundary Layers, (Ed.: D. E. Abbott and C. R. Smith) Lehigh University, pp. 396-401. Also included in AFOSR-TR-78-1533, available from DTIC as AD-A100 632.

Steiner, A., 1971. On the reverse transition of a turbulent flow under the action of buoyancy forces. J. Fluid Mech., 47, pp. 503-512.

Tan-Atichat, J., H. M. Nagib and R. I. Loehrke, 1982. Interaction of free stream turbulence with screens and grids: a balance between turbulence scales.

J. Fluid Mech., 47, pp. 501-528.

Taylor, M. F., 1967. A method of correlating local and average friction coefficients for both laminar and turbulent flow of gases through a smooth tube with surface to fluid bulk temperature ratios from 0.35 to 7.35 . Int. J. Heat Mass Transfer, 10, pp. 1123-1128.

Taylor, M. F., 1982. Computer program REDUCEW, listing of 12 May 1982. Aero. Mech. Engr. Dept., Univ. Arizona.

Torii, S., A. Shimuzu, S. Hasegawa and M. Higasa, 1993. Numerical analysis of laminarizing circular tube flows by means of a Reynolds stress turbulence model. Heat Transfer - Japanese Research, 22, pp. 154- .

van Driest, E. R., 1956. On turbulent flow near a wall. J. Aerospace Sci., 23, pp 1007-1011 and 1036.

Wardena, I. N. G., T. Ueda and M. Mizomoto, 1992. Structure of turbulent two-dimensional channel flow with strongly heated wall. Exper. Fluids, 13 , pp. 17-25.

Wardena, I. N. G., T. Ueda and M. Mizomoto, 1994. Effect of strong wall heating on turbulence statistics of a channel flow. Exper. Fluids, 18 pp. 87-94. 